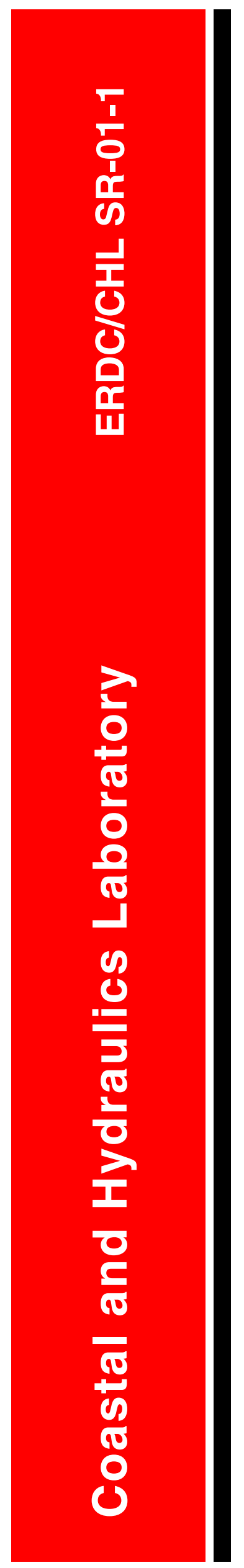

\title{
STWAVE: Steady-State Spectral Wave Model User's Manual for STWAVE, Version 3.0
}

Jane McKee Smith, Ann R. Sherlock, and Donald T. Resio 
The contents of this report are not to be used for advertising, publication, or promotional purposes. Citation of trade names does not constitute an official endorsement or approval of the use of such commercial products.

The findings of this report are not to be construed as an official Department of the Army position, unless so designated by other authorized documents. 


\section{STWAVE: Steady-State Spectral Wave Model User's Manual for STWAVE, Version 3.0}

by Jane McKee Smith, Ann R. Sherlock, Donald T. Resio

Coastal and Hydraulics Laboratory

U.S. Army Engineer Research and Development Center 3909 Halls Ferry Road

Vicksburg, MS 39180-6199

Final report

Approved for public release; distribution is unlimited 


\section{Contents}

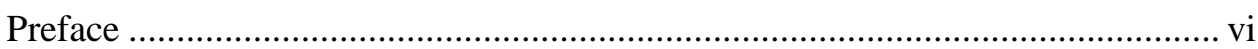

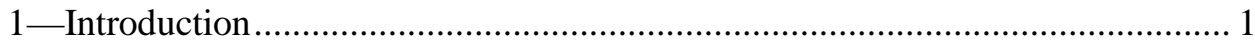

2-Governing Equations and Numerical Discretization ................................... 3

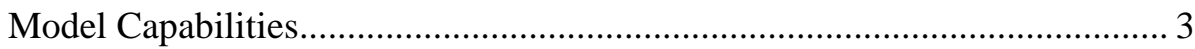

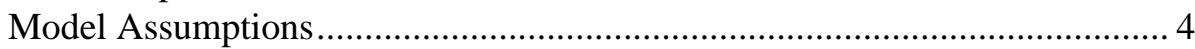

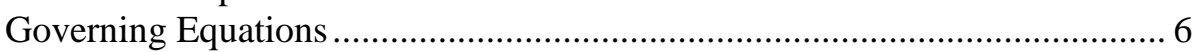

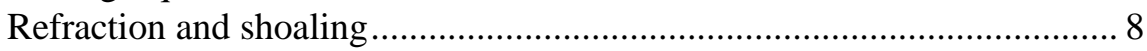

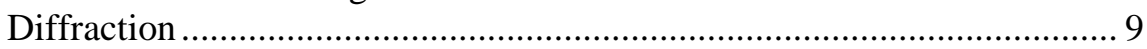

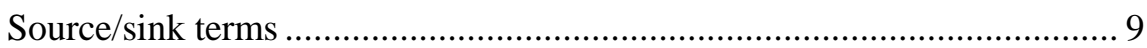

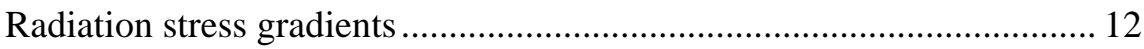

Numerical Discretization ....................................................................... 12

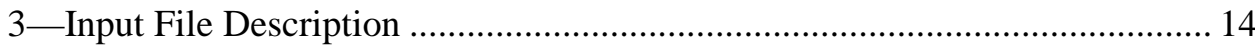

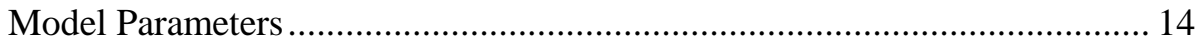

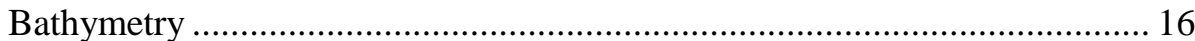

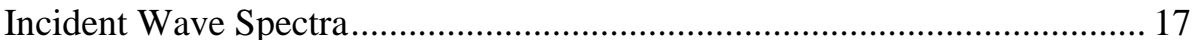

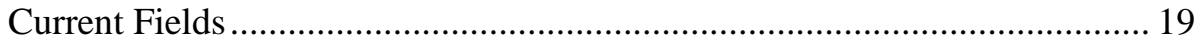

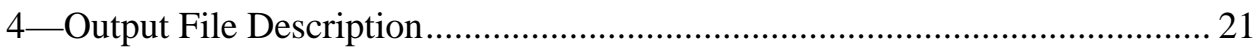

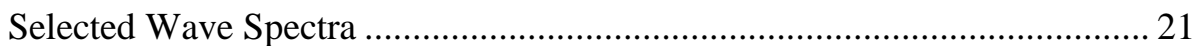

Selected Wave Parameters.......................................................................... 22

Wave Parameter Fields .................................................................................. 22

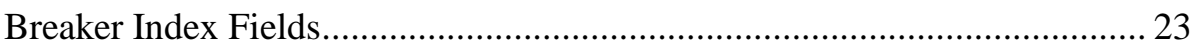

Radiation Stress Gradient Fields .............................................................. 23

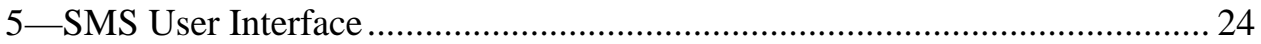

Build STWAVE Cartesian Grid ............................................................... 26

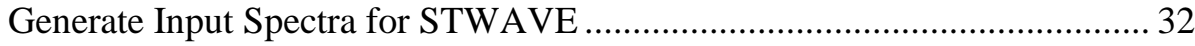

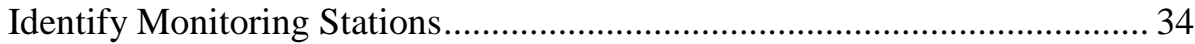

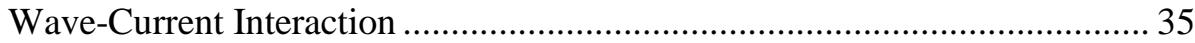

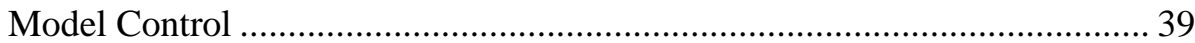

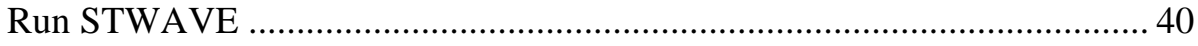




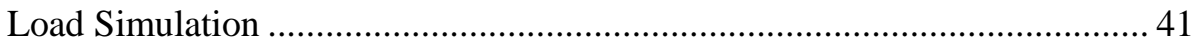

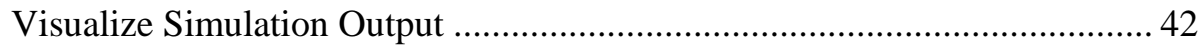

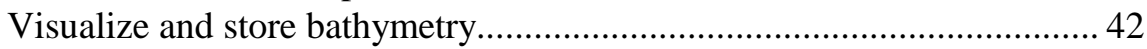

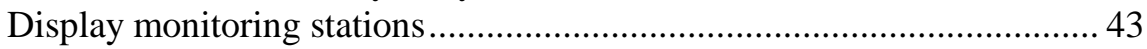

Visualize calculated wave height, period, or direction fields .................. 43

Visualize calculated wave height, period, or direction cell....................... 44

Dynamically visualize calculated wave height, period, or direction cell .. 44

Visualize observation spectra at monitoring station ................................ 44

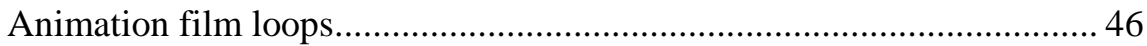

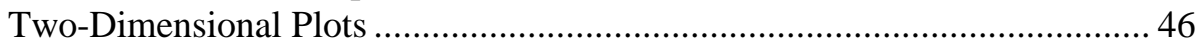

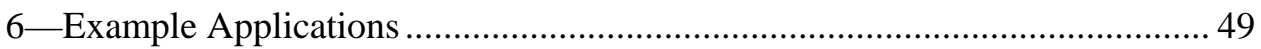

Example 1: Wave Propagation at Ponce de Leon Inlet............................... 49

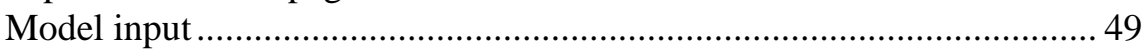

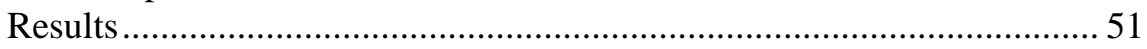

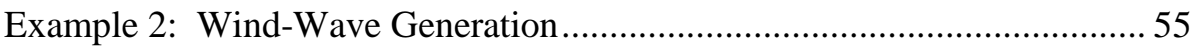

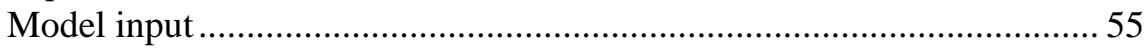

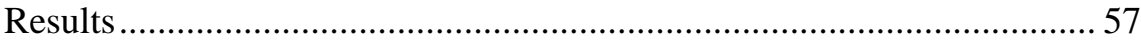

Example 3: Wave Propagation at Yaquina Bay Entrance, OR .................... 59

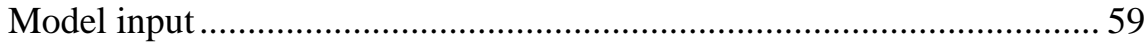

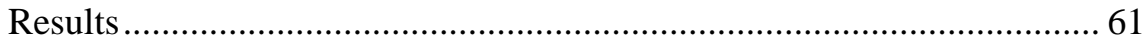

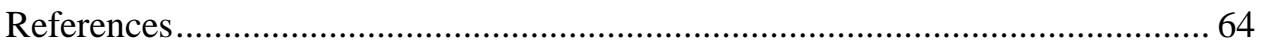

Appendix A: Sample Model Parameter File …............................................. A1

Appendix B: Sample Bathymetry File …............................................................ 1

Appendix C: Sample Incident Wave Spectrum File........................................... 1

Appendix D: Sample Current Field File …….............................................. D1

Appendix E: Sample Wave Parameter File ……..............................................

Appendix F: Sample Wave Breaking File ..................................................F1

Appendix G: Sample Radiation Stress Gradient File ........................................ G1

\section{List of Figures}

Figure 1. Sample one-dimensional wave spectrum ........................................... 4

Figure 2. Definition sketch of wave and current vectors ...................................... 7

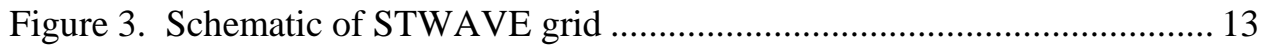


Figure 4. STWAVE input and output files

Figure 5. SMS GUI menu bar and edit window 25

Figure 6. SMS GUI. 25

Figure 7. Bathymetry scatter set with excess river points featured in black area 27

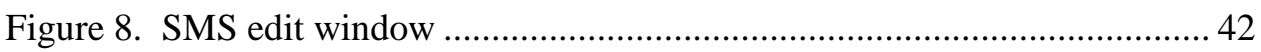

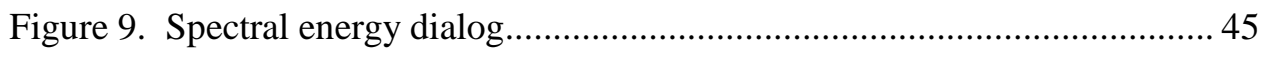

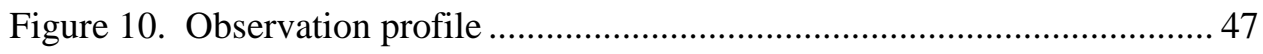

Figure 11. Ponce Inlet bathymetry and gauge positions ....................................50

Figure 12. Currents for Ponce Inlet example................................................ 52

Figure 13. One-dimensional wave spectra for Ponce Inlet ................................ 53

Figure 14. Directional distribution of Ponce Inlet wave spectra........................ 53

Figure 15. Wave-height contours for Ponce Inlet example .............................. 54

Figure 16. Schematic of Example 2 grid domain ........................................... 55

Figure 17. Wave height and period as a function of distance for $20 \mathrm{~m} / \mathrm{sec}$ wind speed.............................................................................. 58

Figure 18. One-dimensional wave spectra for $20 \mathrm{~m} / \mathrm{sec}$ wind speed.................. 58

Figure 19. Nearshore Yaquina Bay Entrance bathymetry (from SMS) .............. 60

Figure 20. Ebb current vectors and wave height contours near the Yaquina jetty tips (indicent conditions: $H_{m o}=12.5 \mathrm{~m}$, $T_{p}=20 \mathrm{sec}$, waves from the southwest, tide $=-0.90 \mathrm{~m}$ mean tide level)

Figure 21. Flood current vectors and wave height contours near the Yaquina jetty tips (indicent conditions: $H_{m o}=12.5 \mathrm{~m}$, $T_{p}=20 \mathrm{sec}$, waves from the southwest, tide $=0.61 \mathrm{~m}$ mean tide level)

Figure 22. Wave height difference (flood - ebb) near the Yaquina jetty tips (incident conditions: $H_{m o}=12.5 \mathrm{~m}, T_{p}=20 \mathrm{sec}$, waves from the southwest). 


\section{Preface}

The work described herein was conducted at the U.S. Army Engineer Research and Development Center (ERDC), Coastal and Hydraulics Laboratory (CHL), under the Coastal Navigation Hydrodynamics Program work unit Waves in Entrance Channels. Overall program management is directed by the Hydraulic Design section of Headquarters, U.S. Army Corps of Engineers (HQUSACE). Program Monitors are Messrs. Charles Chesnutt, Barry Holliday, and Mike Klosterman, HQUSACE. The Program Manager is Ms. Carolyn Holmes, CHL.

This study was conducted under the general supervision of Mr. Bruce A. Ebersole, Chief, Coastal Processes Branch (CPB), and Mr. Thomas W.

Richardson, Acting Director, CHL. The report was prepared by Drs. Jane McKee Smith, Research Hydraulic Engineer, CPB, and Donald T. Resio, Senior Research Scientist, CHL, and Ms. Ann R. Sherlock, Computer Specialist, CPB. Ms. Mary A. Cialone (CPB) and Mr. Ty V. Wamsley (CPB) provided technical review of this report.

At the time of publication of this report, Dr. James R. Houston was Director of ERDC, and COL James S. Weller was Commander.

The contents of this report are not to be used for advertising, publication, or promotional purposes. Citation of trade names does not constitute an official endorsement or approval of the use of such commercial products. 


\section{Introduction}

Estimating nearshore wind-wave growth and transformation is a critical component of most coastal engineering projects, e.g., predicting bathymetric and shoreline change, estimating navigation channel shoaling and migration, designing or repairing coastal structures, assessing navigation conditions, and evaluating natural evolution of coastal inlets or beaches versus consequences of engineering actions. Nearshore wave propagation is influenced by complex bathymetry (including shoals and navigation channels); tide-, wind-, and wavegenerated currents; tide- and surge-induced water level variation; and coastal structures. Use of numerical wave models has become widespread to represent wave transformation primarily because of their increasing sophistication and economy of application relative to the large expense of field measurements or physical model studies.

This report describes version 3.0 of the steady-state spectral wave model, STWAVE. The purpose of STWAVE is to provide an easy-to-apply, flexible, and robust model for nearshore wind-wave growth and propagation. Upgrades to the model since the release of version 2.0 (Smith, Resio, and Zundel 1999) include:

a. Calculation of radiation stress gradients. These stresses can be used to calculate wave-driven currents and water level changes in a circulation model. This feature has been used to link with the Advanced 3-D Circulation model (ADCIRC) (e.g., Militello et al. 2000; Smith and Ebersole 2000)

$b$. Increased model efficiency of 25 to 40 percent compared to STWAVE version 2.0. The greatest speedup is for cases that include wave-current interaction.

c. Addition of an input current option ICUR $=2$ to read a single current field for multiple input spectra.

d. Addition of an output file designating grid cells where wave breaking occurs.

e. Revised format of the spectral output file. This modification eliminates an error in free format reads for spectra with high energy levels.

f. Revised calculation of wave parameters on the offshore boundary that 
occurred in version 2.0 when the offshore boundary included both land and water cells.

g. Improved Surface-Water Modeling System (SMS) user interface and supporting software for grid generation, interpolation of current fields, generation of input spectra, and visualization of model output.

Version 7.1 of SMS provides significant improvements for conversion of coordinate systems, interpolating current fields, and generating and visualizing input/output wave spectra. This version also includes the additional input parameters required for STWAVE version 3.0 and visualization of breaking wave fields.

This report describes procedures for using STWAVE. In Chapter 2, an overview of the model governing equations and the numerical discretization is presented. In Chapter 3, the necessary input files are described. Guidelines for selecting parameter values are also given. In Chapter 4, the content and format of the STWAVE output files are described. Chapter 5 gives a tutorial on SMS application (version 7.1) using data from the Yaquina Entrance in Oregon.

Chapter 6 provides three example applications of the model for wave growth and transformation over simple bathymetry and wave transformation over complex bathymetry with wave-current interaction. Sample input and output files are given in Appendices A-G. 


\section{Governing Equations and Numerical Discretization}

This chapter gives an overview of the phase-averaged spectral wave model STWAVE (STeady-state spectral WAVE model) (Resio 1987, 1988a, 1988b; Davis 1992; Smith, Resio, and Zundel 1999). STWAVE is a steady-state finitedifference model based on the wave action balance equation. This report describes STWAVE version 3.0, which includes calculation of radiation stresses and identification of regions of active wave breaking.

\section{Model Capabilities}

The purpose of applying nearshore wave transformation models is to describe quantitatively the change in wave parameters (wave height, period, direction, and spectral shape) between the offshore and the nearshore (typically depths of $40 \mathrm{~m}$ or less). In relatively deep water, the wave field is fairly homogeneous on the scale of kilometers; but in the nearshore, where waves are strongly influenced by variations in bathymetry, water level, and current, wave parameters may vary significantly on the scale of tens of meters. Offshore wave information is typically available from a wave gauge or a global- or regionalscale wave hindcast or forecast. Nearshore wave information is required for the design of almost all coastal engineering projects. Waves drive sediment transport and nearshore currents, induce wave setup and runup, excite harbor oscillations, or impact coastal structures. The longshore and cross-shore gradients in wave height and direction can be as important as the magnitude of these parameters for some coastal design problems.

STWAVE simulates depth-induced wave refraction and shoaling, currentinduced refraction and shoaling, depth- and steepness-induced wave breaking, diffraction, wind-wave growth, and wave-wave interaction and whitecapping that redistribute and dissipate energy in a growing wave field.

A wave spectrum is a statistical representation of a wave field.

Conceptually, a spectrum is a linear superposition of monochromatic waves. A spectrum describes the distribution of wave energy as a function of frequency (one-dimensional spectrum) or frequency and direction (two-dimensional spectrum). An example of a one-dimensional wave spectrum is given in Figure 1. The peak period of the spectrum is the reciprocal of the frequency of 


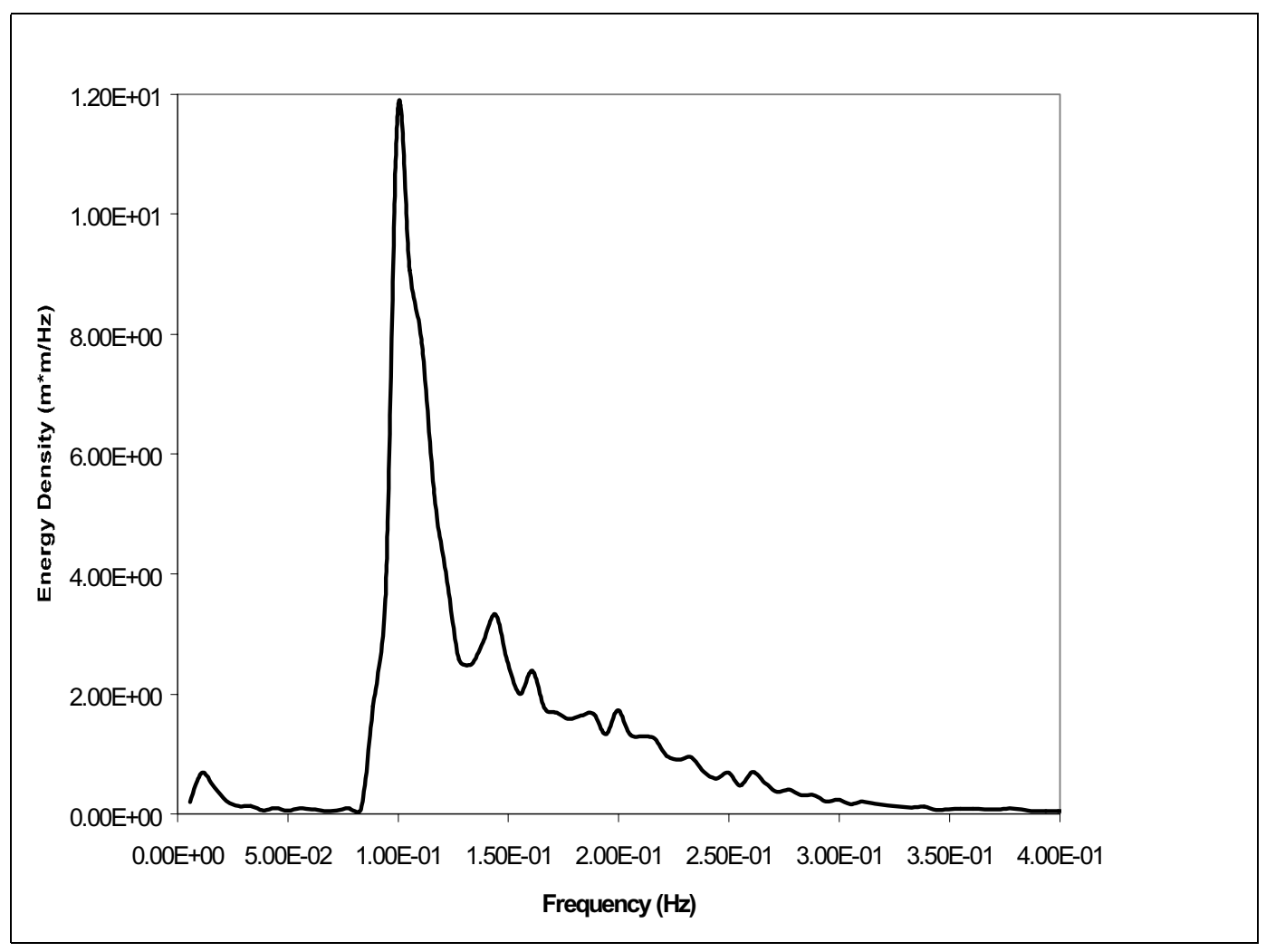

Figure 1. Sample one-dimensional wave spectrum

the peak of the spectrum. The wave height (significant or zero-moment wave height) is equal to four times the square root of the area under the spectrum. For the example spectrum given in Figure 1, the peak frequency is $0.105 \mathrm{~Hz}$, the peak period is $9.5 \mathrm{sec}$, and the wave height is $2.8 \mathrm{~m}$. STWAVE is based on the assumption that the relative phases of the spectral components are random, and thus phase information is not tracked (i.e., it is a phase-averaged model). In practical applications, wave phase information throughout a model domain is rarely known accurately enough to initiate a phase-resolving model. Typically, wave phase information is only required to resolve wave-height variations near coastal structures for detailed, near-field reflection and diffraction patterns. Thus, for these situations, a phase-resolving model should be applied.

\section{Model Assumptions}

The assumptions made in STWAVE version 3.0 are:

a. Mild bottom slope and negligible wave reflection. STWAVE is a halfplane model, meaning that wave energy can propagate only from the offshore toward the nearshore $( \pm 87.5 \mathrm{deg}$ from the $\mathrm{x}$-axis of the grid, which is typically the approximate shore-normal direction). Waves reflected from the shoreline or from steep bottom features travel in directions outside this half plane and thus are neglected. 
Forward-scattered waves, e.g., waves reflected off a structure but traveling in the $+\mathrm{x}$-direction, are also neglected.

b. Spatially homogeneous offshore wave conditions. The variation in the wave spectrum along the offshore boundary of a modeling domain is rarely known, and for domains on the order of tens of kilometers, is expected to be small. Thus, the input spectrum in STWAVE is constant along the offshore boundary. Future versions of the model will allow variable input.

c. Steady-state waves, currents, and winds. STWAVE is formulated as a steady-state model. A steady-state formulation reduces computation time and is appropriate for wave conditions that vary more slowly than the time it takes for waves to transit the computational grid. For wave generation, the steady-state assumption means that the winds have remained steady sufficiently long for the waves to attain fetch-limited or fully developed conditions (waves are not limited by the duration of the winds).

d. Linear refraction and shoaling. STWAVE incorporates only linear wave refraction and shoaling, thus does not represent wave asymmetry. Model accuracy is therefore reduced (wave heights are underestimated) at large Ursell numbers.

e. Depth-uniform current. The wave-current interaction in the model is based on a current that is constant through the water column. If strong vertical gradients in current occur, their modification of refraction and shoaling is not represented in the model. For most applications, threedimensional current fields are not available.

$f$. Bottom friction is neglected. The significance of bottom friction on wave dissipation has been a topic of debate in wave modeling literature. Bottom friction has often been applied as a tuning coefficient to bring model results into alignment with measurements. Although bottom friction is easy to apply in a wave model, determining the proper friction coefficients is difficult. Also, propagation distances in a nearshore model are relatively short (tens of kilometers), so that the cumulative bottom friction dissipation is small. For these reasons, bottom friction is neglected in STWAVE.

g. Linear radiation stress. Radiation stress is calculated based on linear wave theory.

Ongoing research will enhance present model capabilities and eliminate some model assumptions. The following sections describe wave propagation and source/sink terms in STWAVE version 3.0. 


\section{Governing Equations}

Interaction of waves with currents is considered in a reference frame moving with the current. Wave parameters in this frame are denoted with the subscript $r$, for being "relative" to the current, and parameters in the nonmoving reference frame are subscripted $a$, for "absolute." The wave dispersion relationship is given in the moving reference frame as (Jonsson 1990 and others):

$$
\omega_{r}^{2}=g k \tanh k d
$$

where

$$
\begin{aligned}
& \omega=\text { angular frequency } \\
& g=\text { gravitational acceleration } \\
& k=\text { wave number } \\
& d=\text { water depth }
\end{aligned}
$$

In the absolute frame of reference, the dispersion equation is:

$$
\omega_{a}=\omega_{r}+k U \cos (\delta-\alpha)
$$

where

$$
\begin{aligned}
& U=\text { current speed } \\
& \delta=\text { direction of the current relative to a reference frame (the x-axis, here) } \\
& \alpha=\text { wave orthogonal direction (normal to the wave crest) (Figure 2) }
\end{aligned}
$$

The wave number is solved by substituting Equation 1 into Equation 2 and iteratively solving for $k$. The wave number and wavelength $(L=(2 \pi) / k)$ are the same in both reference frames.

Solutions for refraction and shoaling also require wave celerities, $C$, and group celerities, $C_{g}$, in both reference frames. In the reference frame relative to the current,

$$
\begin{aligned}
& C_{r}=\frac{\omega_{r}}{k} \\
& C_{g r}=0.5 C_{r}\left(1+\frac{2 k d}{\sinh 2 k d}\right)
\end{aligned}
$$




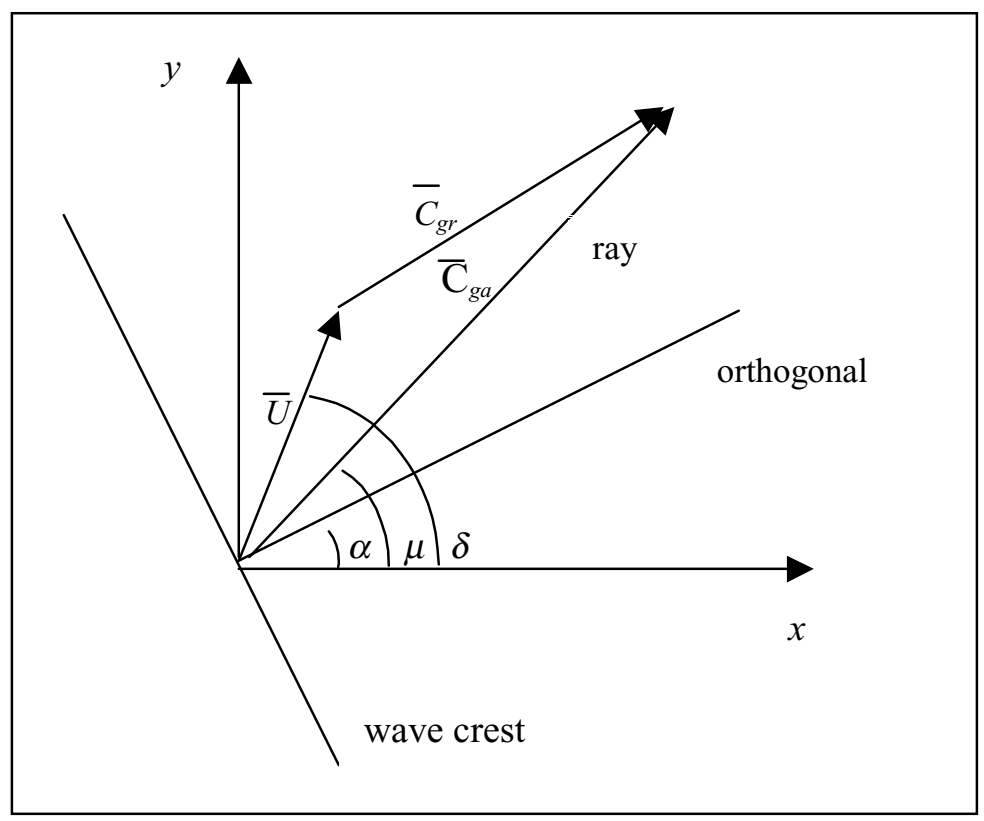

Figure 2. Definition sketch of wave and current vectors

The direction of both the relative celerity and group celerity is $\alpha$, the wave orthogonal direction. In the absolute reference frame,

$$
\begin{aligned}
& C_{a}=C_{r}+U \cos (\delta-\alpha) \\
& \left(C_{g a}\right)_{i}=\left(C_{g r}\right)_{i}+(U)_{i}
\end{aligned}
$$

where subscript $i$ is tensor notation for the $x$ - and $y$-components. The direction of the absolute celerity is also in the wave orthogonal direction. The absolute group celerity defines the direction of the wave ray, so the wave ray direction (Figure 2) is defined as:

$$
\mu=\tan ^{-1}\left(\frac{C_{g r} \sin \alpha+U \sin \delta}{C_{g r} \cos \alpha+U \cos \delta}\right)
$$

The distinction between the wave orthogonal (direction perpendicular to the wave crest) and the wave ray (direction of energy propagation) is important in describing wave-current interaction. Without currents, the wave rays and orthogonals are the same, but with currents, the wave energy moves along the rays whereas the wave direction is defined by the orthogonals.

The wave orthogonal direction for steady-state conditions is given by (Mei 1989; Jonsson 1990):

$$
C_{g a} \frac{D \alpha}{D R}=-\frac{C_{r} k}{\sinh 2 k d} \frac{D d}{D n}-\frac{k_{i}}{k} \frac{D U_{i}}{D n}
$$


where

$$
D=\text { derivative }
$$

$R=$ coordinate in the direction of the wave ray

$n=$ coordinate normal to the wave orthogonal

The governing equation for steady-state conservation of spectral wave action along a wave ray is given by (Jonsson 1990):

$$
\left(C_{g a}\right)_{i} \frac{\partial}{\partial x_{i}} \frac{C_{a} C_{g a} \cos (\mu-\alpha) E\left(\omega_{\mathrm{a}}, \alpha\right)}{\omega_{r}}=\Sigma \frac{S}{\omega_{r}}
$$

where

$$
\begin{aligned}
& E=\text { wave energy density divided by }\left(\rho_{w} g\right) \text {, where } \rho_{w} \text { is density of } \\
& \text { water } \\
& S=\text { energy source and sink terms }
\end{aligned}
$$

\section{Refraction and shoaling}

Refraction and shoaling are implemented in STWAVE by applying the conservation of wave action along backward traced wave rays. Rays are traced in a piecewise manner, from one grid column to the next. The two-dimensional wave spectra are set as input along the first grid column (the offshore boundary). For a point on the second grid column, the spectrum is calculated by back tracing a ray for each frequency and direction component of the spectrum. The ray direction, $\mu$, is determined by Equation 7 . Only ray directions propagating toward the shore $(-87.5$ to $+87.5 \mathrm{deg})$ are included. Energy propagating toward the offshore is neglected.

The wave ray is traced back to the previous grid column, and the length of the ray segment $D R$ is calculated. Derivatives of depth and current components normal to the wave orthogonal are estimated (based on the orthogonal direction at column 2) and substituted into Equation 8 to calculate the wave orthogonal direction at column 1 . Then, the wave number, wave and group celerities, and ray angle in the previous column are calculated. The energy is calculated as a weighted average of energy between the two adjacent grid points in the column and the direction bins. The energy density is corrected by a factor that is the ratio of the 5-deg standard angle band width to the width of the back-traced band to account for the different angle increment in the back-traced ray. The shoaled and refracted wave energy in column 2 is then calculated from the conservation of wave action along a ray (Equation 9).

In a strong opposing current (e.g., ebb currents at an entrance), waves may be blocked by the current. Blocking occurs if there is no solution to the dispersion equation (Equation 2). Or, to state it another way, blocking occurs if the relative 
wave group celerity is smaller than the magnitude of the opposing current, so wave energy cannot propagate against the current. In deep water, blocking occurs for an opposing current with magnitude greater than one-fourth the deepwater wave celerity without current $\left(0.25 \mathrm{~g} T_{a} /(2 \pi)\right.$, where $T_{a}$ is the absolute wave period). If blocking occurs, the wave energy is dissipated through breaking. Lai, Long, and Huang (1989) performed laboratory experiments that showed that wave energy can pass through the linear blocking point through nonlinear energy transfers to lower frequencies (which are not blocked). These nonlinear energy transfers are not included in STWAVE.

\section{Diffraction}

Diffraction is included in STWAVE in a simple manner through smoothing of wave energy. The model smoothes energy in a given frequency and direction band using the following form:

$$
E_{j}\left(\omega_{a}, \alpha\right)=0.55 E_{j}\left(\omega_{a}, \alpha\right)+0.225\left[E_{j+1}\left(\omega_{a}, \alpha\right)+E_{j-1}\left(\omega_{a}, \alpha\right)\right]
$$

where $E$ is the energy density in a given frequency and direction band, and the subscript $j$ indicates the grid row index (alongshore position). Equation 10 provides smoothing of strong gradients in wave height that occur in sheltered regions, but provides no turning of the waves. This formulation is grid-spacing dependent, which is a serious weakness. Efforts are ongoing to implement a more rigorous diffraction representation.

\section{Source/sink terms}

Surf-zone wave breaking. The wave-breaking criterion applied in the first version of STWAVE was a function of the ratio of wave height to water depth:

$$
\frac{H_{m o_{\max }}}{d}=0.64
$$

where $H_{m o}$ is the energy-based zero-moment wave height. At a coastal entrance, where waves steepen because of the wave-current interaction, wave breaking is enhanced because of the increased steepening. Smith, Resio, and Vincent (1997) performed laboratory measurements of irregular wave breaking on ebb currents and found that a breaking relationship in the form of the Miche criterion (1951) was simple, robust, and accurate:

$$
H_{m o_{\max }}=0.1 L \tanh k d
$$

(see also Battjes 1982 and Battjes and Janssen 1978). Equation 12 is applied in version 3.0 of STWAVE as a maximum limit on the zero-moment wave height. The energy in the spectrum is reduced at each frequency and direction in proportion to the amount of pre-breaking energy in each frequency and direction 
band. Nonlinear transfers of energy to high frequencies that occur during breaking are not represented in the model. Model grid cells where the wave height is limited by Equation 12 are flagged as actively breaking cells. These breaking regions can be visualized in SMS.

Wind input. Waves grow through the transfer of momentum from the wind field to the wave field. The flux of energy, $F_{i n}$, into the wave field in STWAVE is given by (Resio 1988a):

$$
F_{i n}=\lambda \frac{\rho_{a}}{\rho_{w}} 0.85 C_{m} \frac{u_{*}^{2}}{g}
$$

where

$$
\begin{aligned}
& \lambda=\text { partitioning coefficient that represents the percentage of total } \\
& \rho_{a}=\text { density of air } \\
& C_{m}=\text { mean wave celerity } \\
& u_{*}=\text { friction velocity (equal to the product of the wind speed, } U \text {, and } \\
& \text { the square root of the drag coefficient, } C_{D}=.0012+.000025 U \text { ) }
\end{aligned}
$$

In deep water, STWAVE provides a total energy growth rate that is consistent with Hasselmann et al. (1973).

The energy gain to the spectrum is calculated by multiplying the energy flux by the equivalent time for the wave to travel across a grid cell:

$$
\Delta t=\frac{\Delta x}{\beta \bar{C}_{g} \cos \alpha_{m}}
$$

where

$$
\begin{aligned}
& \Delta t=\text { equivalent travel time } \\
& \Delta \mathrm{x}=\text { grid spacing } \\
& \beta=\text { factor equal to } 0.9 \text { for wind seas } \\
& \bar{C}_{g}=\text { average group celerity of the spectrum } \\
& \alpha_{m}=\text { mean wave direction, relative to the grid }
\end{aligned}
$$


Because STWAVE is a half-plane model, only winds blowing toward the shore ( $+x$ direction) are included. Wave damping by offshore winds and growth of offshore-traveling waves are neglected.

Wave-wave interaction and whitecapping. As energy is fed into the waves from the wind, it is redistributed through nonlinear wave-wave interaction. Energy is transferred from the peak of the spectrum to lower frequencies (decreasing the peak frequency or increasing the peak period) and to high frequencies (where it is dissipated).

In STWAVE, the frequency of the spectral peak is allowed to increase with fetch (or equivalently propagation time across a fetch). The equation for this rate of change of $f_{p}$ is given by:

$$
\left(f_{p}\right)_{i+1}=\left[\left(f_{p}\right)_{i}^{7 / 3}-\frac{9}{5} \varsigma\left(\frac{u_{*}}{g}\right)^{4 / 3} \Delta t\right]^{-3 / 7}
$$

where the $i$ and $i+1$ subscripts refer to the grid column indices within STWAVE and $\zeta$ is a dimensionless constant (Resio and Perrie 1989). The energy gained by the spectrum is distributed within frequencies on the forward face of the spectrum (frequencies lower than the peak frequency) in a manner that retains the self-similar shape of the spectrum.

Wave energy is dissipated (most notably in an actively growing wave field) through energy transferred to high frequencies and dissipated through wave breaking (whitecapping) and turbulent/viscous effects. There is a dynamic balance between energy entering the wave field because of wind input and energy leaving the wave field because of nonlinear fluxes to higher frequencies (Resio 1987, 1988a). The energy flux to high frequencies is represented in STWAVE as:

$$
\Gamma_{E}=\frac{\varepsilon g^{1 / 2} E_{t o t}^{3} k_{p}^{9 / 2}}{\tanh ^{3 / 4}\left(k_{p} d\right)}
$$

(Resio 1987), where

$$
\begin{aligned}
\Gamma_{E} & =\text { energy flux } \\
\varepsilon & =\text { coefficient equal to } 30 \\
E_{t o t} & =\text { total energy in the spectrum divided by }\left(\rho_{w} g\right) \\
k_{p} & =\text { wave number associated with the peak of the spectrum }
\end{aligned}
$$

The energy loss from the spectrum is calculated by multiplying the energy flux by the equivalent time for the wave to travel across a grid cell $(\Delta t)$ (Equation 14) with $\beta$ equal to 1.0 for the swell portion of the spectrum and 
0.9 for the sea portion of the spectrum. This dissipation is only applied in the model if wind input is included.

\section{Radiation stress gradients}

Gradients in radiation stress are calculated in STWAVE to provide wave forcing to external circulation models to drive nearshore currents and water level changes (i.e., wave setup and setdown). Wave-driven currents are generally the dominant forcing for sediment transport in the surf zone. Radiation stress tensors are calculated based on linear wave theory:

$$
\begin{aligned}
& S_{x x}=\rho_{w} g \iint E(f, \alpha)\left[0.5\left(1+\frac{2 k d}{\sinh 2 k d}\right)\left(\cos ^{2} \alpha+1\right)-0.5\right] d f d \alpha \\
& S_{x y}=\rho_{w} g \iint \frac{E(f, \alpha)}{2}\left[0.5\left(1+\frac{2 k d}{\sinh 2 k d}\right) \sin 2 \alpha\right] d f d \alpha \\
& S_{y y}=\rho_{w} g \iint E(f, \alpha)\left[0.5\left(1+\frac{2 k d}{\sinh 2 k d}\right)\left(\sin ^{2} \alpha+1\right)-0.5\right] d f d \alpha
\end{aligned}
$$

The gradients in radiation stress are calculated as:

$$
\begin{gathered}
\tau_{x}=-\frac{\partial S_{x x}}{\partial x}-\frac{\partial S_{x y}}{\partial y} \\
\tau_{y}=-\frac{\partial S_{x y}}{\partial x}-\frac{\partial S_{y y}}{\partial y}
\end{gathered}
$$

Values of $\tau_{x} / \rho_{w}$ and $\tau_{y} / \rho_{w}$ are output from STWAVE for use in circulation modeling.

\section{Numerical Discretization}

STWAVE is a finite-difference numerical model, formulated on a Cartesian grid. Grid cells are square $(\Delta x=\Delta y)$. Variable grid resolution can be obtained by nesting model runs. This is accomplished by running the model at a coarse resolution and saving a spectrum at a nearshore point. This nearshore spectrum can then be used as a boundary condition for another grid of finer resolution. A schematic of a grid is shown in Figure 3. STWAVE operates in a local coordinate system, with the $\mathrm{x}$-axis oriented in the cross-shore direction (origin offshore) and the y-axis oriented alongshore, forming a right-handed coordinate system. The orientation of the $\mathrm{x}$-axis $( \pm 87.5 \mathrm{deg})$ defines the half plane that is 
represented in the model. The y-axis is typically aligned with the bottom contours. Wave angles are defined in a mathematical sense, measured counterclockwise from the $\mathrm{x}$-axis.

Lateral boundaries in the model can be specified as land or water by specifying the cell depths as positive (water) or negative (land). Note that specifying land around the entire grid will give different results than if the lateral boundaries are water. Land boundaries reduce wave growth near the boundary because they "block" propagation from landward directions. If the boundaries are specified as water, a zero-gradient type of boundary is applied that allows energy, consistent with neighboring cells, to propagate into or out of the domain along the lateral boundary.

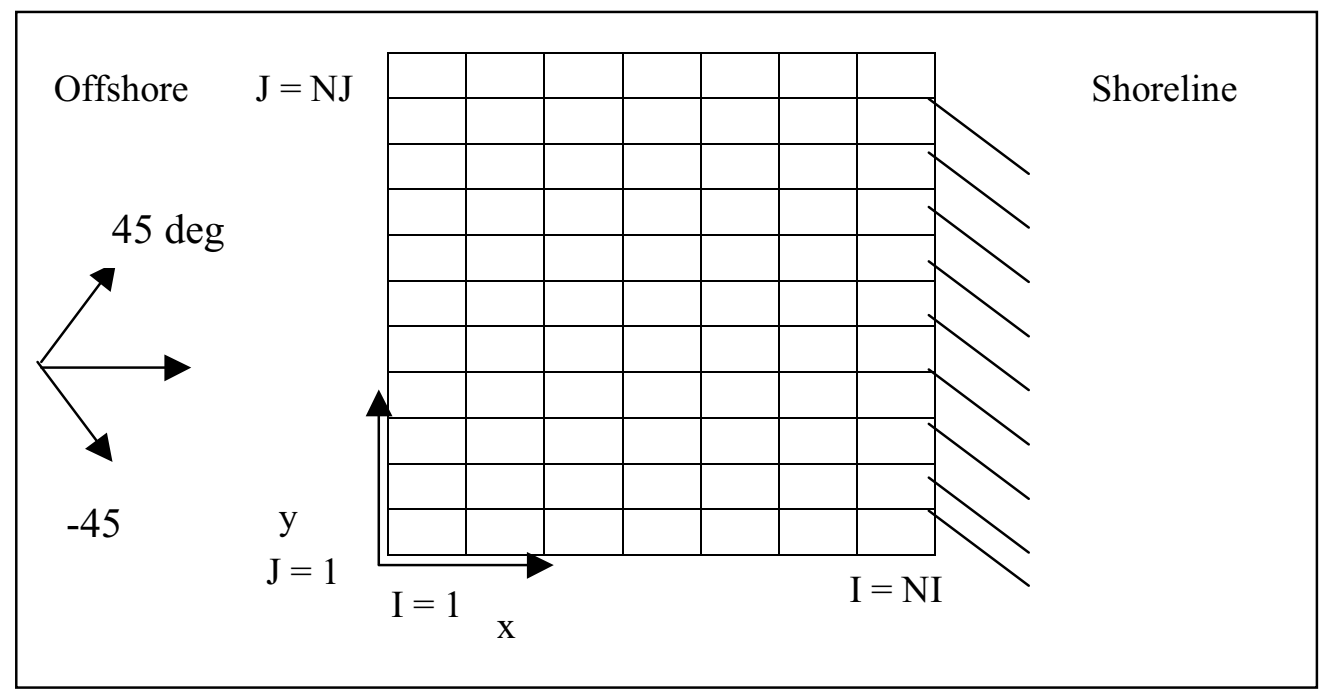

Figure 3. Schematic of STWAVE grid 


\section{Input File Description}

STWAVE has four input files. These files specify model parameters, bathymetry, incident wave spectra, and current fields. The current field file is optional and required only if the wave-current interaction is specified. The other three files are required. The input files are most easily generated using the SMS interface discussed in Chapter 5, but may also be generated using an editor or other programs. File formats for the input files must remain the same, regardless of how the files are generated. Parameter names starting with "N," "I," or "J" indicate integer parameter values are required. All other names indicate real parameter values. A schematic of the STWAVE input and output files is given in Figure 4.

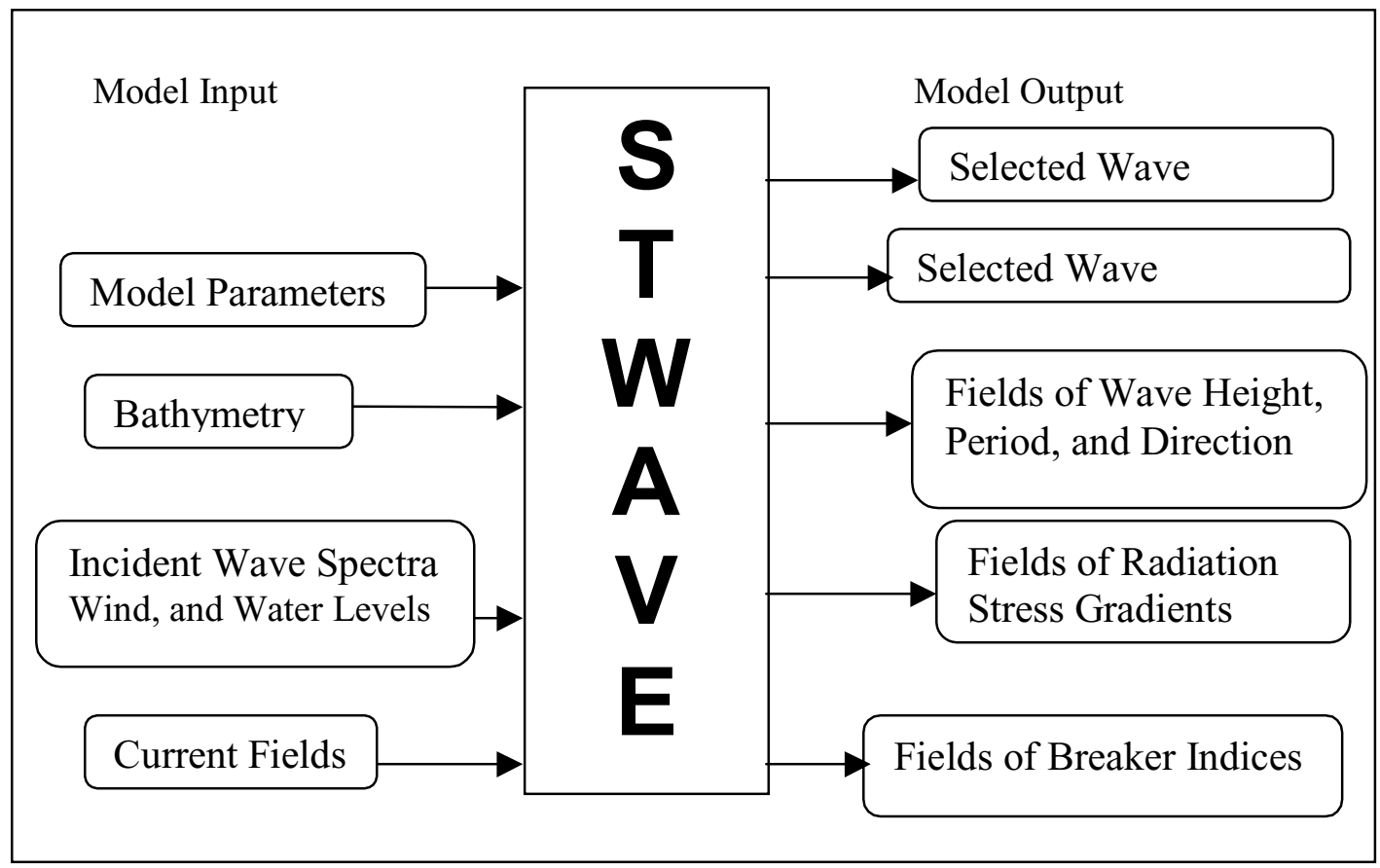

Figure 4. STWAVE input and output files

\section{Model Parameters}

The model-parameter file specifies options for running STWAVE and special output points. The first line of the model parameter file, read using free format 
(parameters must be delimited by spaces, commas, or new lines), includes (in the following order):

IPRP $=$ Switch for including propagation only $($ IPRP $=1)$ or both propagation and source terms $($ IPRP $=0)$. Surf-zone wave breaking is included for either option, but wind-wave generation, wave-wave interactions, and whitecapping are included only for IPRP $=0$. In applications where the wave propagation distances are short (on the order of kilometers), propagation only is usually sufficient. For longer wave propagation distances or cases where only locally generated waves exist, the source terms should be included.

ICUR $=$ Switch for including $(I C U R=1)$ or excluding $($ ICUR $=0)$ wavecurrent interaction. A current field must be specified for each incident wave condition (see "Current Fields" in a following section) if ICUR $=1$. A new option in STWAVE version 3 is ICUR $=2$ to specify a single current field for all incident wave conditions. This option is useful for climatic studies where peak ebb or peak flood current fields may be used with a number of typical or extreme incident wave conditions. Currents can increase (opposing current) or decrease (following current) wave height as well as change wave direction because of wave-current interaction. These interactions are strongest for short wave periods and large current magnitudes. Smith, Militello, and Smith (1998) showed that current magnitudes less than about $1 \mathrm{~m} / \mathrm{sec}$ had minor impacts on wave transformation at an East Coast entrance in Florida (peak wave periods in the range of 5-15 sec). Currents are read from the file current. in (or project. cur in SMS).

IBREAK $=$ Switch for printing $($ IBREAK $=1)$ or not printing $(\operatorname{IBREAK}=0)$ binary indices to indicate cells in which the waves are actively dissipating wave energy. These breaker indices are written to a file called break (project.brk in SMS). Wave breaking is defined by Equation 12. The value of IBREAK has no impact on the output wave fields, but determines if the break output file is written.

IRS $=$ Switch for calculating $(I R S=1)$ or not calculating $(I R S=0)$ radiation stress gradients. The radiation stress gradients are written to the file radstress. The radiation stress gradients are defined by Equations 17-21. The radiation stress output file is not used by STWAVE, but it can be used as input to a circulation model (e.g., ADCIRC) to force wave-driven currents and water level changes. The output file can be relatively large ( $\tau_{x}$ and $\tau_{y}$ are written for each grid cell for each input wave condition).

NSELCT $=$ Number of special output points. The two-dimensional wave spectra will be saved only for these output points (spec. out). Also, a file that summarizes wave height, period, and direction for these points will be written ("selected heights" file selhts). Wave height, period, and direction are saved by the model at all grid points (see Chapter 4), but this summary file makes it easy to spot-check results at critical locations or to isolate only the locations of interest. The spectral output file can become large if NSELCT is large and many input wave conditions are run. 
The final information in the model-parameter file is specification of the special output points. These points are I, $\mathrm{J}$ ( $x$ grid cell index, $y$ grid cell index) pairings of these special output points. There must be NSELCT pairs of numbers. The values are again read in free format and may occupy as many lines as needed (one pair per line).

The default name of the model parameter file is options. std. In SMS, the file is specified with a project name and the "std" extension, project. std. A sample model parameter file is given in Appendix A. The sample file specifies that the model run will consider propagation and source terms (IPRP $=0$ ), wavecurrent interaction is included (ICUR $=1$ ), breaker indices are written to a file $($ IBREAK $=1)$, and radiation stress gradients are written to a file (IRS=1). Three output points have been selected (at I, J coordinates $(110,157),(131,117)$, and $(146,86))$.

\section{Bathymetry}

The bathymetry file gives the STWAVE grid size and grid spacing and defines the grid bathymetry. The first line of the file, read using free format, includes (in the following order):

$\mathrm{NI}=$ Number of cross-shore $(x)$ grid cells or columns. The value of NI, together with the grid spacing (DXINC), determines the cross-shore extent of the modeling domain and the location of the offshore grid boundary. The offshore boundary is typically placed in a region where the bathymetry contours are relatively straight and parallel and where incident wave information is available from a gauge or hindcast.

$\mathrm{NJ}=$ Number of alongshore $(y)$ grid cells or rows. The value of $\mathrm{NJ}$, together with the grid spacing, determines the alongshore extent of the modeling domain and the location of the lateral grid boundaries. The lateral extent of the grid is a balance between keeping the lateral boundaries as far away as possible from the region of engineering interest and keeping the grid domain small for computational efficiency. The grid should extend sufficiently far alongshore to include the bathymetric features that influence the engineering project (e.g., if a project is centered on a coastal entrance, the entire ebb shoal and any offshore features that influence refraction should be included in the model domain).

DXINC $=$ Grid spacing in meters, which is the same in the $x$ and $y$ directions. The grid spacing determines how finely bathymetric features and current fields are resolved in the model and the spatial resolution of the output fields of wave height, period, and direction. Grid spacing should be sufficient to define bathymetric features and gradients (shoals, canyons, and channels) that are important to the engineering project. Typical resolutions are tens to hundreds of meters. For a fixed grid domain, increasing the grid resolution increases computational time.

The remainder of the file gives the water depth (relative to some datum, such as mean sea level or mean lower low water) for each grid cell in an STWAVE 
application, in meters. Water depths are defined as positive numbers and land elevations are negative numbers. The depths are read with a free format. The file begins with the depth at cell $(1, \mathrm{NJ})$ and reads in the cross-shore direction $(\mathrm{I}=1$ to $\mathrm{NI})$. The read is repeated for $\mathrm{J}=\mathrm{NJ}-1(\mathrm{I}=1$ to $\mathrm{NI})$, and progresses to $J=1$. The default name for the bathymetry file is dep. in. In SMS, the file is specified as project. dep. A sample bathymetry file is given in Appendix B. The sample grid has 188 cells in the cross-shore direction and 236 cells in the alongshore direction. The grid spacing is $25 \mathrm{~m}$.

\section{Incident Wave Spectra}

Incident two-dimensional wave spectra are specified as energy density as a function of frequency and direction. A single input spectrum is applied along the entire offshore boundary of the STWAVE grid (the spectrum is set to zero for any land points along the boundary). Thus, it is good practice to establish the offshore boundary of the bathymetry grid along a depth contour where the wave spectrum is fairly homogeneous (no large shoals or canyons offshore of the boundary). The first line of the input spectra file describes the number of frequency and direction bins in the spectra (read in free format):

$\mathrm{NF}=$ Number of frequency bins in the spectra. The number of frequency bins determines how finely the calculated spectra are resolved. A large number of frequency bins increases the computation time, and a small number of bins reduces model resolution. Typically, 20-30 bins are used.

$\mathrm{NA}=$ Number of direction bins in the spectra. This value must be set to 35 , which gives 5-deg resolution in direction.

The next lines of the incident wave spectra file specify the frequencies for model spectra (used for the input spectra, internal computations, and output spectra), starting from the lowest frequency. There must be NF frequencies specified. The frequencies are again read in free format and may occupy as many lines as needed. These frequencies should span the frequency range where significant wave energy is contained in the spectrum. This can be estimated by inspecting the input spectrum or estimating the peak period expected using the wave growth curves in the Coastal Engineering Manual (in preparation). A rule of thumb is that the spectral peak should fall at about the lower one-third of the frequency range (e.g., if the peak frequency is $0.1 \mathrm{~Hz}$, the range may be 0.01 to $0.3 \mathrm{~Hz}$ ). Wave frequencies higher (or periods shorter) than the highest frequency bin or lower than the lowest frequency bin will not be resolved by the model. Typically, frequency increments are on the order of $0.01 \mathrm{~Hz}$, but the increment need not be constant. West Coast applications will tend to require finer resolution focused at lower frequencies (because of long wave periods), and Gulf Coast or Great Lakes applications will tend to require coarser resolution covering a broader range of frequencies (because of shorter wave periods).

Following specification of the frequency bins is a header line containing a spectrum identifier, wind information, peak frequency, and water elevation correction: 
IDD = Integer event identifier, such as a date or test number. The integer is limited to nine digits.

$\mathrm{U}=$ Wind speed in meters/second. This wind speed is considered constant over the entire grid. Winds that are blowing offshore ( $-x$ direction) are neglected by the model, because the model only treats generation in a half plane. For wind directions greater than 60 deg relative the x-axis, STWAVE underpredicts wave generation (because of the half-plane model coverage). To model large ranges of wind direction, multiple STWAVE grid orientations may be required.

UDIR = wind direction relative to the STWAVE coordinate system in degrees. Wind direction is measured counterclockwise from the $\mathrm{x}$-axis (same convention used for wave direction, see Figure 3).

$\mathrm{FM}=$ Peak spectral frequency in Hz. If a spectrum is specified with no energy (i.e., waves will be locally generated in the modeling domain), FM should be set to the highest frequency specified in the model parameter file. This parameter is no longer used in the STWAVE computations, but is calculated from the input spectrum. A value for FM must be included in the input spectra file to maintain backward compatibility with STWAVE version 2.0.

DADD $=$ Water elevation correction (tide or storm surge) in meters, relative to the bathymetry datum. Users should take special care to ensure a consistent datum is used to specify the bathymetry and the water elevation correction. The water elevation correction is constant over the entire grid. Positive values of DADD increase water depth and negative values decrease water depths.

The header line is read in free format and is followed by the energy densities in the units of meters squared/hertz/radian. The spectrum is read starting with the lowest frequency and reading all the wave directions (from $-85 \mathrm{deg}$ to $85 \mathrm{deg}$ ), then reading energy densities for all directions for the next lowest frequency, etc. The total number of energy densities read equals the number of frequencies times the number of directions.

Multiple wave model runs can be executed by inserting multiple spectra, with identifying header lines, in the input file (the number of frequency and direction bins and the frequencies are not repeated for each spectrum, but must remain the same). The model will loop through the execution until it runs out of input spectral information (model parameters and bathymetry will stay constant). If wave-current interaction is specified (ICUR=1), the number of current fields in the current input files must equal the number of input spectra. The default name for the incident spectra file is spec . in. In SMS, the file is specified as project.eng (.eng for energy density). A sample incident spectrum file is given in Appendix C. The sample spectrum file has 25 frequencies and 35 directions. The spectral frequencies are from 0.01 to $0.25 \mathrm{~Hz}$, incrementing by $0.01 \mathrm{~Hz}$. The event identifier is 200700 (12 March 1996 at 0200 GMT). The wind speed is $15 \mathrm{~m} / \mathrm{sec}$, wind direction is $10 \mathrm{deg}$, and the tide/surge elevation is $-1.0 \mathrm{~m}$ relative to mean sea level (which corresponds to the mean sea level datum used to develop the bathymetry file). 
The incident wave spectrum can be specified using a measured twodimensional spectrum, by generating a spectrum using a parametric shape, or from a spectrum calculated by a global- or regional-scale wave model. Rarely do measured spectra have the directional resolution required by the model; thus, measured spectra require interpolation to finer resolution. A parametric spectral shape together with a directional spreading function can also be applied to specify an incident spectrum, knowing the wave height, period, and direction. SMS includes the capability to generate incident spectra using a TMA onedimensional shallow-water spectral shape (named for the three data sets used to develop the spectrum: TEXEL storm, MARSEN, and ARSLOE) (Bouws et al.

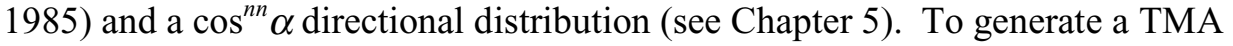
spectrum, the following parameters must be specified: peak wave period $\left(T_{p}\right)$, wave height, water depth, and a spectral peakedness parameter $(\gamma)$. The peakedness parameter controls the width of the frequency spectrum (small numbers give broad peaks and large numbers give narrow peaks). The directional distribution of the spectrum is specified with a mean direction and a directional spreading coefficient $(n n)$. The energy in the frequency spectrum is spread proportional to $\cos ^{n n}\left(\alpha-\alpha_{m}\right)$, where $\alpha$ is direction of the spectral component and $\alpha_{m}$ is the mean wave direction. Guidance for selecting $\gamma$ and $n n$ is given in Table 1 (Thompson et al. 1996). Spectra with large peak periods are generally narrow in both frequency and direction (swell). For small peak periods, spectra are typically broad in both frequency and direction (sea).

\section{Table 1}

\section{Approximate Spectral Peakedness and Directional Spreading} Parameters

\begin{tabular}{||l|l|l|}
\hline \hline $\mathrm{T}_{p}, \mathrm{Sec}$ & $\gamma$ & $n n$ \\
\hline$\leq 10$ & 3.3 & 4 \\
\hline 11 & 4 & 8 \\
\hline 12 & 4 & 10 \\
\hline 13 & 5 & 12 \\
\hline 14 & 5 & 16 \\
\hline 15 & 6 & 18 \\
\hline 16 & 6 & 20 \\
\hline 17 & 7 & 22 \\
\hline 18 & 7 & 26 \\
\hline 19 & 8 & 28 \\
\hline 20 & 8 & 30 \\
\hline
\end{tabular}

\section{Current Fields}

A current field input file is required only if ICUR $=1$ or 2 in the model parameter file (it is ignored if ICUR $=0$ ). The current vector is specified as $x$ - and $y$-components of the current at each grid cell, $u$ and $v$, in the units meters/second. The $\mathrm{x}$ - and $\mathrm{y}$-directions correspond to the $\mathrm{x}$ - and $\mathrm{y}$-axes of the grid in the local STWAVE coordinates (Figure 3). The first line of the current input file is NI, NJ, and DXINC, identical to the parameters specified in the bathymetry file. STWAVE checks that these values are consistent with the bathymetry file, and if they are not, model execution is terminated with the error "current field does not match depth grid size." Next, the header for the current 
field is given, which is an event identifier. This header is not used by the model, but is helpful to ensure that the current and spectral input files coincide. Similar to the bathymetry file, the current file begins with the $u / v$ pair at cell $(1, \mathrm{NJ})$ and reads in the cross-shore direction ( $\mathrm{I}=1$ to $\mathrm{NI}$ ). Then the read is repeated for $\mathrm{J}=$ NJ-1 ( $\mathrm{I}=1$ to NI), and progresses to $\mathrm{J}=1$. The current components are read in free format. The default name for the current field file is current.in. In SMS, the file is specified as project. cur. A sample current field file is given in Appendix D. In the sample file, the first line repeats the grid parameters from the bathymetry file. The grid is defined as 188 cells in the cross-shore direction and 236 cells in the alongshore direction with a grid spacing of $25 \mathrm{~m}$. The event identifier for the current field is 200700, which matches the event identifier in the incident spectrum file. As with the spectral file, multiple wave model runs can be executed by inserting multiple current fields (with their event-identifier headers) in the input file (as well as the same number of input spectra in the spec . in file) for ICUR $=1$. The model will loop through the execution until it runs out of input spectral and current information. For ICUR $=2$, one current field will be used for all model runs (the first or only current field in the current. in file). This is a new option in STWAVE version 3. 


\section{Output File Description}

STWAVE has up to five output files. These files contain wave spectra at the selected output points; wave height, period, and direction at the selected output points; fields of wave height, period, and direction over the entire STWAVE modeling domain; fields of breaker indices indicating active regions of breaking over the entire domain; and fields of radiation stress gradients over the entire domain. If multiple incident wave spectra are specified in the input file (and current fields, if wave-current interaction is specified), then output from each of these model runs is appended to the output files.

\section{Selected Wave Spectra}

Wave spectra at selected grid cells, specified in the model parameters file (see Chapter 3, "Input File Description"), are saved in a spectral output file. Similar to the input spectra file, the first line of the output file describes the number of frequencies and number of directions (NF and NA), and the following lines give the frequencies. Each spectrum in the file is proceeded by the following header information:

IDD = Integer event identifier, specified in the incident wave spectrum file.

$\mathrm{I}=$ Integer $x$ grid cell index of the special output point, specified in the model parameter file.

$\mathrm{J}=$ Integer $y$ grid cell index of the special output point, specified in the model parameter file.

$\mathrm{N}=$ Integer index of the special output point (values are 1 to NSELCT, based on the order in which the points are specified in the model parameter file).

The header format is (i10,3i5). Following the header line, the output spectrum is written in the same order and units in which the incident spectrum was read. Energy densities are given in the units meters squared/hertz/radian. The spectrum is written starting with the lowest frequency and writing energy density for all wave directions (from $-85 \mathrm{deg}$ to $85 \mathrm{deg}$ ), followed by the energy densities for all directions for the next lowest frequency, etc. The format of the energy densities is $(17 \mathrm{f} 8.3)$. 
The spectra will be written to the file in an order based on the I cell index, starting from the smallest index and proceeding to the largest index. This is because spectra are not saved over the entire grid, so the output spectra are written to the file as the grid column is solved and then are overwritten in memory. Thus, the order may not coincide with $\mathrm{N}=1$, NSELCT. The default file name for the output spectra file is spec. out. In SMS, the file is specified with a project name and the extension .obs.

\section{Selected Wave Parameters}

The wave parameters $H_{m o}, T_{p}$, and mean wave direction, $\alpha_{m}$, at selected grid cells, specified in the model parameters file (see Chapter 3, "Input File Description"), are saved in a selected parameter output file. The selected grid cells are the same locations where spectra are saved. For each output point, the following information is written:

IDD $=$ Integer event identifier, specified in the incident wave spectrum file.

$\mathrm{I}=$ Integer $x$ grid cell index of the special output point, specified in the model parameter file.

$\mathrm{J}=$ Integer $y$ grid cell index of the special output point, specified in the model parameter file.

$H_{m o}=$ Zero-moment wave height at cell (I, J), in meters.

$T_{p}=$ Peak wave period at cell (I, J), in seconds.

$\alpha_{m}=$ Mean wave direction at cell (I, J), in degrees relative to the STWAVE grid (see Figure 3).

The format of each line is $(\mathrm{i} 10,2 \mathrm{i} 3, \mathrm{f6} .2, \mathrm{f6} .1, \mathrm{f6} .0)$. Information for each selected grid cell is written on a separate line in the file. The parameters are written to the file in an order based on the I cell index, starting from the smallest index and proceeding to the largest index. The default file name is selhts. This file is not used in SMS because wave height, period, and direction for all grid cells are displayed graphically on the screen over the entire domain (values at any cell in the domain are displayed by clicking on the cell with the mouse). A sample of a wave parameter file is given in Appendix E.

\section{Wave Parameter Fields}

The wave parameters $H_{m o}, T_{p}$, and $\alpha_{m}$ are also saved for all grid cells into a wave field file. Written first in the file are the grid dimensions (NI and NJ) and grid spacing (DXINC) repeated from the bathymetry input file. Next in the file is the event identifier (IDD from the incident wave spectrum file) in the format (i10). After this header line, all the wave heights are written, beginning at cell (1, 
$\mathrm{NJ})$ and proceeding in the cross-shore direction $(\mathrm{I}=1, \mathrm{NI})$. The write is repeated for each grid row from $J=N J-1$ to $J=1$. The format is (16f6.2). Following the wave heights, the wave periods are written in the same order with the format (16f5.1). Then the wave directions are written (again in the same order) with the format (16i5). If multiple input spectra are specified, the event identifier and the wave heights, periods, and directions for each condition are appended to the end of the file.

The default file name for the wave field file is wavfld. In SMS, the file is specified with a project name and the extension . wav.

\section{Breaker Index Fields}

The regions where waves are actively breaking are of interest for sediment transport and navigation studies. Grid cells with active breaking (see Equation 12) are specified with an index of 1 and nonbreaking cells with an index of 0 . These indices for the entire domain are written to the file break (or project. brk in SMS) if the input parameter IBREAK = 1 (see Chapter 3). Written first in the file are the grid dimensions (NI and NJ) and grid spacing (DXINC) repeated from the bathymetry input file. After this header line, all the breaker indices are written, beginning at cell $(1, \mathrm{NJ})$ and proceeding in the crossshore direction $(I=1, N I)$. The write is repeated for each grid row from $J=N J-1$ to $\mathrm{J}=1$. The format is (16i5). If multiple input spectra are specified, the breaker indices for each condition are appended to the end of the file. No file is written when the input parameter IBREAK $=0$. A partial listing of a sample wave breaking file is given in Appendix F.

\section{Radiation Stress Gradient Fields}

The radiation stress gradients $\tau_{x} / \rho_{w}$ and $\tau_{y} / \rho_{w}$ are calculated at all grid cells when IRS $=1$. These stress gradient fields are written to the file radstress. Written first in the file are the grid dimensions (NI and NJ) and grid spacing (DXINC) repeated from the bathymetry input file. Next in the file is the event identifier (IDD from the incident wave spectrum file) in the format (i10). After this header line, the $\left(\tau_{x} / \rho_{w}, \tau_{y} / \rho_{w}\right)$ pair are written beginning at cell $(1, \mathrm{NJ})$ and proceeding in the cross-shore direction $(\mathrm{I}=1, \mathrm{NI})$. The write is repeated for each grid row from $J=N J-1$ to $J=1$. The stress gradients are written in free format. If multiple input spectra are specified, the event identifier and the radiation stress gradients for each condition are appended to the end of the file. A partial listing of a sample radiation stress gradient file is given in Appendix F. 


\section{$5 \quad$ SMS User Interface}

Information contained in the STWAVE input files (Chapter 3) and output files (Chapter 4) is conceptually easy to understand, but practically, these files contain large amounts of data that can be difficult to generate and interpret. To assist STWAVE users in generating input files and visualizing output files, a user interface has been built for STWAVE within the Surface-water Modeling System (Brigham Young University Engineering Computer Graphics Laboratory (ECGL) 1997). The SMS interface supports grid generation, interpolation of current fields, generation of input spectra, visualization of wave heights, periods, and directions, and visualization of output spectra. U.S. Army Corps of Engineers users are supported through the Coastal and Hydraulics Laboratory (http://chl.wes.army.mil/software/sms/), and non-Corps users can get information from ECGL (http://www.ecgl.byu.edu).

STWAVE is a self-contained numerical model capable of executing from a DOS command prompt. However, SMS has a comprehensive environment that provides powerful pre- and post-processing tools to develop and visualize STWAVE input and output files as well as launch an external execution of STWAVE.

This chapter provides a brief tutorial on an application of STWAVE within SMS version 7.1 Beta (October 2000). It does not cover all the SMS features, but describes a typical application of the model starting with grid development from bathymetry, generation of multiple input spectra, monitoring station identification, interpolation of multiple current fields from an ADCIRC finiteelement bathymetry grid, model control, model execution, and visualization of the model results.

Commands in SMS are accessed through pulldown menus located on the menu bar (Figure 5) along the top of the Graphical User Interface (GUI) (Figure 6). The edit window (Figure 5) lies below the menu bar. It includes controls editing coordinates (type in a new value and press the enter or tab key). Powerful modules, tools, and macros are accessible from icons in the tool palette (Figure 6) on the left side of the GUI below the edit window.

The SMS GUI supports six distinct modules, one for each of the following data types: mesh 感, grid 䫆, Cartesian 團, scatterpoint $\stackrel{++}{+}$, , map, and river modules 㗊. The six module icons are located at the top of the tool palette. As you switch from one module to another, the tool palette and menu bar changes. 


\begin{tabular}{|c|c|c|c|c|c|c|c|}
\hline \multicolumn{5}{|l|}{ SMS 7.1} & \multicolumn{3}{|c|}{$-\square x$} \\
\hline \multicolumn{8}{|c|}{ File Edit Display Data STWAVE Window Help } \\
\hline Coverage: & default coverage $\nabla$ & Solution: & Generic Datasets & $\nabla$ & Time Step: $\sqrt{1}$ & No Time & $\nabla$ \\
\hline$X$ coordinate: & 0.000000 & $Y$ coordinate: & 0.000000 & & Z coordinate: & $\longdiv { 0 . 5 0 }$ & \\
\hline X Location: & 50.30 & Y Location: & 508.14 & & Z Location: & $?$ & \\
\hline
\end{tabular}

Figure 5. SMS GUI menu bar and edit window

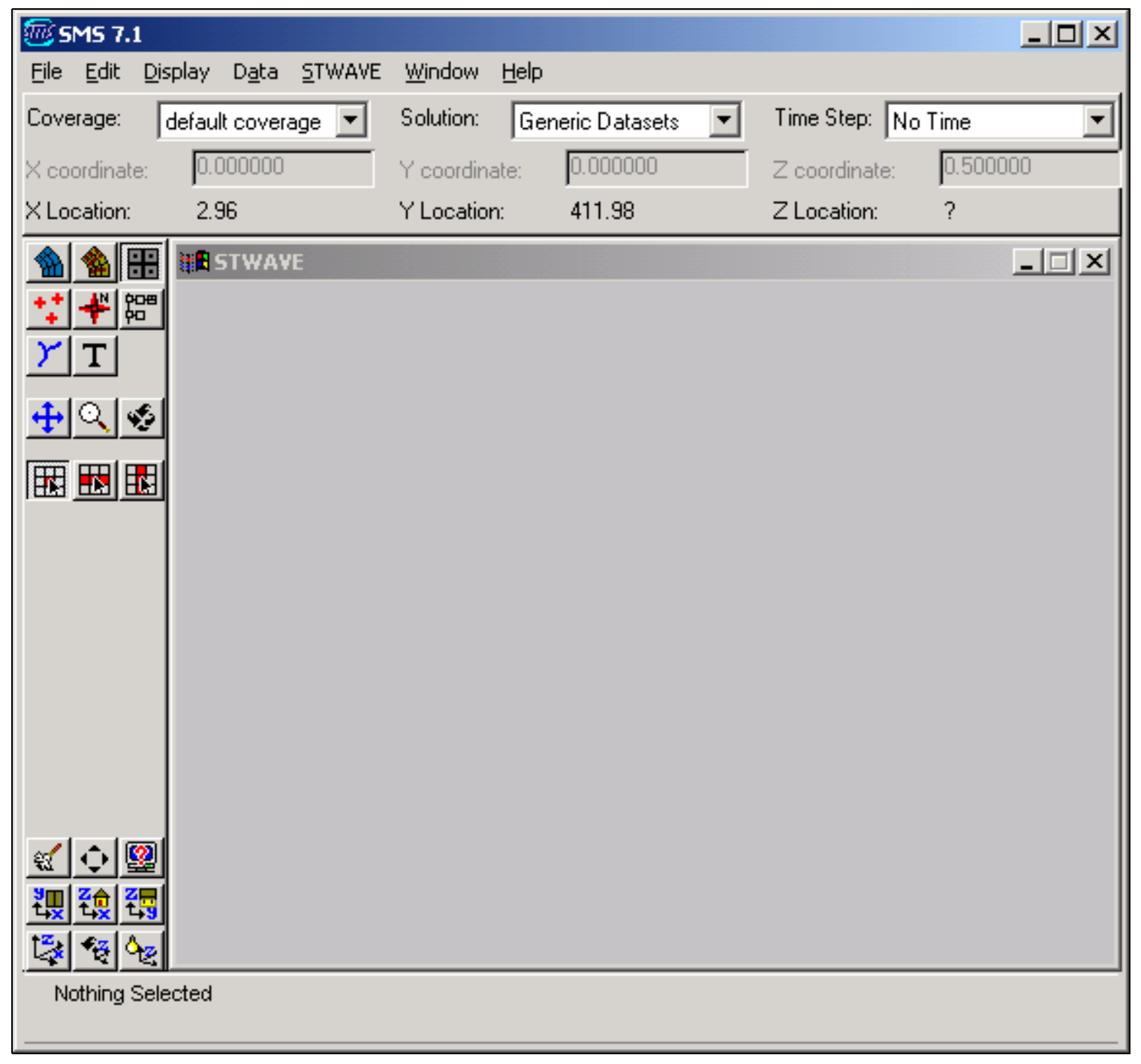

Figure 6. SMS GUI

This allows the user to focus only on the tools and commands related to the data you are currently processing.

To promote clarity throughout this chapter, the SMS GUI menu selections are expressed as Menu | Selection and modules are expressed as DataType 
Module. SMS saves all its working data and settings in project files. These SMS created project files are given the project's name followed by an extension. In this chapter, the primary SMS project file is expressed as project.spr while other SMS project files are designated in the text as project. ext.

\section{Build STWAVE Cartesian Grid}

To begin building a grid in SMS, the input bathymetry (xyz) file should be in column format, with comma-, tab-, or space-delimited fields. The bathymetry file may include a file header of any number of lines. These lines may be used for recording the coordinate system, vertical datum, source of data, point of contact, and other pertinent information. SMS can perform coordinate system conversions, add information from nautical charts by digitizing sounding depths, and import map images.

The following series of SMS instructions illustrates the development of a 2-D grid file (project . dep) that is used as the input bathymetry file for STWAVE (Chapter 3, "Bathymetry"):

\section{Start SMS.}

a. Open and read bathymetry file, YAQbath.xyz, and make necessary coordinate system conversions:

\section{Scatter Module $-\stackrel{++}{+}$}

\section{(a) File | Open->YAQbath.xyz.}

(1) File Import Wizard dialog automatically displays. Apply defaults with these exceptions:

i. Scatter Options: Tolerance $=.1$

ii. Convert bathymetry units from feet to meters.

- Current Horizontal System:

$\S \quad$ State Plane NAD27, Oregon North, meters.

$\S \quad$ NGVD27, meters.

- Convert incoming data from:

$\S$ State Plane NAD27, Oregon North, feet.

§ NGVD27, feet. 


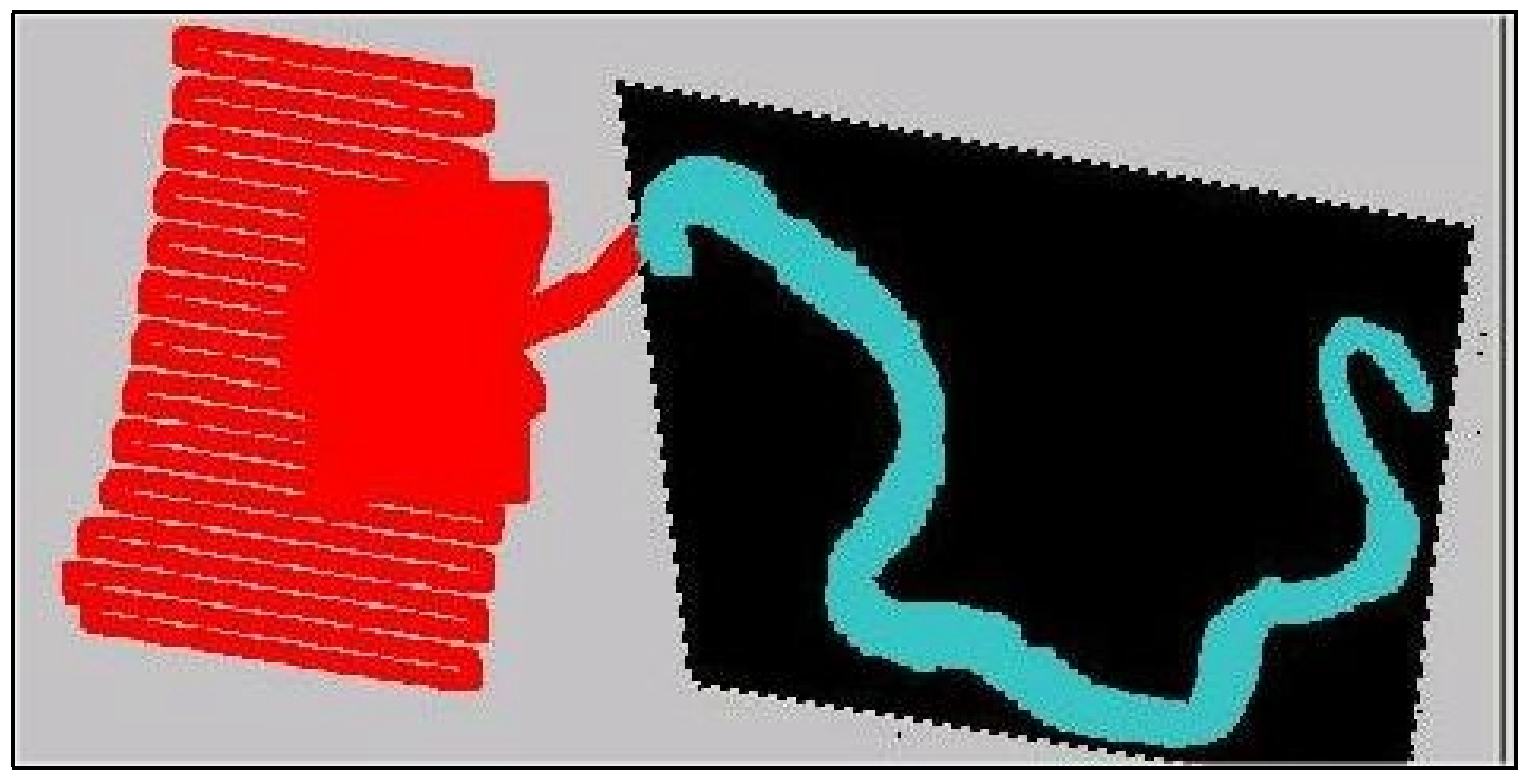

Figure 7. Bathymetry scatter set with excess river points featured in black area

$b$. Remove excess river points from bathymetry scatter set. River points to be removed are outlined in black in Figure 7.

1. Scatter Module $-\stackrel{++}{+}$

(a) Edit | Select with poly...

(1) Click mouse at points around river section to be removed.

(2) Double-click to close selection area.

(3) Edit $\mid$ Delete to remove points.

(4) Repeat the previous steps as needed.

c. STWAVE requires positive Z-coordinate values. YAQbath.xyz bathymetry file has negative Z-coordinates that SMS can convert to positive Z-coordinates by:

1. Scatter Module $-\stackrel{++}{+}$

(a) Data | Transform-

(1) Depth $<->$ Elevations.

d. The land/ocean boundary can be improved for this data set by importing a scanned image (18581a.tif) of the Yaquina area from NOS chart 
18581 to display in SMS with the bathymetry points (aerial photographs may also be used). The image should be in TIFF format.

1. Scatter Module $-\stackrel{++}{+}$

(a) File | Open -> 18581 a.tif. The Register Image dialog automatically appears. See the SMS "Register Image" Help topic for further explanation of registering an image.

(b) To register the image for use as a background display, you need to know the coordinates of three locations (street, railroad, or latitude/longitude point on a map, etc.) on the image. Align each + symbol with its known reference point on the image. This alignment defines the three $\mathrm{U}, \mathrm{V}$ coordinates (local image coordinates) in the edit fields below the image. Then, enter the $\mathrm{X}, \mathrm{Y}$ values, which are the state plane coordinates in meters corresponding to these reference points, in the edit fields below the image.

(1) To enlarge an area on the image, click the Zoom Tool $Q$ and drag the mouse cursor over the + symbol to form a rectangle (click the Frame Macro Tool to zoom out). For this example, the user can directly input the U, V, X, and $\mathrm{Y}$ to properly register the image.

i. Point \#1

1. $\mathrm{U}: 660$

2. $\quad \mathrm{V}: 2134$

3. $\mathrm{X}: 329335.841$

4. $\mathrm{Y}: 113546.3735$

ii. Point \#2

1. $\mathrm{U}: 622$

2. $\mathrm{V}: 578$

3. $\mathrm{X}: 325372.4217$

4. Y: 113721.0504

iii. Point \#3

1. U: 2807

2. $\mathrm{V}: 525$

3. $\mathrm{X}: 325126.0839$

4. Y: 108170.6839

(c) Click OK. 
e. Land boundaries are not defined in the scatter set. The following instructions set the shoreline to $0.0 \mathrm{~m}$ and the land to $-2.0 \mathrm{~m}$ by digitizing those features from the NOS chart image:

1. Map Module - $\$$

(a) FeatureObjects | Coverage

(1) CoverageType -> STWAVE.

(b) ToolPallette->Create Feature Arc Tool - $5^{\circ}$

(c) Click mouse cursor along shoreline. Continue clicking the cursor around the land area until the arc is completed.

(d) FeatureObjects | BuildPolygon. In response to the dialog asking whether to Use all arcs?, click OK.

(e) Select the Feature Polygon Tool - Then, double-click inside the land polygon. Select Land and OK.

f. To edit or delete a node:

1. Map Module - $\$$

(a) FeatureObjects | Coverage -> CoverageType -> STWAVE.

(b) ToolPallette->Select Feature Arc Tool -

(c) Click on the node ->

(1) hold down left mouse button -> drag node to reposition.

(2) Select Edit | Delete to delete the node.

g. Mapping to the Grid defines the grid origin, orientation, and cell size:

1. Map Module - +

(a) Feature Objects -> Grid Frame->New Grid:

(1) Origin: $x=321470 \mathrm{~m}, \mathrm{y}=108765 \mathrm{~m}$.

(2) Orientation: $350 \mathrm{deg}$. The orientation is the direction of the x-axis, measured counterclockwise from East. This information is used in SMS to visualize the grid in the correct orientation. 
(3) Grid size: $4,700 \mathrm{~m}$ by $5,890 \mathrm{~m}$.

(4) $\mathrm{OK}$

(b) Feature Objects -> Map -> 2D Grid

(1) Cell size $=25 \mathrm{~m}$

(2) Depth $=$ Interpolated (use defaults).

(3) $\mathrm{OK}$

2. Alternatively, the grid position may be defined graphically. Rotate the grid by putting the cursor on the open circle in the lower right corner of the grid and dragging to a new orientation. Translate the grid by grabbing the purple frame or resize by grabbing the black circles on the grid corners or sides. The grid origin is the corner with the I,J axis. Refer to the SMS Grid Frame help topic for more information.

$h$. Map jetty locations. Jetty elevations are not included in the xyz bathymetry, so the jetty elevations must be added to the grid. A scanned image (yaq_entrance.tif) of the jetty location in Tiff format is imported to visualize the jetty location. This image (yaq_entrance.tif) is more current than the NOS image (18581a.tif):

1. Map Module - +

(a) File | Open -> yaq_entrance.tif.

This image will replace any previous image -> OK.

(b) Register the image for use as the grid's background display by identifying three points on the image $(\mathrm{U}, \mathrm{V})$ which correspond to locations having known real world $(\mathrm{X}, \mathrm{Y})$ coordinates.

(1) Coordinates of the three registration points, shown by a + symbol, are listed in edit fields below the image. Drag the large + symbol over the small + symbol having a

corresponding number. Click the Zoom Tool $\mathrm{Q}$ and drag the mouse cursor over the + symbol to form a rectangle. This enlarges the area inside the rectangle. Ensure that the large $\&$ small + symbols are aligned. If not, click on the Select Point Tool $i$ and adjust the small + symbol so that it is centered over the large. Click the Frame Macro Tool to zoom out.

(2) Enter State Plane coordinates (in meters) for the three registration points. 
i. Point \#1:

1. $\mathrm{X}: 323798.2$

2. $\mathrm{Y}: 109018.4$

ii. Point \#2:

1. $\mathrm{X}: 324897.9$

2. $\mathrm{Y}: 113080.5$

iii. Point \#3:

1. $\mathrm{X}: 326104.3$

2. $\mathrm{Y}: 110565.9$

iv. $\mathrm{OK}$

$i$. Turn off bathymetry scatter points:

1. Scatter Module $-\stackrel{++}{+}$

(a) Display | Display Option.

(b) Remove check from Points by clicking the checked box.

j. Change elevations along the jetty to $-4.8 \mathrm{~m}$, which is the jetty crest elevation:

1. Cartesian Grid Module - 國

(a) Display | Display Options.

(1) Check Cells.

(2) Press Contours Options button.

i. Contour Method: Normal Linear

ii. $\mathrm{OK}$

(3) $\mathrm{OK}$.

(b) Select the Zoom Tool 9 . Drag the mouse cursor over the jetty to zoom in on the jetty.

(c) Select the Cell Tool 国. Hold down shift key and click the mouse on cells to be modified. Select the jetty grid cell and at least one grid cell on either side of the jetty center line to total 3 grid cells. Grid cells selected will be color enhanced. From the Edit Window, change the $\mathrm{Z}$ coordinate to -4.8 and press the Enter key. All selected cells are changed to $-4.8-\mathrm{m}$ elevation.

(d) Zoom out by pressing Frame the Data Set in the Tool Palette. 
(e) Cartesian grid completed.

k. Turn off grid frame, nodes \& arcs:

1. Map Module - +

(a) Display | Display Options -> Remove check from Nodes, Arcs, and Grid Frame.

l. File | Save Project... Saves all the SMS working files, updates project.spr, and creates the STWAVE 2-D input bathymetry grid file project . dep. Grid building may be temporarily terminated at any time in the process previously outlined and resumed at a later time if the project was saved.

$m$. To resume the project:

1. File | Open -> project.spr

\section{Generate Input Spectra for STWAVE}

SMS can generate one or more 2-D energy spectra and save the spectra in a file, project.eng. Parameters, which are entered in the Spectral Energy dialog for generating spectra, are saved by SMS in project.txt. This file, project. txt, is not required by SMS or STWAVE. If the file is available, SMS will display the contents in the Spectral Energy dialog providing you with parameters used for generating the 2-D energy spectra.

The number of input wave spectral events determines the number of STWAVE model simulations performed. This example features two events (spectra) having identifiers 175500 and 200700 . When running multiple simulations, the number of events and the event identifiers should be the same for spectra and current fields (Chapter 3, "Incident Wave Spectra"). For this example, 5- and 10-m, 15-sec waves from the west will be generated with ebb and flood current fields.

Begin SMS.

a. Cartesian Grid Module - 回

1. Stwave | Spectral Energy $->$ Solution=Generic Data Sets (Default)

2. Select, Generate Spectra.

3. Enter input spectral parameters. Guidance on selecting these parameters is given in Chapter 3. 
(a) $\mathrm{F}$ num $=25$ (25 frequencies)

(b) $\mathrm{F} \min =0.01(\mathrm{~Hz})$

(c) $\mathrm{F}$ delta $=0.01(\mathrm{~Hz})$

(d) Water depth $=47$ (Depth at offshore boundary in meters)

(e) Wave dir = Global (Use standard wave direction convention or select Local to use STWAVE local convention as defined in Figure 3.)

(f) Check option to Replace Old Spectra.

(g) Number of Rows: 2 (number of events to generate)

(h) Index $=175500, \mathrm{H}=5 \mathrm{~m}, \mathrm{~T}=15 \mathrm{sec}$, Angle $=250 \mathrm{deg}$, WindSpeed $=15 \mathrm{~m} / \mathrm{sec}$, WindDir $=270 \mathrm{deg}$, Tide $=-1.0 \mathrm{~m}$.

(i) Index $=200700, \mathrm{H}=10 \mathrm{~m}, \mathrm{~T}=15 \mathrm{sec}$, Angle $=250 \mathrm{deg}$, WindSpeed $=15 \mathrm{~m} / \mathrm{sec}$, WindDir $=270 \mathrm{deg}$, Tide $=-1.0 \mathrm{~m}$.

(j) Press Generate.

4. If spectra are not visualized on the Spectral Energy Dialog, move the cursor around the window and look at the top of the dialog for numbers to display after each Cursor parameter: Freq, Angle, and Energy. If Cursor parameter values do not appear, this indicates that spectra have not been generated. Repeat steps provided previously to generate spectra. If Cursor parameter values do appear, click the Contour Options in the upper left corner of the Spectral Energy Dialog.

(a) Change the option, Contour between Specified Range, to

(1) Maximum Value $=1.0$ (energy density)

(2) Press $\mathrm{OK}$

5. To plot frequency and directional distributions of spectra:

(a) Select Freq. Plot button.

(b) Select Dir. Plot button.

6. When multiple input spectra are available for visualization, choose one by selecting a time or integer from the Time Step option at top right of the Spectral Energy Dialog or click the Data Browser and select a Time Step. 
7. Press OK to close the Spectral Energy Dialog.

b. File | Save Project... Saves all the SMS working files, updates project. spr, and creates the STWAVE 2-D energy spectra file project. eng. If the project was saved, development of input spectra may be temporarily discontinued at any time in the process outlined above and resumed at a later time.

c. To resume a project:

1. File | Open -> project.spr

\section{Identify Monitoring Stations}

A convenient point and click capability is available in SMS for the user to select monitoring stations. Then, monitoring station locations are saved in the STWAVE input file project . std as I- and J-grid-cell indices (Chapter 3, "Model Parameters"). After running the model, wave spectra for each monitoring station are written to the STWAVE output file project. obs (Chapter 4, "Selected Wave Spectra"). Also, model results for wave parameters $H_{m o}, T_{p}$, and mean wave direction, $\alpha_{m}$, are written to the STWAVE output file selhts for each monitoring station.

\section{Start SMS}

a. Cartesian Grid Module - 回

1. Display monitoring station (cell) on the grid by denoting with a red box inside the cell. The red box symbol can be changed in the STWAVE Display Options.

(a) Display | Display Options->check Cells.

(b) Press Options...

(c) Only check, Observation Symbol -> OK

(d) $\mathrm{OK}$

2. Repeat the following steps for each cell you wish to identify as a monitoring station. In this example three monitoring stations are identified at cell locations: $(110,157),(131,117),(146,86)$

(a) Click Select Cell 国 in the Tool Palette.

(1) OPTION: Click your mouse cursor on the screen. The I,J location of the cell is displayed in the bottom right of the 
screen in the edit window. Hold down the shift key to select more than one cell.

(b) From the Menu Bar, select DATA | Find Cell

(1) You may enter the I,J location or the $\mathrm{X}, \mathrm{Y}$ coordinates to identify the cell.

(2) Press OK.

(c) STWAVE | Assign Cell Atts... Check, Monitoring Station. Then, press OK.

File | Save Project... Saves all the SMS working files, updates project.spr, and creates the monitoring station file project. std.

\section{Wave-Current Interaction}

Wave-current interaction requires current fields imported from a hydrodynamic model (e.g., ADCIRC, RMA2, or some other source) on the STWAVE grid. The extent of the current model domain must be the same or larger than the wave model domain. Many STWAVE simulations can be made using one current field (ICUR $=2$, Chapter 3 ) or current fields may be specified for each input wave spectrum (ICUR=1, Chapter 3). If the second option is chosen, the number of current fields must equal the number of input spectra. For this example, there are two input current fields having event identifiers, 175500 and 200700. Because wave-current interaction is also specified for this example, the number of input spectra events equals the number of current field events, and the event identifiers for input spectra match the event identifiers for current fields (Chapter 3, "Current Fields").

Two ADCIRC model files are used to build the SMS current grid. The first file, grid.14, is an ADCIRC input file containing the finite-element grid, bathymetry, and boundaries. The second file, Current_base.64, is an ADCIRC output file containing velocities ( $u$ and $v$ ) at each grid node.

The following SMS instructions create a 2-D current grid file (project.cur) that is used as the input current field file for STWAVE. Note: create a new directory for processing current field data, and place a copy of files grid.14 and Current_base.64 in the new directory. This precautionary measure is to avoid possibly overwriting the STWAVE Cartesian grid or project working files outlined in "Build STWAVE Cartesian Grid."

Start SMS.

a. Mesh Module - 蕆

1. Display | DisplayOption 
(a) Check: elements, contours, and mesh boundary.

2. $\quad$ File | Open -> grid.14 as a file of type: (*.grd, *.14).

3. Data | DataBrowser | Import -> current_base.64 as ADCIRC unit 64: $(* .64, *$.sol $)$.

(a) Create a new solution set? OK.

(b) Press, Vector -> Scalars:

(1) Check, All Time Steps

(2) Select $\vee x \& \vee y$

(3) Perform the conversion.

(4) Done.

(c) Done.

4. Data | MeshToScatterPoint -> scatter1, OK

b. Scatter Module $-\stackrel{++}{++}$

\section{Display | DisplayOptions->Points off.}

c. Reduce image. The area to retain is on the right side of the mesh approximately halfway down where you will notice a sinuous feature. This feature is the river referenced previously in this chapter when discussing how to "Build STWAVE Cartesian Grid." Several iterations of the following commands are needed to remove excess points.

1. Mesh Module -

(a) Edit | Select with Poly...

(1) Click mouse around the grid at points to be removed.

(2) Double-click to close selection area.

(3) Edit->Delete.

(4) Tool Palette | Frame Tool -to zoom out.

(5) Repeat 1-4 as needed.

$d$. Change the coordinate system of the input current field to the coordinate system of the wave model. 
1. Scatter Module $-\stackrel{++}{+}$

(a) Edit | CoordinateConversions:

(1) Select, Current Options (for incoming data):

i. Horizontal $=$ Geographic NAD27

ii. Vertical=NGVD 29, meters

(2) Select, Convert to (same coordinates as STWAVE grid):

i. Horizontal=State Plane NAD 27, Oregon North, meters

ii. Vertical=NGVD29, meters

(3) Select, Conver†

i. A dialog may appear stating: Unable to find NAD27sp. Do you want to search for the file?

ii. Select, OK.

iii. NAD27sp is usually in directory $\mathrm{C}:$ ProgramFiles $\backslash S M S 70 \backslash$ latlon

e. Mapping to the grid defines the grid origin, orientation, and cell size to match the STWAVE grid previously generated:

1. Map Module -

(a) FeatureObjects | Coverages->STWAVE, OK

(b) FeatureObjects | Grid Frame

(1) $X=321470(\mathrm{~m})$

(2) $\mathrm{Y}=108765(\mathrm{~m})$

(3) Angle $=350(\mathrm{deg})$

(4) Grid size: $4700(\mathrm{~m})$ by $5890(\mathrm{~m})$.

(5) Cols/Rows: 188,236

(c) FeatureObjects | Map->2-D Grid

(1) Cell size $=25(\mathrm{~m})$ 
(2) Select, Depth Interpolated

(3) Press, elevation.

i. Interpolated Method: Linear

ii. Scatter Set: scatter1 (Same name assigned in prior mesh to scatter set conversion.)

iii. Function: Magnitude (64)

iv. Time-Steps: Single

v. Time-Step Interpolation: Match Time-Steps

vi. OK

vii. NOTE: This example is using high-resolution bathymetry data to generate the STWAVE grid. When that is not available, this step can also generate an STWAVE depth grid based on the ADCIRC bathymetry.

(4) Check, Current.

(5) Press Interpolated to interpolate the current fields.

(6) Press, Velocity(64).

i. Interpolated Method: Linear.

ii. Scatter Set: Same name assigned in Depth Interpolated.

iii. Time-steps: Multiple.

iv. Select, Velocity64

v. Select, $X / Y$

vi. Time-Step Interpolation: Match Time-Step

vii. $\mathrm{Beg}=175500$, End $=200700$

viii. OK

(7) $\mathrm{OK}$

f. Turn off Mesh Points: 
1. Mesh Module -

(a) Display | DisplayOptions
(1) All off
(2) $\mathrm{OK}$

g. Save all the SMS working files, update project.spr, and create the STWAVE 2-D input current field file project. cur. If the project is saved, current field file building for input to STWAVE may be temporarily discontinued at any time in the process outlined above and resumed at a later time.

\section{File | Save Project...}

h. To resume a project:

\section{File | Open -> project.spr}

$i$. Ensure that project . cur is copied to the STWAVE project directory, and that project. cur reflects the STWAVE directory's project name.

\section{Model Control}

The Model Control dialog lets the user select appropriate settings for the application of the STWAVE model. These settings are saved by SMS in the STWAVE input file, project.std (Chapter 3, "Model Parameters").

\section{Start SMS}

a. Cartesian Grid Module - 㬂

\section{STWAVE | Model Control...}

(a) Check grid definition. The cell size and number of columns/rows are read from project.dep. Do not change these values. The origin and azimuth values (project.sim) do not affect computations, but are used in SMS visualization.

(1) Cell size (m): 25 .

(2) Number of columns: 188

(3) Number of rows: 236

(4) X origin (m): 321470. 
(5) Y origin (m): 108765.

(6) Azimuth (deg): 350.

(b) Index: Time-Step

(c) Source Terms: Source Term \& Propagation

(d) Wave Current Interaction: Currents

(e) Breaking: Write Indices

(f) Radiation Stresses: Calculate

(g) $\mathrm{OK}$

$b$. File $\mid$ Save Project... Saves all the SMS working files, updates project.spr, and creates the STWAVE input parameter file project.std (Chapter 3, "Model Parameters").

\section{Run STWAVE}

When all the necessary input files are created (bathymetry, input spectra, monitoring stations, current (optional), and model control), the model is ready to simulate conditions specified by the input. STWAVE results are saved in project.obs, project.wav, selhts, project.brk, and radstress (Chapter 4 )

\section{Start SMS}

a. Cartesian Grid Module - 回

1. File | Open -> project.sim

(a) STWAVE $\mid$ Run model.

(1) A dialog appears identifying the path to the STWAVE executable.

\section{i. Click OK.}

(2) Then, a DOS window is launched with model output directed to the screen. When the STWAVE model run completes, the message, Press return to continue, is written to the DOS window. The DOS window disappears after you press the return key. 
STWAVE may be run outside of SMS from the command prompt by entering the command stwave3 project. sim. Here, stwave 3 represents the model's executable filename and project.sim identifies the name of the simulation file saved by SMS. If the user wishes to build a project. sim file for input into SMS, the file should be in column format, with comma-, tab-, or spacedelimited fields.

a. The following example project. sim file specifies the STWAVE grid origin, orientation azimuth, and the STWAVE input and output files:

$\begin{array}{ll}\text { STWAVE } & \text { xorg yorg azimuth } \\ \text { DEP } & \text { project.dep } \\ \text { OPTS } & \text { project.std } \\ \text { CURR } & \text { project.cur } \\ \text { SPEC } & \text { project.eng } \\ \text { WAVE } & \text { project.wav } \\ \text { OBSE } & \text { project.obs } \\ \text { BREAK } & \text { project.brk } \\ \text { SPGEN } & \text { project.txt }\end{array}$

\section{Load Simulation}

Visualizing STWAVE model results is possible for simulations launched from within SMS or from the command prompt as described previously in "Run STWAVE." Because STWAVE is a self-contained model, its model results are not saved within SMS. So, when a simulation finishes, you will need to load the simulation file, project.sim, into SMS.

The directory where project.sim resides should also contain the files referenced by project. sim with some exceptions. Three optional project.simfiles, project.cur, project.brk, and project.txt may not be in the directory. If the optional files are not in the directory, a warning dialog will display a message to that effect. Click OK to continue. This helpful warning is only to inform the user of file status. For a list of the files referenced by project.sim, see the previous section, "Run STWAVE."

Start SMS.

a. File | Open-> project.sim. 


\section{Visualize Simulation Output}

As part of the SMS comprehensive environment, powerful post-processing tools are provided to visualize wave information estimated by the model. Estimated wave information is identified in SMS as a data set. Data sets consist of a scalar or vector value for each cell in the grid. Data sets are considered steady state if they have no time steps and are considered dynamic if they represent different points in time. Refer to the SMS Help topic "Data Sets" for more information.

Use the Edit Window (Figure 8) or the Data Browser to select Scalar or Vector data set information. If data sets are representing different points in time, the time-steps for the data sets are listed in the Time-Step list box. The identified data set is called the Active Data set.

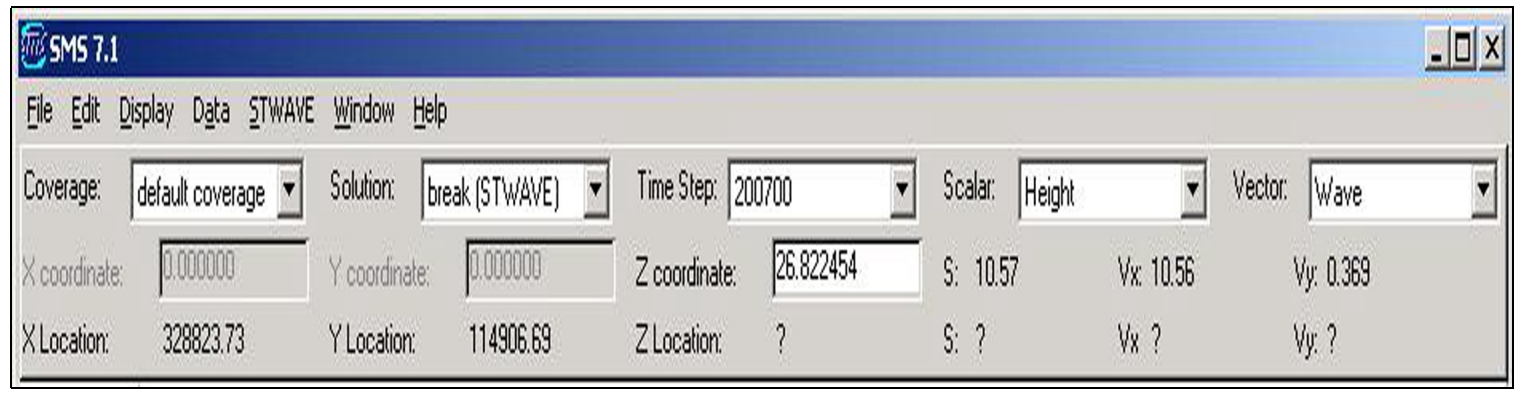

Figure 8. SMS edit window

Wave height estimates are displayed as the default SMS scalar data set. To view wave period and wave direction scalar data sets, locate the Edit Window | Scalar option and change the selection to period or direction. You may also select a specific time-step from the EditWindow | TimeStep list box.

Bathymetry contours may be superimposed over the modeled wave field to visualize a depth frame of reference, as described below.

\section{Visualize and store bathymetry}

To apply bathymetry contours over estimated wave information, store bathymetry contours in a DXF file. Then, load the DXF file to have the bathymetry superimposed on contours of the wave parameters:

\section{Cartesian Grid Module - 國}

a. Save Bathymetry Contours in a DXF file:

1. Edit Window | Solution -> Generic Data sets.

2. Display | Display Options 
3. Check, Contours $->$ Options $->$ Contour Method $->$ Normal linear Contours -> OK.

4. OK.

5. File | SaveAs -> Bathymetry File $->$ File Type = .DXF

b. Load DXF bathymetry contours in SMS:

1. File | Open -> Bathymetry File

2. Open File Format dialog -> Open File As -> .DXF, OK.

3. Dialog, DXF Data Exists. Replace or Append? Replace. OK.

c. Display bathymetry over model wave estimates:

1. Edit Window | Solution -> project(STWAVE)

2. Display | DisplayOptions

3. Check, Contours -> Options -> Contour Method ->Color Filled between Contours -> OK.

4. OK.

\section{Display monitoring stations}

Menu Bar

a. Display | Display Options

b. Check, Cells

c. Click, Cell Options -> Check, Observation Symbol -> OK.

d. OK.

\section{Visualize calculated wave height, period, or direction fields}

\section{Cartesian Grid Module - 國}

a. Select an active data set by setting these three lists in the edit window: 


\section{Scalar}

2. Vector

3. Time-Step

\section{Visualize calculated wave height, period, or direction cell}

Follow previous instructions for "Visualize calculated wave height, period, or direction fields," then:

Select, Cell Tool - 眬

a. Click the mouse cursor anywhere on the display of the calculated wave field.

1. The cell identifier $(\mathrm{I}, \mathrm{J})$ coordinate and other information for the cell is given at the bottom left portion of the SMS screen.

2. The scalar value for the cell of the active data set is displayed in the edit window after "S:". "S:" is located directly below "Scalar" in the edit window.

3. Because this simulation includes currents, the active data set values for "Vx" and "Vy" are displayed to the right of "S:".

\section{Dynamically visualize calculated wave height, period, or direction cell}

Follow previous instructions for "Visualize calculated wave height, period, or direction fields," then:

Select, Cell Tool 国.

a. As the mouse cursor is moved anywhere over the estimated wave field display, notice the third line of the edit window displaying $\mathrm{x}-, \mathrm{y}-, \mathrm{z}-$ coordinates and model results corresponding to the active data set.

\section{Visualize observation spectra at monitoring station}

Energy spectra saved at monitoring stations can be visualized from the Spectral Energy Dialog (Figure 9). Use the Spectral Energy dialog's edit window or data browser to select a monitoring station and time-step. Monitoring stations are identified by their I,J grid location (e.g., Node_110_157, Node_131_117, Node_146_86). Polar and Cartesian contour options and energy frequency and direction plots are available for displaying spectra. 


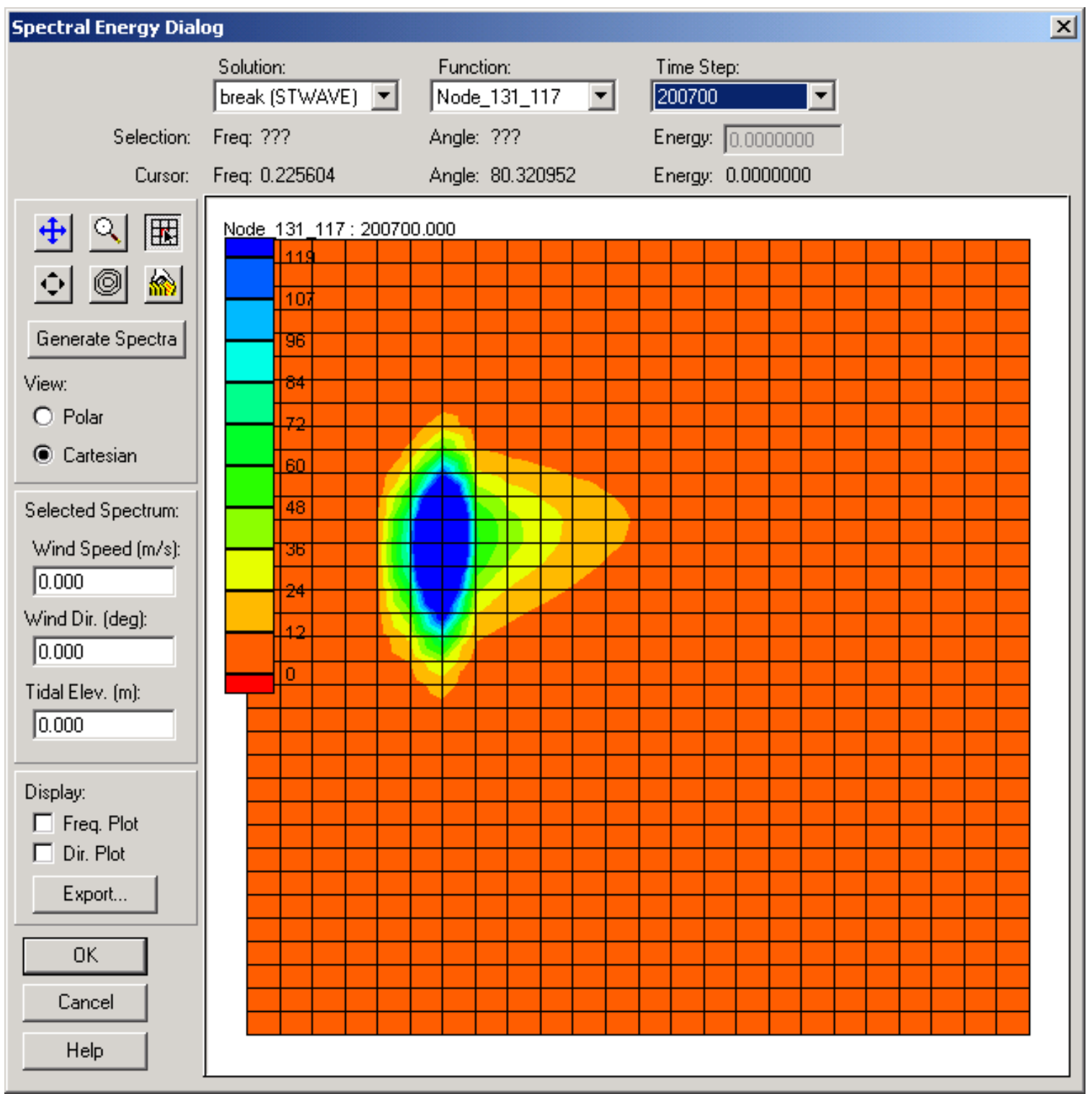

Figure 9. Spectral energy dialog

\section{Cartesian Grid Module - 國}
a. Stwave | Spectral Energy
b. Function: Node_110_157
c. Time-Step: 200700

d. Under the heading, View, check: Cartesian

e. Under the heading, Display, check: Freq. Plot

f. Under the heading, Display, check: Dir. Plot 


\section{Animation film loops}

Multiple STWAVE simulations produce multiple solutions. These solutions can be animated and saved as an AVI file. Refer to the SMS "Animation" Help topic for additional information.

Cartesian Grid Module - 圖

a. Data | Film Loop...

b. Setup

c. On the Film Loop Options dialog in the Data Options section, select:

1. Scalar data set

2. Run simulation from time: 175500

3. Run simulation to time: 200700

4. Match time-steps

5. $\mathrm{OK}$

\section{Two-Dimensional Plots}

SMS offers various 2-D plots. Refer to the SMS Help topic on 2-D plots for a complete list.

A profile plot displays the variation of one or more scalar data sets associated with a mesh or grid along arcs in the observation coverage. For instance, wave heights along an arc may be displayed for a specific event identifier (Figure 10). The arc can be drawn anywhere on the data set:

Map Module - +

a. Feature Objects | Coverages...

1. Coverage Type -> Observation

b. Display | Plot Options

1. New

2. Plot Type: Observation Profile 


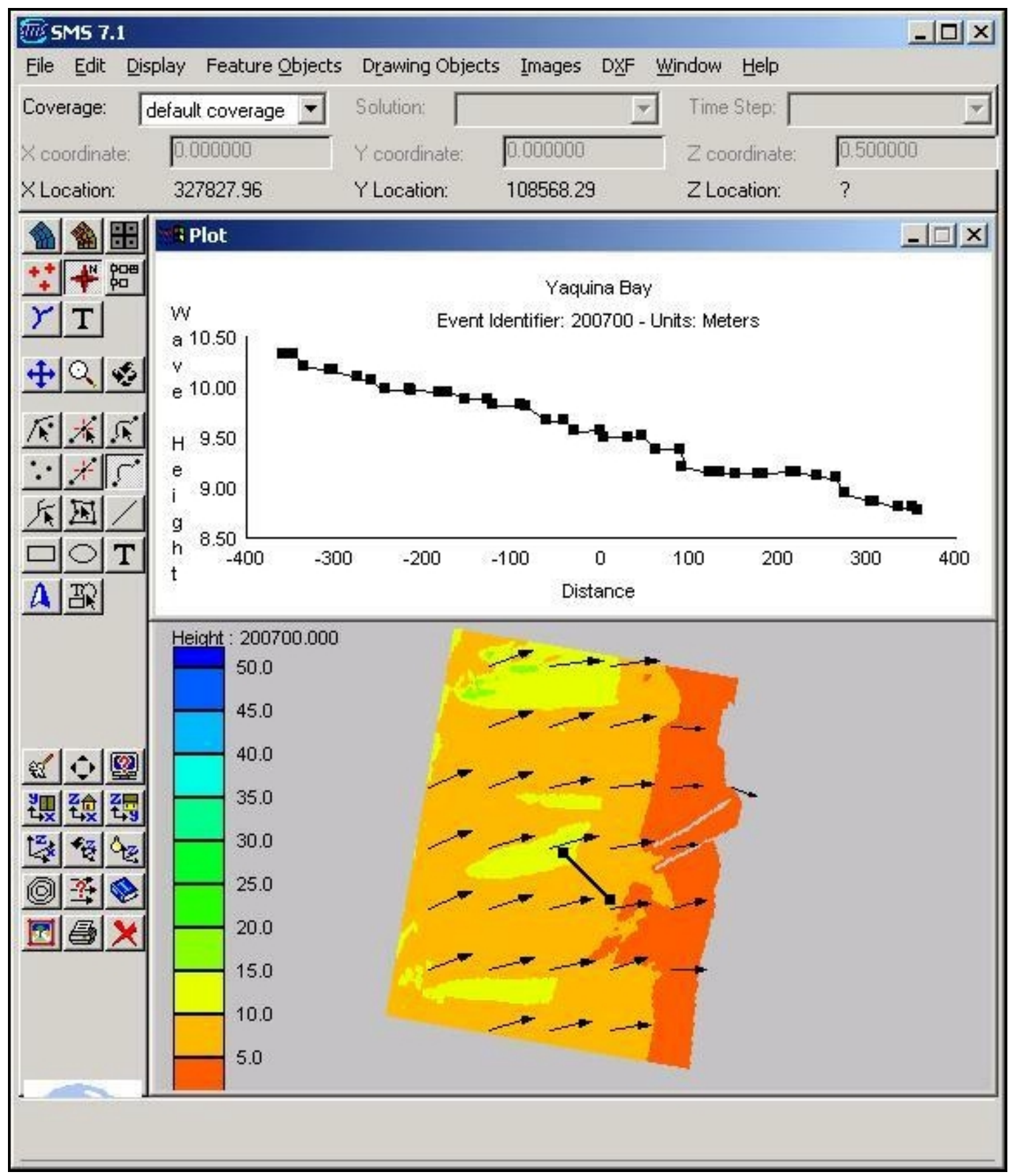

Figure 10. Observation profile 
3. Options:

(a) Select, Use selected data sets:

(1) Highlight: Height

(2) Use time-step: 200700

(3) $\mathrm{OK}$

4. Labels, scales...

(a) Title 2: Event Identifier: 200700 - Units: meters

(b) X-axis: Distance

(c) Y-axis: Wave Height

(d) $\mathrm{OK}$

5. $\mathrm{OK}$

c. Create Feature Arc Tool [

1. Click the mouse on the data set where you want to begin the arc. Move and click the mouse to draw an arc. Double-click the mouse to end the arc.

\section{d. Display | Plot Window}

1. A plot window opens below the edit window and above the STWAVE data set window. You can enlarge the plot window by placing the mouse cursor at the bottom of the window. When the cursor changes to a bar with an arrow- head on each end, press the mouse button and drag the window to the desired size. 


\section{Example Applications}

In this chapter, three example applications of STWAVE are given. The purpose of these examples is to demonstrate how the model can be applied and provide sample problems that a new user can follow to learn the mechanics of model application. The first example is wave transformation and wave-current interaction at a complex coastal entrance on the East Coast. The second example is wind-wave generation over a simple bathymetry. The third example is wave transformation at a West Coast entrance channel using the files generated in SMS following the procedure outlined in Chapter 5. The first and third examples focus on wave propagation and the second example on wave generation (using the source term options).

\section{Example 1: Wave Propagation at Ponce de Leon Inlet}

The first example is based on a field site, Ponce de Leon Inlet, located on the east coast of Florida. The nearshore bathymetry at Ponce Inlet is complex because of the presence of the inlet, a navigation channel, jetties, and a large ebb shoal. Tidal currents at the entrance can exceed $1 \mathrm{~m} / \mathrm{sec}$. Engineering problems at Ponce Inlet that require information about the nearshore wave field include scour in the inlet throat near the north jetty, erosion of the north spit in the interior of the inlet, migration of the navigation channel, and possible breaching shoreward of the north jetty. More information about Ponce Inlet is given in a reconnaissance report by the U.S. Army Engineer District, Jacksonville (1993). Also, a field-data collection program conducted at Ponce Inlet from September 1995 through September 1997 is documented by King et al. (1999). STWAVE applications to Ponce Inlet are documented in Smith, Militello, and Smith (1998) and Smith and Smith (in preparation).

\section{Model input}

Model parameters. Figure 11 shows the bathymetry contours within the STWAVE modeling domain selected for Ponce Inlet. The offshore boundary location is selected at an approximate depth of $18 \mathrm{~m}$. This depth is chosen because the bottom contours are fairly straight and parallel at this depth (out of the influence of the ebb shoal) and because a wave gauge (designated as DWG1 
in Figure 11) was located near this contour to provide the input wave conditions. The lateral boundaries of the domain are positioned away from the influence of the inlet, to areas of fairly straight and parallel depth contours. A 50-m grid cell spacing is selected to resolve the ebb shoal and inlet bathymetry. To cover the domain with $50-\mathrm{m}$ resolution requires 53 cells across the shore (NI) and 112 cells alongshore (NJ). Typical wave periods for this site are 15 to $5 \mathrm{sec}(0.0667$ to $0.2 \mathrm{~Hz}$ ). To resolve this range, 30 frequency bins are used with an initial frequency of $0.031 \mathrm{~Hz}$ and a frequency increment of $0.0078 \mathrm{~Hz}$ (range of frequencies is 0.031 to $0.258 \mathrm{~Hz}$ ). Because the wave propagation distances on the Ponce Inlet grid are short $(2 \mathrm{~km})$, source terms are neglected (IPRP $=1)$. Even with strong winds, wave growth over the short distance would be small. Wave-current interaction, though, could be significant near the inlet, so ICUR $=1$ to include wave-current interaction is selected. Breaker indices are not saved (IBREAK $=0)$, and neither are radiation stress gradients $($ IRS $=0)$. Selected model output locations are chosen to match three directional wave gauge positions at Ponce Inlet (see Figure 11). The depths at the three gauges are approximately 14, 7, and $5 \mathrm{~m}$. The gauges are located near the offshore boundary, on the ebb shoal, and in the outer inlet throat (north of the ebb shoal).

Bathymetry. The bathymetry contours for Ponce Inlet are shown in Figure 11. The grid was developed using the SMS grid generator, which accepts random $x, y$, and depth triplets and interpolates them onto a Cartesian grid with a given origin, orientation, and resolution. In this case, high-resolution bathymetry near the inlet was obtained from a Scanning Hydrographic Operational Airborne Lidar System (SHOALS) (Lillycrop, Parson, and Irish 1996) survey and supplemented with National Oceanic and Atmospheric Administration (NOAA) 
digital bathymetry (used to define offshore and bay bathymetry) and shorelines. The north jetty at Ponce Inlet is represented in the model as a series of land cells. The jetty is specified as being three grid cells wide, which is wider than the real structure. Three cells are required to block wave energy from propagating through the structure. Future upgrades to the model will provide the capability to represent structure widths that are less than the grid cell spacing.

Incident wave spectrum. The incident wave spectrum for Ponce Inlet was generated using a TMA spectral shape (with a spectral peakedness parameter, $\gamma=$ 5.0), $\cos ^{n n} \alpha$ directional distribution (with $n n=12$ ), $H_{m o}=5.2 \mathrm{~m}, T_{p}=12.8 \mathrm{sec}$, and $\alpha_{m}=-7 \mathrm{deg}$ (see Table 1 for guidance on spectra shape and directional spreading parameters). These incident conditions represent extreme high wave conditions measured at Ponce Inlet in March 1996.

Current field. The current field for Ponce Inlet was generated using the tidal circulation model ADCIRC (Luettich, Westerink, and Scheffner 1992). The current field output from ADCIRC was interpolated onto the STWAVE grid using SMS. The current field is plotted in Figure 12.

\section{Results}

The wave parameters for the three gauge positions at Ponce Inlet are given in the selhts file:

$\begin{array}{lrrlll}\text { Date } & \mathrm{I} & \mathrm{J} & H_{m o}(\mathrm{~m}) & T_{p}(\mathrm{sec}) & \alpha_{m}(\mathrm{deg}) \\ 96031202 & 15 & 21 & 5.25 & 12.8 & -6 . \\ 96031202 & 15 & 65 & 4.13 & 12.8 & -5 . \\ 96031202 & 28 & 49 & 2.86 & 12.8 & 18 .\end{array}$

At the first gauge position ( $\mathrm{I}=15, \mathrm{~J}=21$ ), the wave height has shoaled slightly (from $5.2 \mathrm{~m}$ at the boundary to $5.25 \mathrm{~m}$ ) and turned slightly more shore normal (from $-7 \mathrm{deg}$ at the boundary to $-6 \mathrm{deg}$ ). At the second gauge $(I=15, \mathrm{~J}=65$ ), located on the ebb shoal, the wave energy has dissipated because of breaking (reduction of 21 percent in wave height from the offshore boundary). At the most shoreward gauge $(I=28, J=49)$, the energy has been dissipated significantly ( 45 percent reduction in wave height from the offshore boundary) and the mean direction has refracted from $-7 \mathrm{deg}$ at the boundary to $18 \mathrm{deg}$ in the outer throat. The wave directions at this gauge are turning to align normal to the ebb shoal that is located to the south of the gauge (positive angles are more southerly directed and negative angles are more northerly directed).

The trends of wave-height reduction and turning of the wave angle can also be illustrated by examining the one-dimensional wave spectra plotted in Figure 13. The shape of the spectra stays quite similar, but the energy is reduced because of depth-limited breaking from the offshore to the outer throat gauge. Another way to view the spectrum is to integrate over all frequencies to examine the directional distribution of the wave energy (Figure 14). The directional distribution narrows as well as reduces in energy between the offshore and ebb shoal gauges because of refraction. Between the offshore/ebb shoal gauges and 


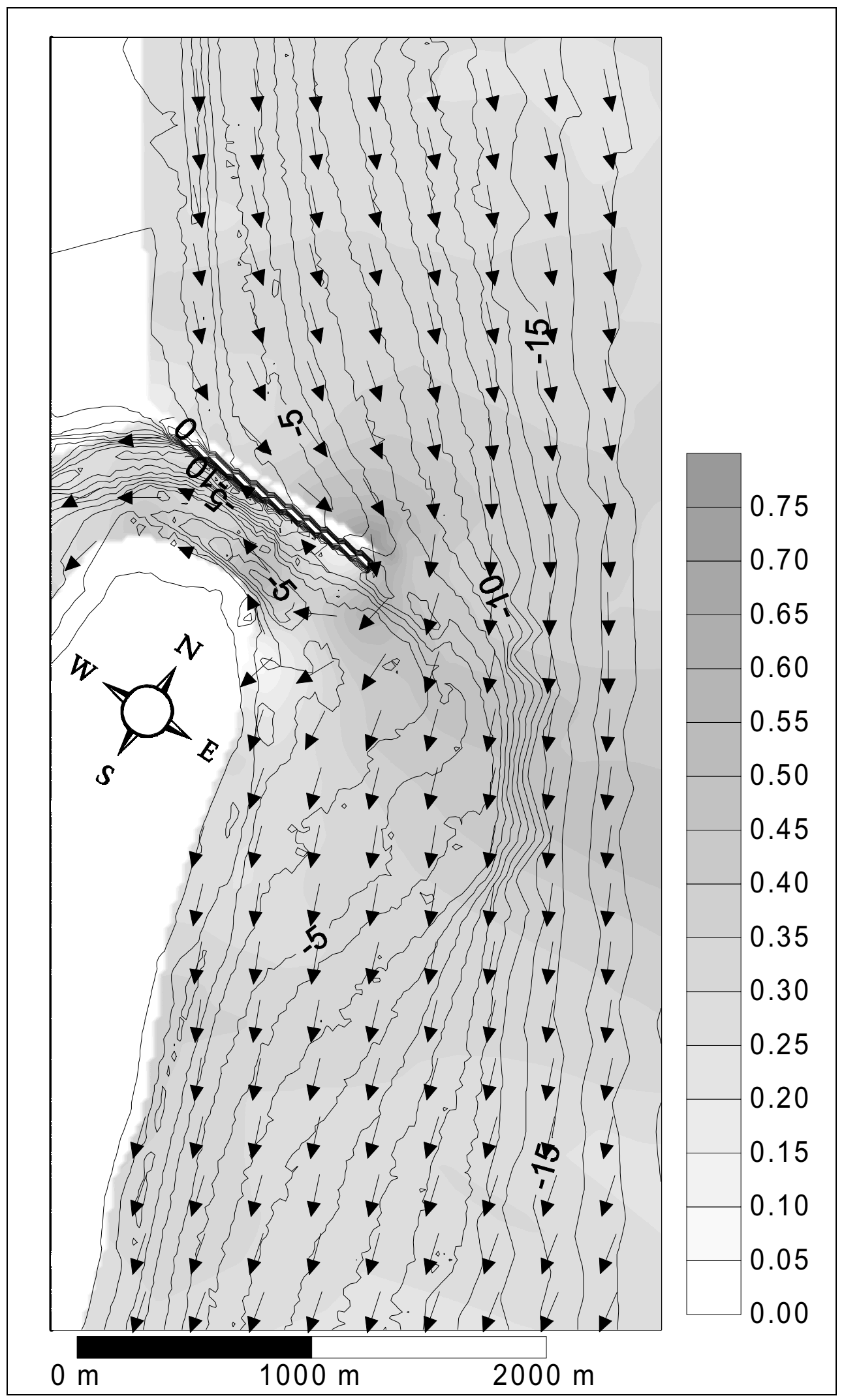

Figure 12. Currents for Ponce Inlet example 


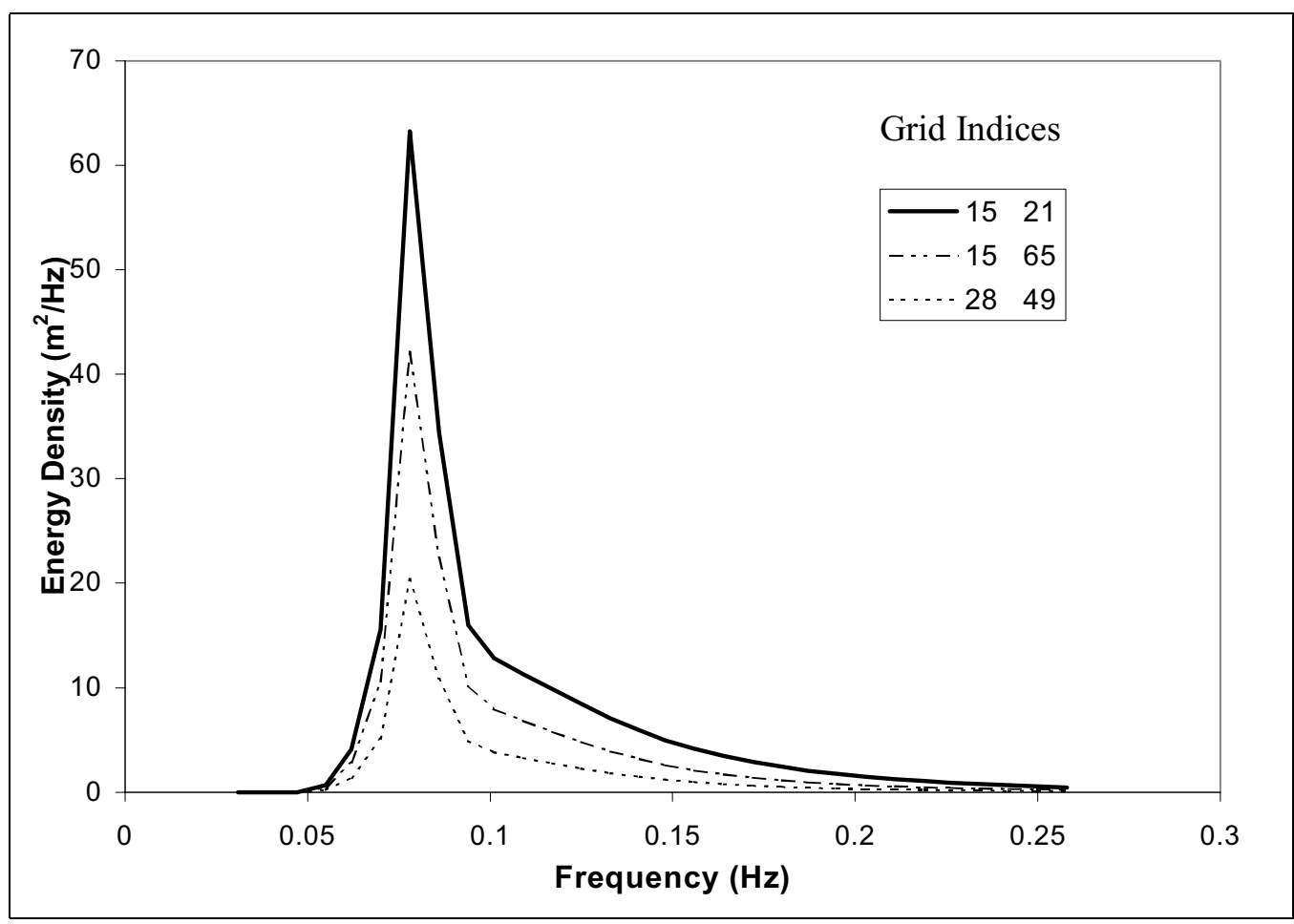

Figure 13. One-dimensional wave spectra for Ponce Inlet

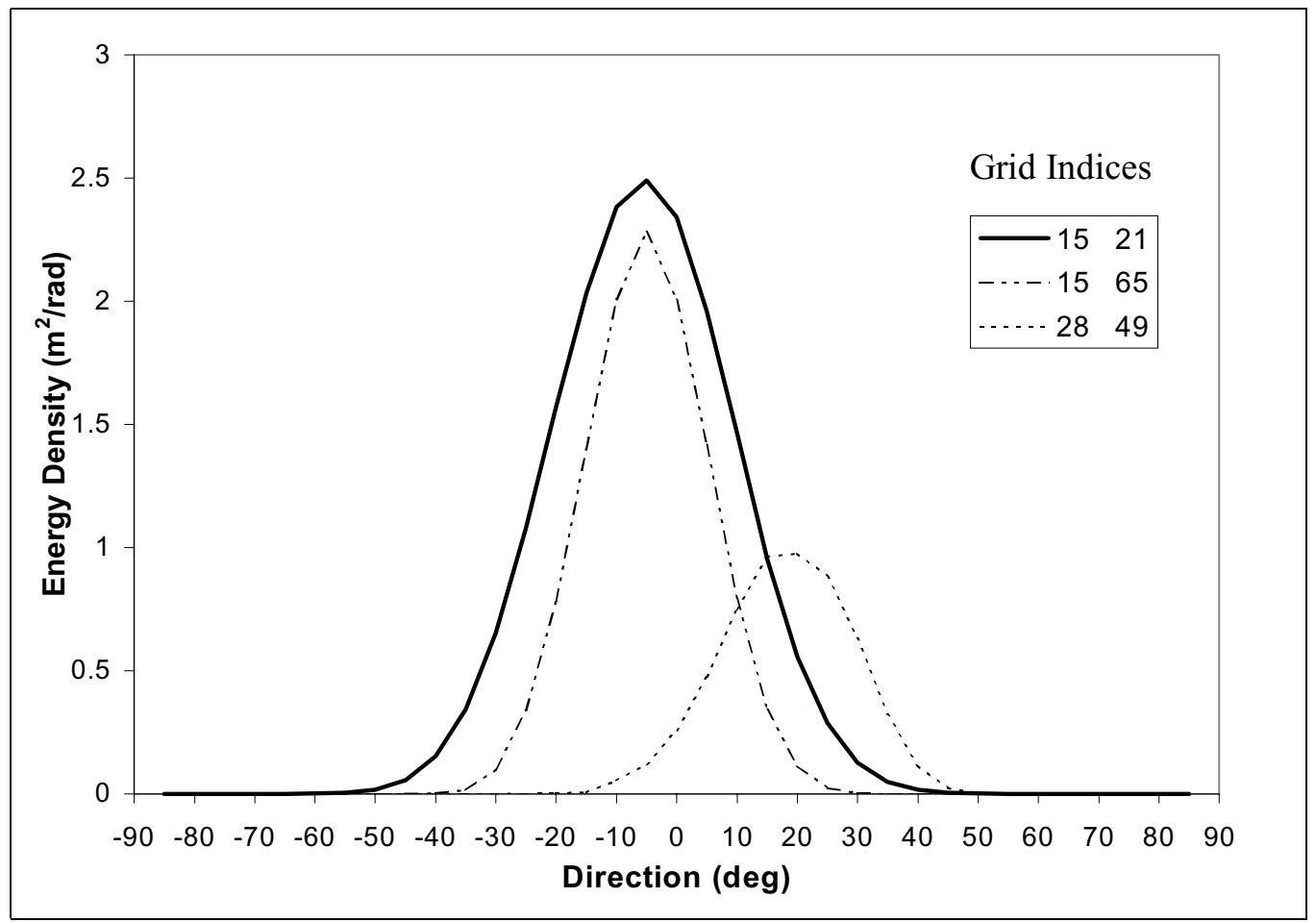

Figure 14. Directional distribution of Ponce Inlet wave spectra 
the outer throat gauge, the mean direction shifts by $25 \mathrm{deg}$, again because of refraction.

Figure 15 shows a contour plot of the wave heights over the entire STWAVE domain. The gray shade contours represent wave height, and the background line contours represent the bathymetry. For these incident wave conditions, the wave-height variations closely follow the depth contours, because depth-limited breaking is the dominant process and thus the wave height contours mimic the depth contours. For cases with less extreme incident wave heights, the maximum wave heights are found on the ebb shoal, where energy is focused by refraction.

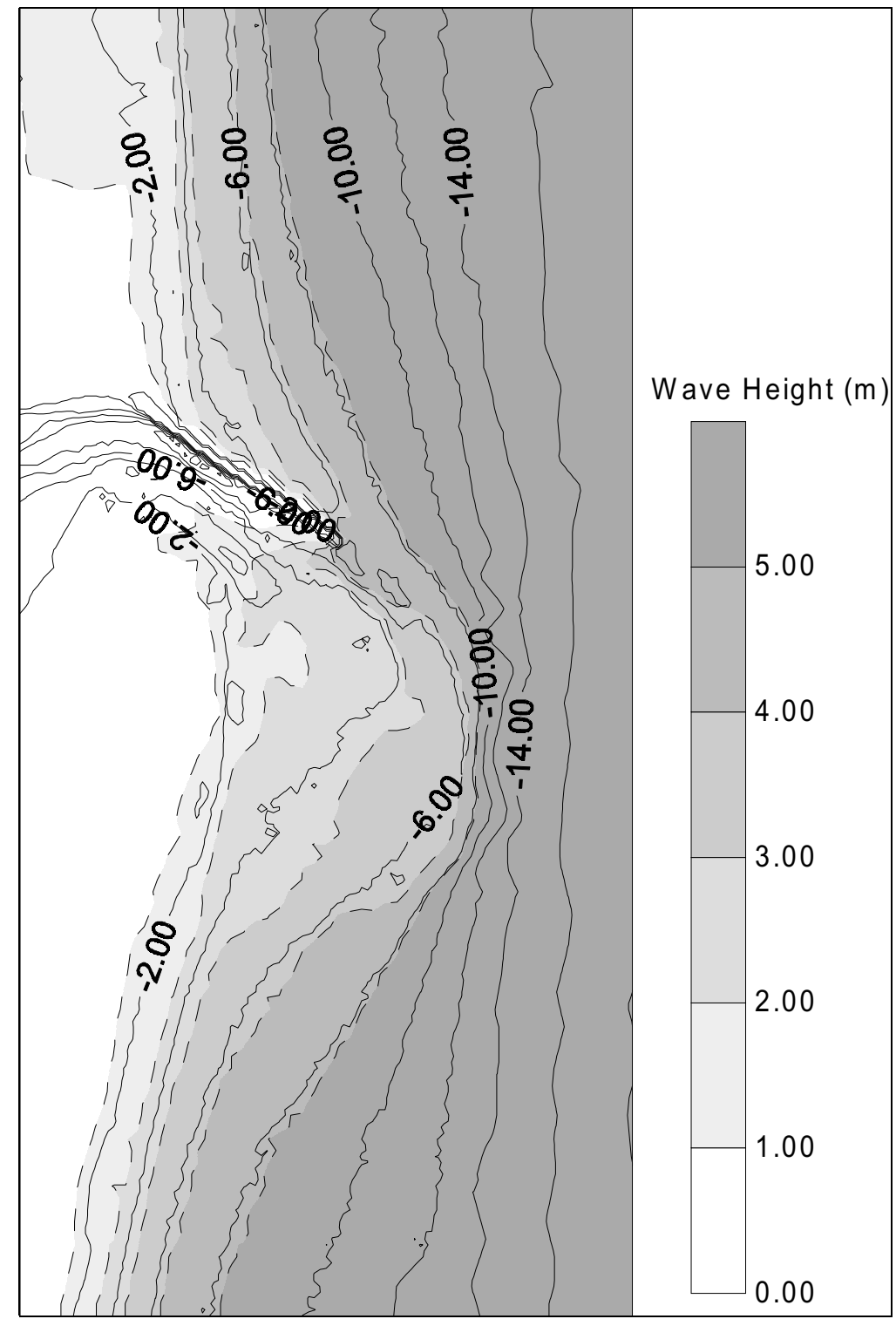

Figure 15. Wave-height contours for Ponce Inlet example 


\section{Example 2: Wind-Wave Generation}

For the second example, consider a bay that is rectangular in shape, $20 \mathrm{~km}$ east-west and $10 \mathrm{~km}$ north-south. For practical purposes, the bay is isolated from ocean waves. The water depth is a constant $15 \mathrm{~m}$, with a gentle side slope of 1:100 at the eastern end of the bay and vertical walls on the other three sides. The bay has a rectangle shape with simplified bathymetry, so users can easily develop the input bathymetry. The grid domain is shown in Figure 16. The area of interest is the eastern shoreline of the bay, where a project is planned to mine sand to construct a beach. For a project such as this, wave information may be required to evaluate sediment-transport rates at the borrow site to estimate infilling rates or evaluate longshore and cross-shore sediment-transport rates at the newly constructed beach to estimate the project's life and renourishment requirements.

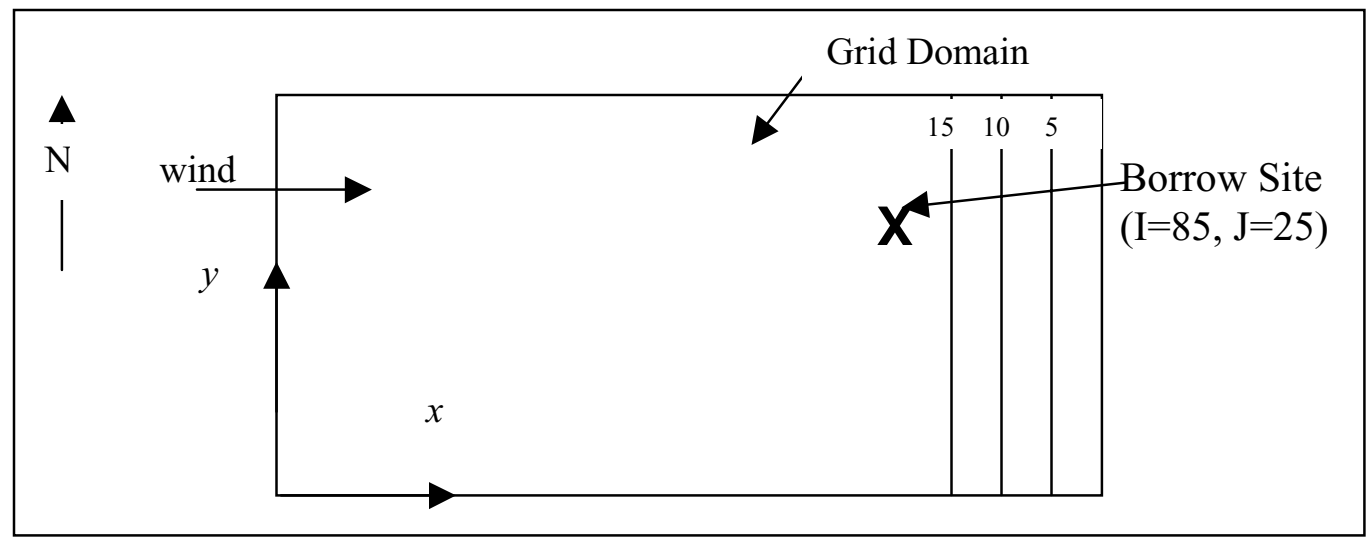

Figure 16. Schematic of Example 2 grid domain

\section{Model input}

Model parameters. Both wave propagation and source terms $($ IPRP $=0)$ are required for this example, but currents are negligible $($ ICUR $=0)$. Breaker indices and radiation stress gradients are not required (IBREAK $=0$ and IRS $=$ $0)$. The special output points are selected to examine wave growth along the major axis of the bay. The borrow site is located near grid cell $(85,25)$. The model parameter input file is:

$\begin{array}{llllll}0 & 0 & 0 & 0 & 10\end{array}$

525

2525

5025

7525

8525

9525

$97 \quad 25$

9825

$99 \quad 25$

10025 
Bathymetry. The bathymetry and shoreline are very simple, and fine bathymetric resolution is not required. A grid spacing (DXINC) of $200 \mathrm{~m}$ is selected, with 101 cells in the cross-shore (NI) and 51 cells in the alongshore (NJ). To simplify the input file for this example, the bay is assumed to have vertical walls on its north, south, and west shores and a 1:100 slope on the eastern shore. The depth in all grid cells along the entire grid boundary is set to 1 for land. The first two grid rows $(\mathrm{J}=51$ and $\mathrm{J}=50)$ of the depth file are given as follows:

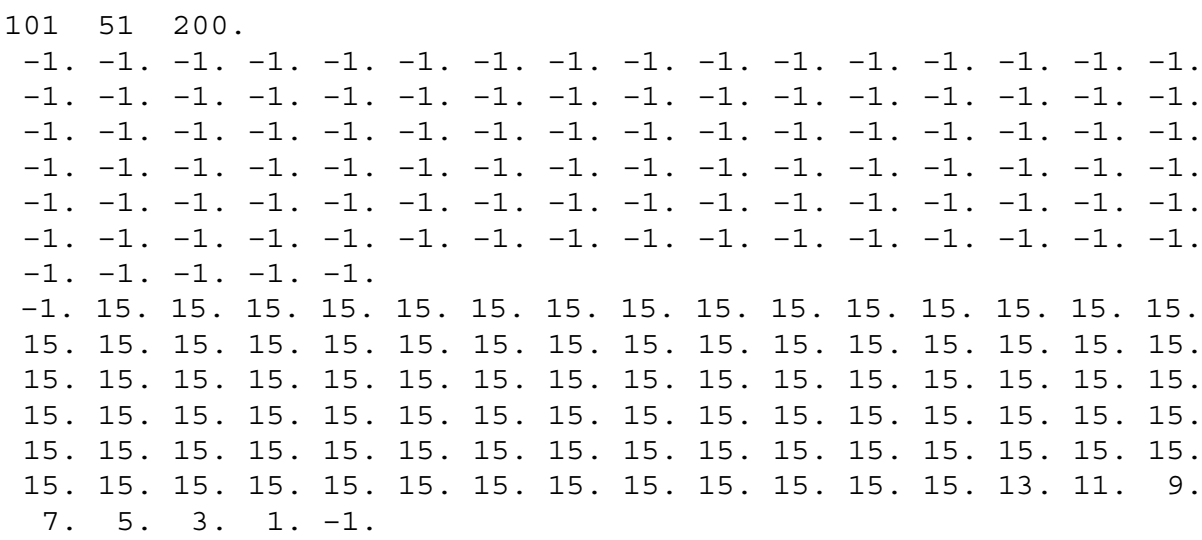

The full depth file would repeat the second series for rows $J=49$ through 2 , and the depths for row $\mathrm{J}=1$ would again all be -1 ., identical to the first series in the file. Note that the first line in the depth file represents the northern edge of the grid $(J=N J)$, reading from west to east $(I=1, N I)$, and the last series in the files would be the southern edge of the grid $(\mathrm{J}=1)$.

Incident wave spectrum. Twenty frequency bins are used with an initial frequency of $0.04 \mathrm{~Hz}$ and a frequency increment of $0.04 \mathrm{~Hz}$. This coarse frequency resolution is sufficient because, even at high wind speeds, the $20-\mathrm{km}$ fetch will limit peak wave periods to approximately 5 to $6 \mathrm{sec}$. The input spectrum is very simple for this example case. Because the bay is treated as an enclosed basin, the spectrum on the "offshore" boundary (the western land boundary for this case) is zero. The input spectrum includes the header with the date and wind information, followed by 700 zeros ( 20 frequencies by 35 directions). For a date identifier of 980923 , a wind speed of $20 \mathrm{~m} / \mathrm{sec}$, a wind direction of 0 deg relative to the STWAVE grid (wind blowing from the west, for this example), a peak frequency of $0.8 \mathrm{~Hz}$ (set to the highest frequency because there is no energy in the input spectrum), and $0.0 \mathrm{~m}$ water elevation correction; the beginning of the spectrum file is given by:

2035

$\begin{array}{llllllllll}0.04 & 0.08 & 0.12 & 0.16 & 0.20 & 0.24 & 0.28 & 0.32 & 0.36 & 0.40\end{array}$

$\begin{array}{lllllllllll}0.44 & 0.48 & 0.52 & 0.56 & 0.60 & 0.64 & 0.68 & 0.72 & 0.76 & 0.80\end{array}$

980923 20. 0.0 .80$.

In the input file, these lines would be followed by 700 zeros ( 35 directions by 20 frequencies) to represent an incident spectrum with no energy. 
Current field. No current field file is specified for this case.

\section{Results}

The results of greatest interest for this case are the wave parameters at the proposed borrow site $(I=85, \mathrm{~J}=25)$. The wave height is $1.52 \mathrm{~m}$, the peak period is $4.6 \mathrm{sec}$, and the direction is $0 \mathrm{deg}$ (from the west, for this grid orientation). The output file with selected wave parameters is given as follows (header has been added):

$\begin{array}{lcclll}\text { Date } & \mathrm{I} & \mathrm{J} & H_{m o}(\mathrm{~m}) & T_{p}(\mathrm{sec}) & \alpha_{m}(\mathrm{deg}) \\ 980923 & 25 & 25 & 0.86 & 3.2 & 0 . \\ 980923 & 50 & 25 & 1.22 & 3.9 & 0 . \\ 980923 & 75 & 25 & 1.45 & 4.4 & 0 . \\ 980923 & 85 & 25 & 1.52 & 4.6 & 0 . \\ 980923 & 95 & 25 & 1.55 & 4.7 & 0 . \\ 980923 & 96 & 25 & 1.53 & 4.7 & 0 . \\ 980923 & 97 & 25 & 1.50 & 4.7 & 0 . \\ 980923 & 98 & 25 & 1.47 & 4.8 & 0 . \\ 980923 & 99 & 25 & 1.23 & 4.8 & 0 . \\ 980923 & 100 & 25 & 0.59 & 4.8 & 0 .\end{array}$

These output wave parameters across the long axis of the bay demonstrate the wave growth as a function of distance along the fetch. These wave heights and periods are plotted as a function of distance in Figure 17. The wave height grows with fetch until the depth decreases on the eastern shore of the bay, and the wave height decays because of depth-limited breaking. The wave direction down the long axis of the bay is aligned with the wind direction $(0 \mathrm{deg})$. Figure 18 shows selected one-dimensional spectra along the long axes of the bay (legend provides I, J locations). Moving from west to east ( $\mathrm{I}=25$ to 95$)$, the peak frequencies decrease (peak periods increase) and the total energy increases, as the waves grow from input wind energy. Between $I=95$ and 100, the energy density decreases because of depth-limited breaking. These one-dimensional spectra were calculated from the spec. out file by integrating the spectra over all directions.

To evaluate the impacts of the borrow site on the shoreline or the sediment infilling rate at the borrow site, additional STWAVE runs would be required. Typically, the local wave climate would be examined, and representative as well as maximum wind conditions would be used as input for multiple model runs. Results from these runs would then be used statistically to evaluate sedimenttransport potential at the borrow site and along the shoreline. Note that the strongest wind speed does not necessarily lead to the largest waves or largest sediment-transport rates. Wind direction is also a critical parameter.

This example of wave growth was for a completely enclosed basin. The wave growth capabilities of the model are also applicable on the open coast. For open-coast applications, the input spectrum would likely not equal zero, and the offshore and lateral grid boundaries would not be land. For open coastal 


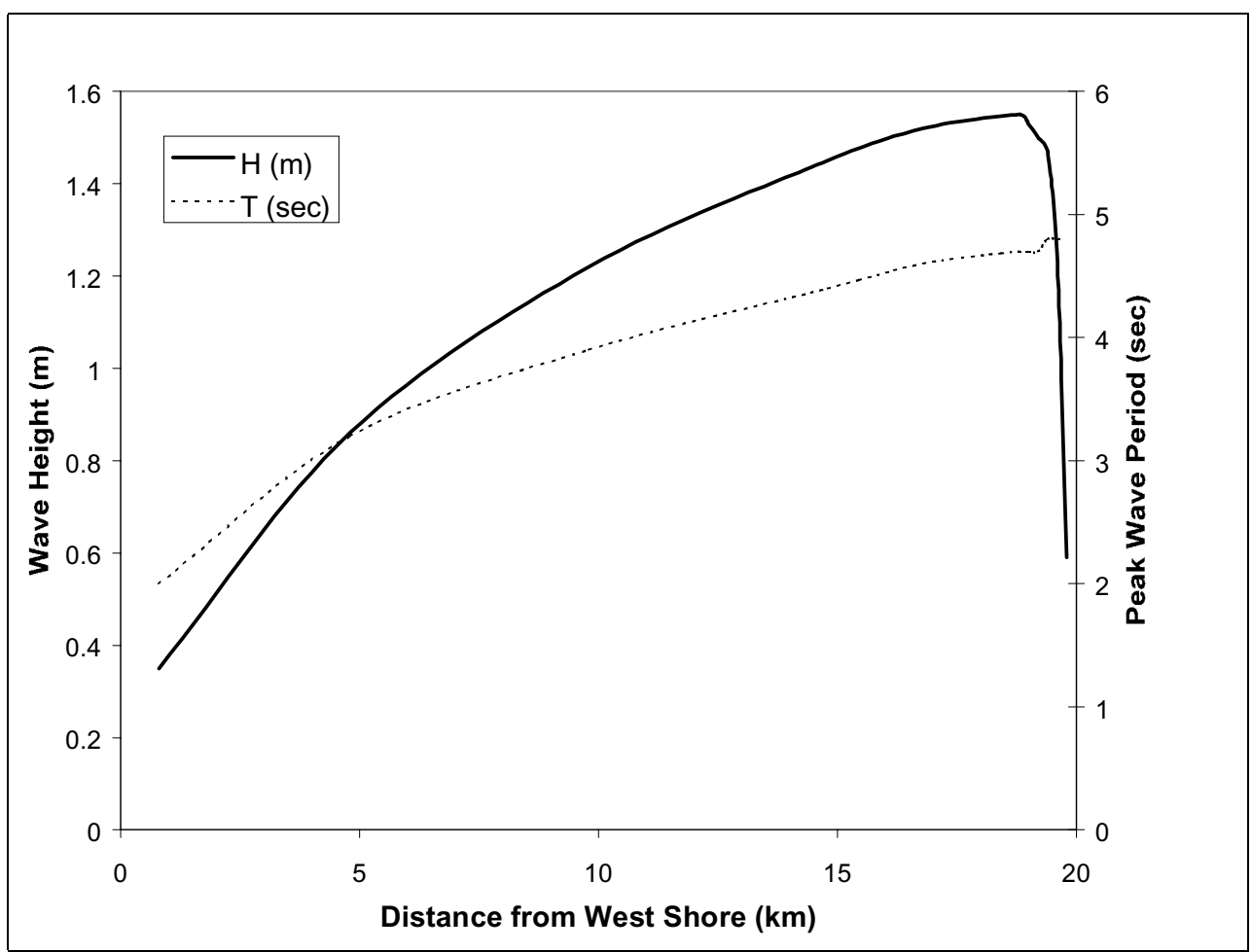

Figure 17. Wave height and period as a function of distance for $20 \mathrm{~m} / \mathrm{sec}$ wind speed

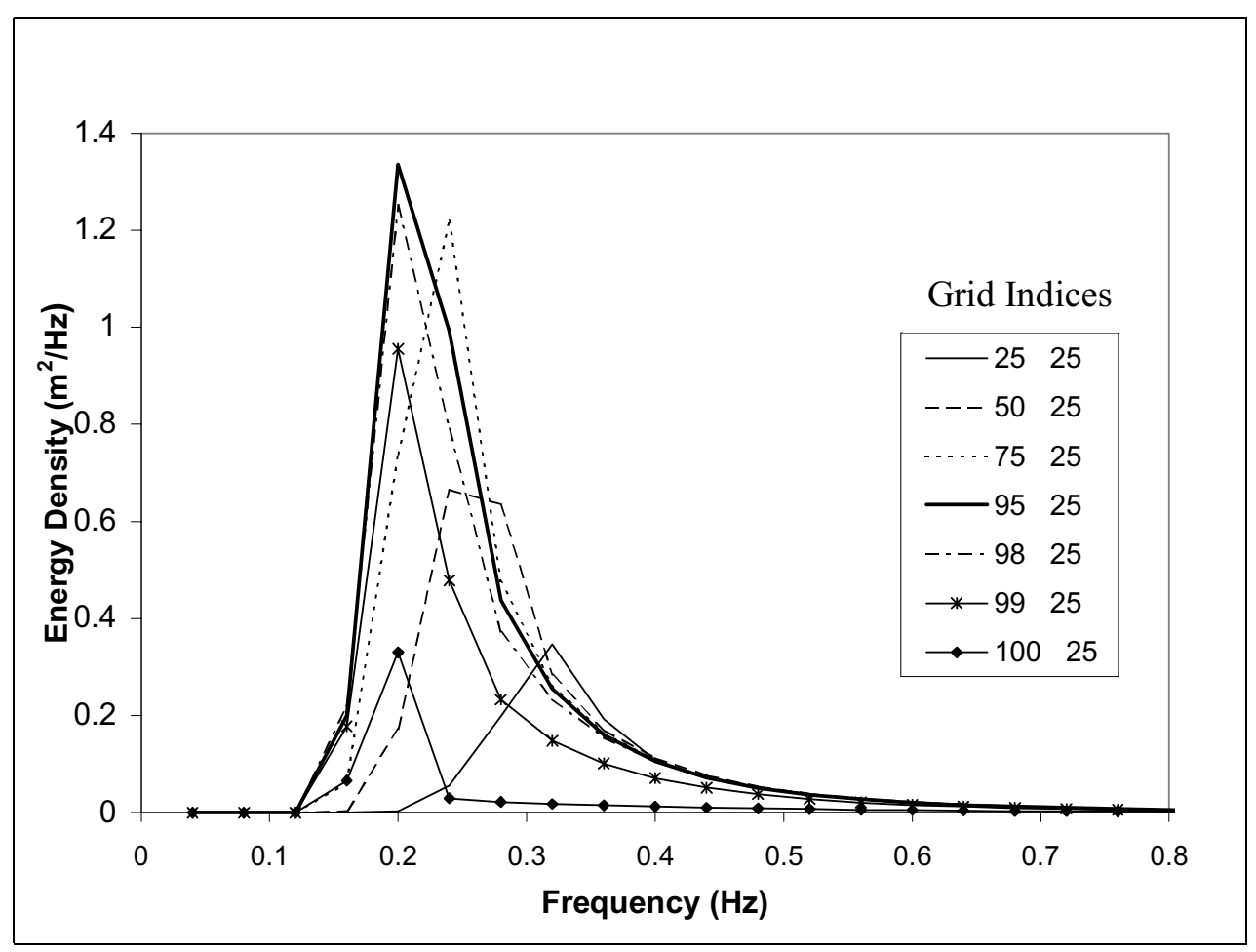

Figure 18. One-dimensional wave spectra for $20 \mathrm{~m} / \mathrm{sec}$ wind speed 
applications, the local wave generation (represented by the source terms) is often an essential process, increasing the wave height near shore and altering wave directions.

\section{Example 3: Wave Propagation at Yaquina Bay Entrance, OR}

The final example is based on a field site, Yaquina Bay Entrance, OR. The nearshore bathymetry at Yaquina is complex because of the presence of the entrance channel, rock reefs, and jetties. Tidal currents at the entrance exceed $1.5 \mathrm{~m} / \mathrm{sec}$, and the tidal range is greater than $2 \mathrm{~m}$. The wave climate off the Oregon coast is severe with observed deepwater wave heights exceeding $12 \mathrm{~m}$. The north Yaquina jetty was repaired in 1988 and has experienced progressive loss of the head of the jetty since 1996 (approximately $110 \mathrm{~m}$ of jetty length has been lost). Quantitative information about waves at the entrance was required to support structure redesign and to evaluate navigability. More information about the Yaquina Bay Entrance north jetty is given by Hughes et al. (1995).

The nearest wave gauge to Yaquina Bay is a National Data Buoy Center buoy located $35 \mathrm{~km}$ off the coast in a depth of $130 \mathrm{~m}$. It is not practical to transform the measured waves from the buoy to the entrance at fine resolution. Although high resolution $(25 \mathrm{~m})$ is required in the nearshore to define the reefs and entrance channel, coarser resolution is sufficient offshore (where highresolution bathymetry is not available). For this application, a fine nearshore grid was nested with a coarse offshore grid. The offshore grid has a resolution of $250 \mathrm{~m}$ with 125 cells across the shore and 253 cells along the shore. The grid extends from an offshore depth of $130 \mathrm{~m}$ (at the buoy location) to a nearshore depth of $47 \mathrm{~m}$. NOAA bathymetry was used. Both the offshore and nearshore grids were aligned with the nearshore contours ( $\mathrm{x}$-axis at 350 deg counterclockwise from west), so no rotation of the spectra was required between offshore and nearshore simulations. Measured heights, periods, and directions from the offshore buoy were then transformed across the offshore grid (including wind input, but excluding currents and tide variations). Output spectra were saved in the most landward column and used as the input spectra for the nearshore grid. The nearshore model runs are described in the following paragraphs.

\section{Model input}

Model parameters. Figure 19 shows the bathymetry contours within the STWAVE nearshore modeling domain selected for the Yaquina Bay Entrance. The offshore boundary location is selected at an approximate depth of $47 \mathrm{~m}$. This depth is chosen because the bottom contours are fairly straight and parallel at this depth (out of the influence of the ebb shoal). The lateral boundaries of the domain are positioned away from the influence of the entrance, to areas of fairly straight and parallel depth contours. A $25-\mathrm{m}$ grid cell spacing is selected to resolve the reefs and entrance bathymetry. To cover the domain with $25-\mathrm{m}$ resolution requires 188 cells across the shore (NI) and 236 cells alongshore (NJ). 
Typical wave periods for this site are 20 to $6 \mathrm{sec}(0.05$ to $0.167 \mathrm{~Hz})$. To resolve this range, 30 frequency bins are used with an initial frequency of $0.02 \mathrm{~Hz}$ and a frequency increment of $0.01 \mathrm{~Hz}$ (range of frequencies is 0.02 to $0.31 \mathrm{~Hz}$ ). The same frequency range and resolution were used in both the offshore and nearshore simulations, so no interpolation was required between offshore grid output spectra and the nearshore grid input spectra. Because the wave propagation distances on the nearshore grid are relatively short $(5 \mathrm{~km})$, source terms are neglected (IPRP $=1)$. Wave-current interaction, though, is significant near the inlet, so ICUR $=1$ to include wave-current interaction was selected. Breaker indices and radiation stress gradients are saved (IBREAK $=1$ and IRS $=1$ ).

Bathymetry. The bathymetry contours for Yaquina Bay are shown in Figure 19. The grid was developed using the SMS grid generator as presented in Chapter 5. The Portland District provided high-resolution bathymetry near the entrance from multibeam fathometry. These data were supplemented with NOAA bathymetry and shorelines. The Yaquina jetties are represented in the model as a series of land cells. The jetty is specified as being three grid cells wide, which is wider than the real structure. Three cells are required to block wave energy from propagating through the structure.

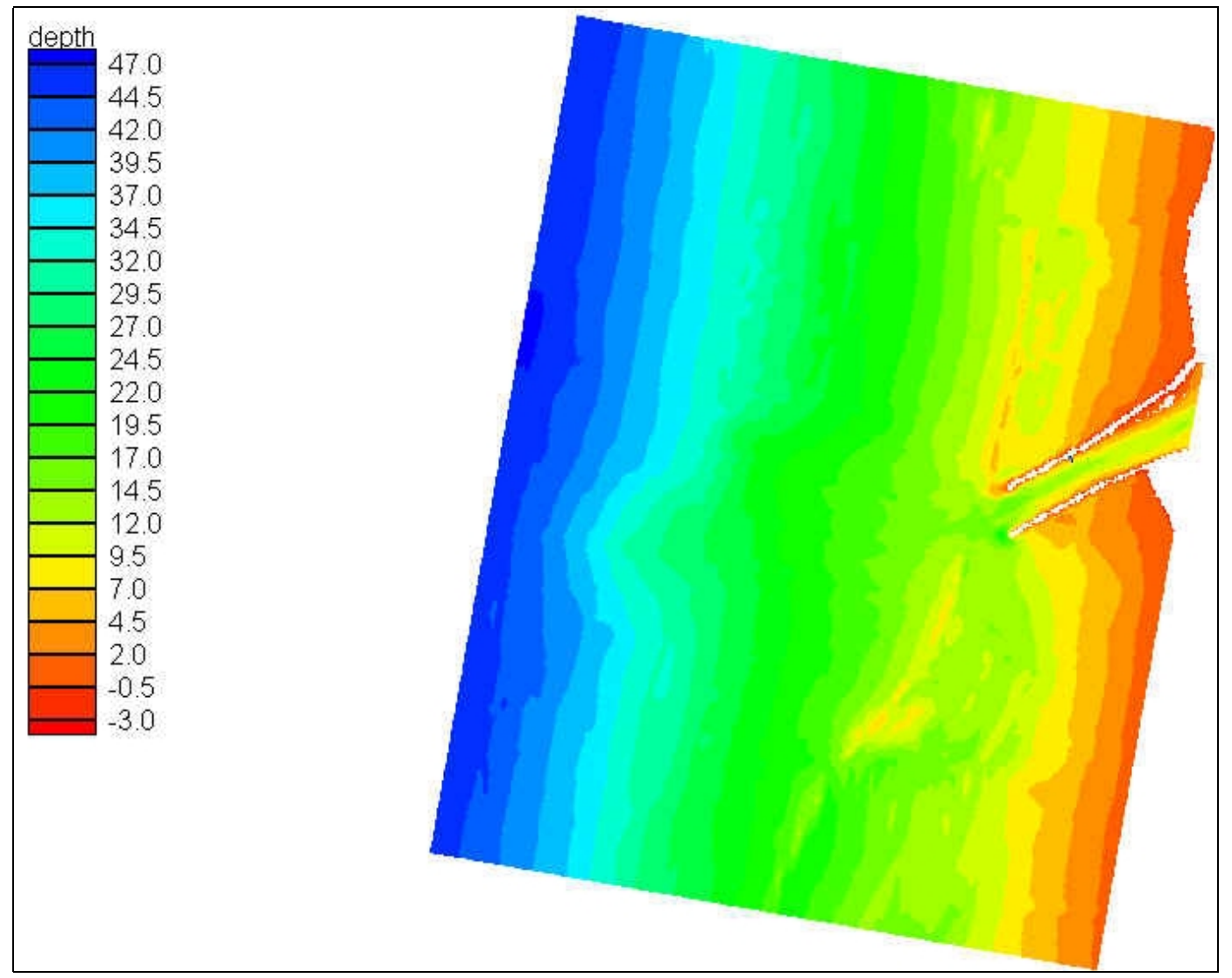

Figure 19. Nearshore Yaquina Bay Entrance bathymetry (from SMS) 
Incident wave spectrum. The incident wave spectrum for Yaquina Bay was generated using a TMA spectral shape (with a spectral peakedness parameter, $\gamma=8$ ), $\cos ^{n n} \alpha$ directional distribution (with $n n=30$ ), $H_{m o}=12.5 \mathrm{~m}, T_{p}=20 \mathrm{sec}$, and $\alpha_{m}=55 \mathrm{deg}$ (from the Southwest) on the offshore grid. The nearshore grid was forced with the output spectrum at a depth of $47 \mathrm{~m}$ from the offshore grid. These incident conditions represent extreme high wave conditions from a storm in 1999.

Current field. The current field for Yaquina Bay was generated using the tidal circulation model ADCIRC. The current field output from ADCIRC was interpolated onto the STWAVE grid using SMS as described in Chapter 5. The ebb and flood current fields are plotted in Figures 17 and 18 for the area near the jetty tips. The current fields show not only the tidal current through the entrance, but also a longshore current toward the north generated by strong alongshore storm winds. Representative nearshore tide levels of $-0.90 \mathrm{~m}$ (at peak ebb) and $0.61 \mathrm{~m}$ (at peak flood) from ADCIRC were applied in STWAVE.

\section{Results}

The wave height contours in Figures 20 and 21 show that the waves in the nearshore in this extreme storm event are breaking due to depth limitations (note gradient in the wave height contours). The $1.5-\mathrm{m}$ higher water level on flood accounts for the larger wave heights during flood than during ebb (generally, larger wave heights are expected on ebb due to wave-current interaction, unless the wave heights are depth limited, as they are in this example). Figure 22 (generated in SMS) shows the difference in wave height (flood minus ebb) for this example. The red/orange contours show areas where the wave height is 1.5 to $2 \mathrm{~m}$ higher on flood (at the jetty tips). The blue contours show areas where the wave height is 0.5 to $1.0 \mathrm{~m}$ higher on ebb (in the interior channel, where the water depth is greater and the current stronger). 


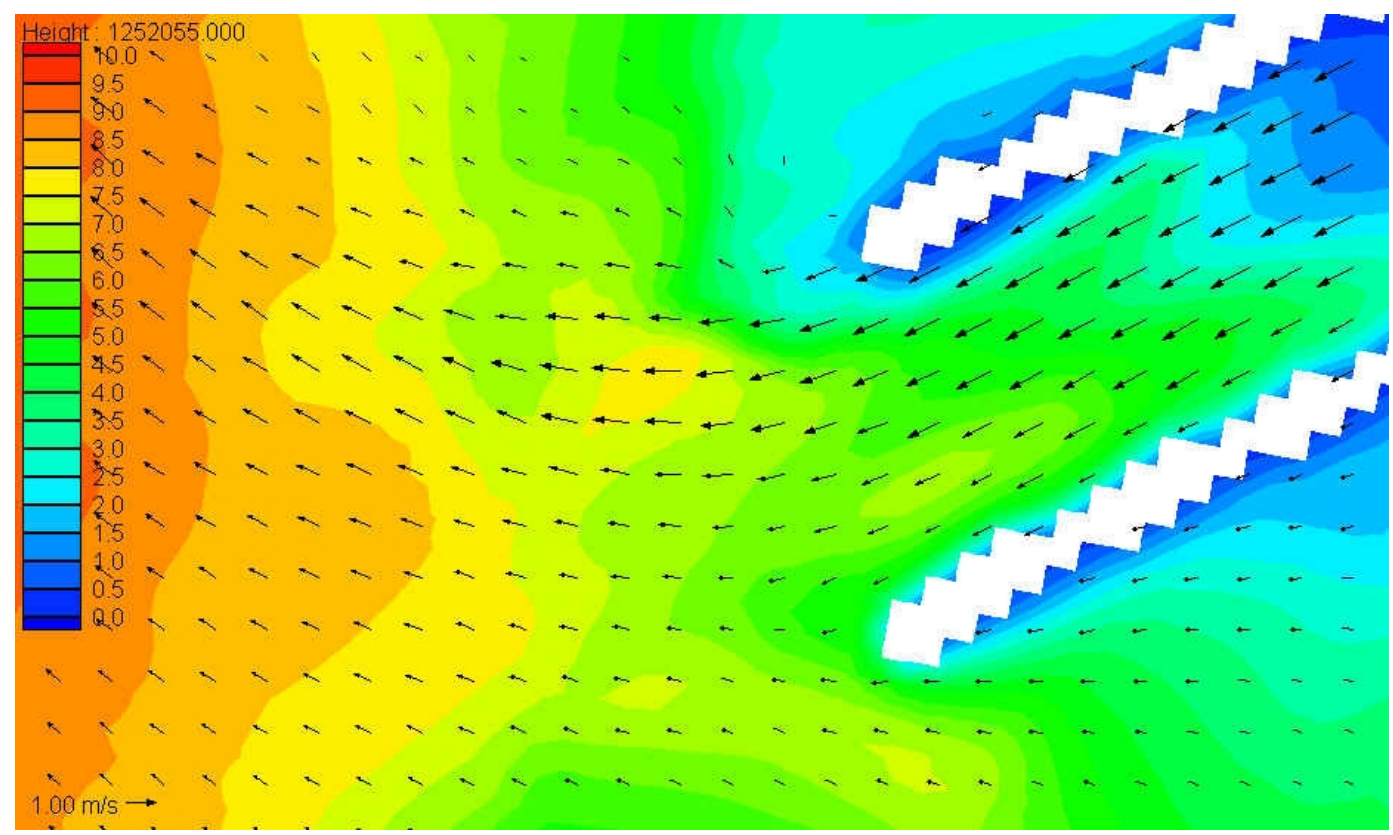

Figure 20. Ebb current vectors and wave height contours near the Yaquina jetty tips (incident conditions: $H_{m o}=12.5 \mathrm{~m}, T_{p}=20 \mathrm{sec}$, waves from the southwest, tide $=-0.90 \mathrm{~m}$ mean tide level)

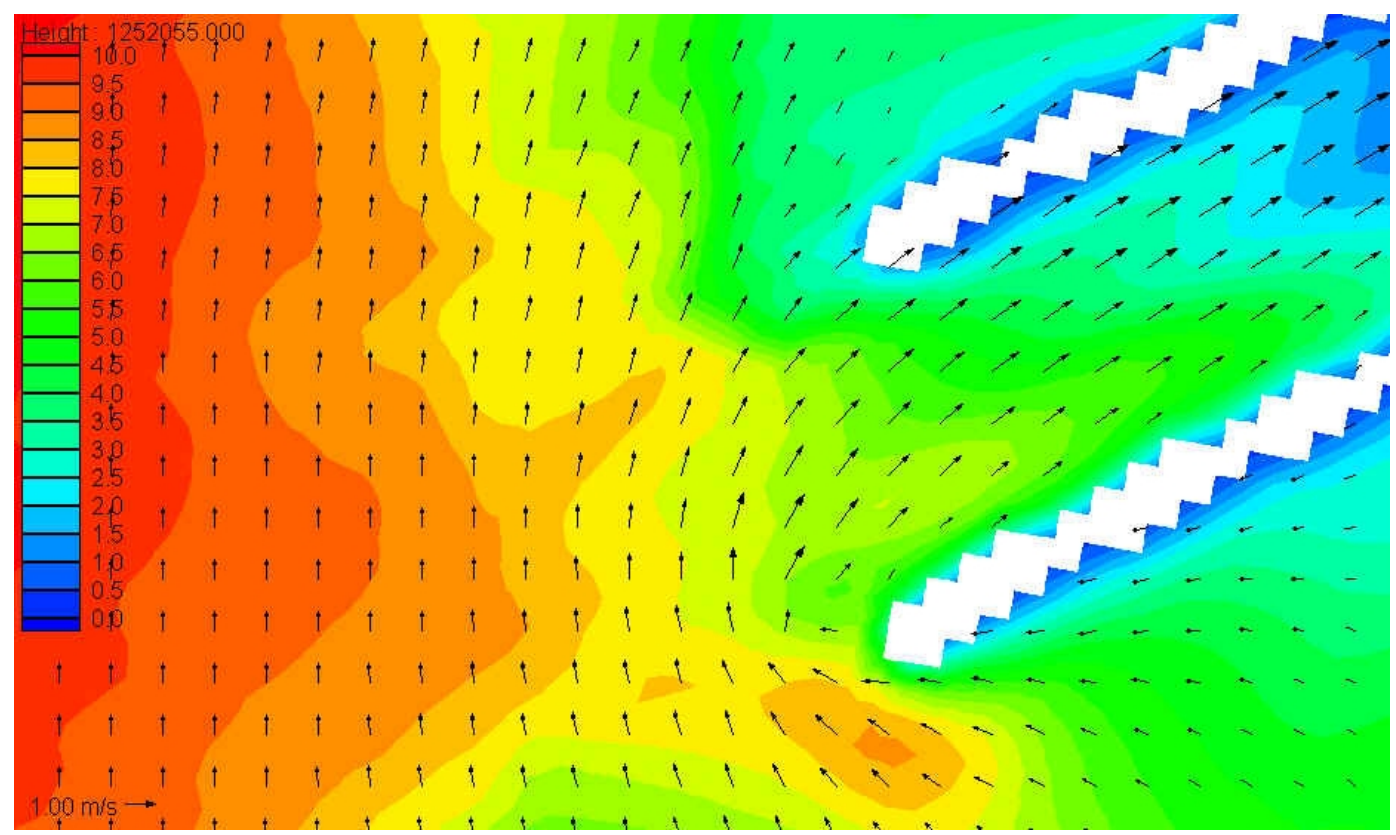

Figure 21. Flood current vectors and wave height contours near the Yaquina jetty tips (incident conditions: $H_{m o}=12.5 \mathrm{~m}, T_{p}=20 \mathrm{sec}$, waves from the southwest, tide $=0.61 \mathrm{~m}$ mean tide level) 


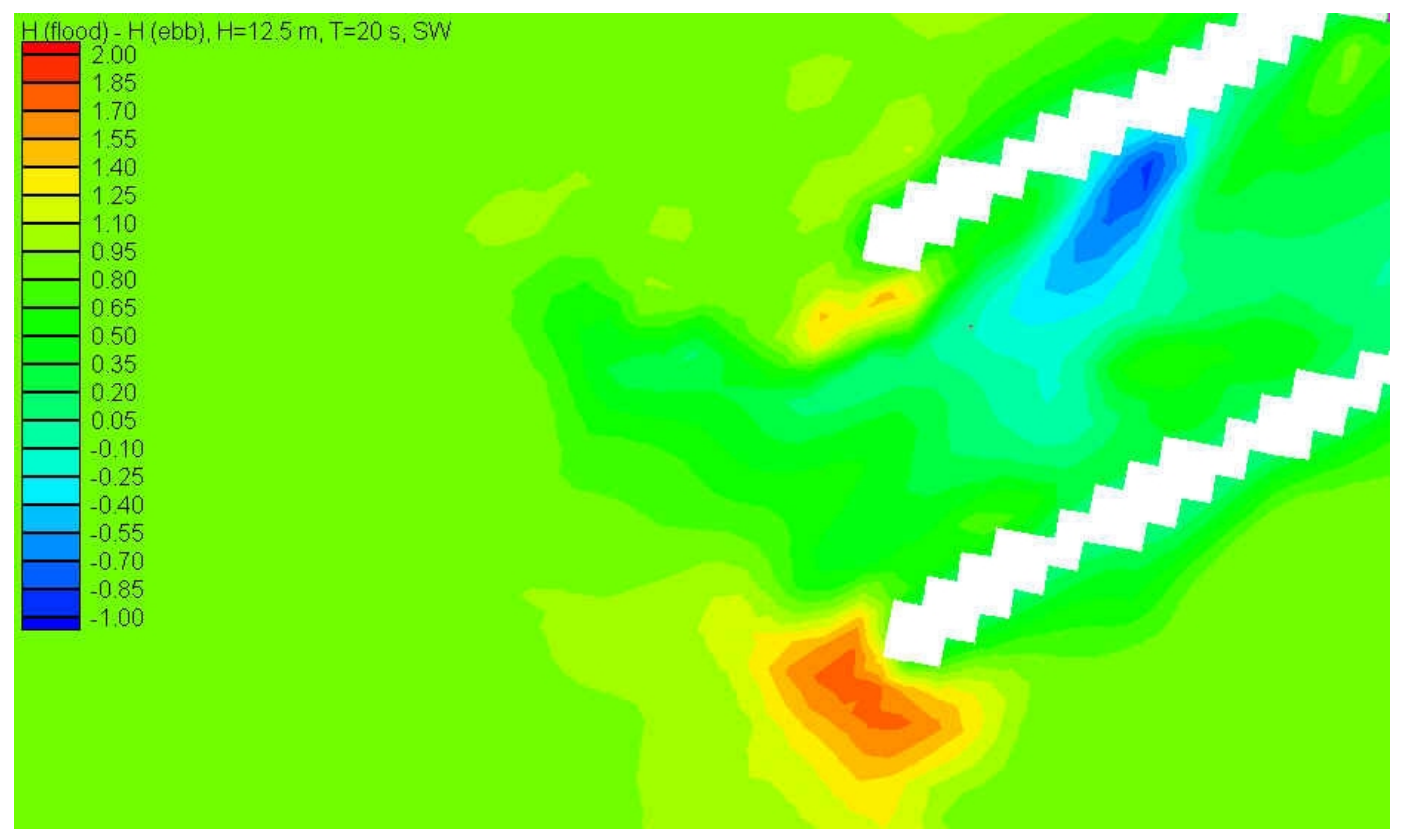

Figure 22. Wave height difference (flood $-\mathrm{ebb}$ ) near the Yaquina jetty tips (incident conditions: $H_{m o}=12.5 \mathrm{~m}, T_{p}=20 \mathrm{sec}$, waves from the southwest) 


\section{References}

Battjes, J. A. (1982). "A case study of wave height variations due to currents in a tidal entrance," Coast. Engrg. 6, 47-57.

Battjes, J. A., and Janssen, J. P. F. M. (1978). "Energy loss and set-up due to breaking of random waves." Proc. 16th Coast. Engrg. Conf., ASCE, 569587.

Brigham Young University Engineering Computer Graphics Laboratory. (1997). "Surface-water modeling system reference manual." Brigham Young University, Provo, UT. (http://hlnet.wes.army.mil/software/sms/docs.htp)

Bouws, E., Gunther, H., Rosenthal, W., and Vincent, C. L. (1985). "Similarity of the wind wave spectrum in finite depth waves; 1 . Spectral form," $J$. Geophys. Res. 90(C1), 975-986.

Coastal Engineering Manual. U.S. Army Engineer Research and Development Center, Coastal and Hydraulics Laboratory, Vicksburg, MS (in preparation).

Davis, J. E. (1992). "STWAVE theory and program documentation, Coastal Modeling System User's Manual," Instruction Report CERC-91-1, Supplement 1, M. A. Cialone, ed., U.S. Army Engineer Waterways Experiment Station, Vicksburg, MS.

Hasselmann, K., Barnett, T. P., Bouws, E., Carlson, H., Cartwright, D. E., Enke, K., Ewing, J. A., Gienapp, H., Hasselmann, D. E., Kruseman, P., Meerburg, A., Muller, P., Olbers, D. J., Richter, K., Sell, W., and Walden, H. (1973). "Measurements of wind-wave growth and swell decay during the Joint North Sea Wave Project (JONSWAP)," Deut. Hydrogr. Z., Suppl. A, 8(12), 1-95.

Hughes, S. A., Prickett, T. L., Tubman, M. W., and Corson, W. D. (1995). "Monitoring of the Yaquina Bay Entrance north jetty at Newport, Oregon; Summary and results," Technical Report CERC-95-9, U.S. Army Engineer Research and Development Center, Vicksburg, MS.

Jonsson, I. G. (1990). "Wave-current interactions." The sea. Vol. 9, Part A, B. LeMehaute and D. M. Hanes, ed., John Wiley \& Sons, Inc., New York. 
King, D. B., Smith, J. M., Militello, A., Waller, T., and Stauble, D. K. (1999). "Ponce de Leon Inlet, Florida site investigation, Report 1: Selected portions of long-term measurements 1995-1997," Technical Report CHL-99-1, U.S. Army Engineer Research and Development Center, Vicksburg, MS.

Lai, R. J., Long, S. R., and Huang, N. E. (1989). "Laboratory studies of wavecurrent interaction: Kinematics of the strong interaction." J. Geophys. Res., 97(C11), 16201-16214.

Lillycrop, W. J., Parson, L. E., and Irish, J. L. (1996). "Development and operation on the SHOALS airborne lidar hydrographic survey system." Laser remote sensing of natural waters: From theory to practice. V. I. Feigels and Y. I. Kopilevich, ed., Proceedings, International Society for Optical Engineering (SPIE) 2964, 26-37.

Luettich, R. A., Westerink, J. J., and Scheffner, N. W. (1992). "ADCIRC: An advanced three-dimensional circulation model for shelves, coasts, and estuaries, Report 1: Theory and methodology of ADCIRC-2DDI and ADCIRC-3DL," Technical Report DRP-92-6, U.S. Army Engineer Waterways Experiment Station, Vicksburg, MS.

Mei, C. C. (1989). The applied dynamics of ocean surface waves. World Scientific Publishing, Singapore.

Miche, M. (1951). "Le pouvoir reflechissant des ouvrages maritimes exposes a 1' action de la houle." Annals des Ponts et Chaussess, 121e Annee, 285-319 (translated by Lincoln and Chevron, University of California, Berkeley, Wave Research Laboratory, Series 3, Issue 363, June 1954).

Militello, A., Scheffner, N. W., Bratos, S. M., Brown, M. E., and Fenical, S. (2000). "Circulation and transport modeling," Technical Report ERDC-00-6, U.S. Army Engineer Research and Development Center, Vicksburg, MS.

Resio, D. T. (1987). "Shallow-water waves. I: Theory," J. Wtrway., Port, Coast., and Oc. Engrg., ASCE, 113(3), 264-281.

. (1988a). "Shallow-water waves. II: Data comparisons," J. Wtrway., Port, Coast., and Oc. Engrg., ASCE, 114(1), 50-65. . (1988b). "A steady-state wave model for coastal applications." Proc. 21st Coast. Engrg. Conf., ASCE, 929-940.

Resio, D. T., and Perrie, W. (1989). "Implications of an $f^{-4}$ equilibrium range for wind-generated waves," J. Phys. Oceanography 19, 193-204.

Smith, J. M., and Ebersole, B. A. (2000). "Modeling and analysis of short waves," Technical Report ERDC-00-6, U.S. Army Engineer Research and Development Center, Vicksburg, MS. 
Smith, J. M., Militello, A., and Smith, S. J. (1998). "Modeling waves at Ponce de Leon Inlet, Florida." Proc. 5th International Workshop on Wave Hindcasting and Forecasting, Environment Canada, Downsview, Ontario, 201-214.

Smith, J. M., Resio, D. T. and Vincent, C. L. (1997). "Current-induced breaking at an idealized inlet." Proc. Coastal Dynamics '97, ASCE, 9931002.

Smith, J. M., Resio, D. T. and Zundel, A. K. (1999). "STWAVE: Steady-State Spectral Wave Model; Report 1: User's manual for STWAVE version 2.0," Instructional Report CHL-99-1, U.S. Army Engineer Research and Development Center, Vicksburg, MS.

Smith, S. J., and Smith, J. M. (in preparation) "Modeling waves at Ponce de Leon Inlet, Florida," J. Wtrway., Port, Coast., and Oc. Engrg., ASCE.

Thompson, E. R., Hadley, L. L., Brandon, W. A., McGehee, D. D., and Hubertz, J. M. (1996). "Wave response of Kahului Harbor, Maui, Hawaii," Technical Report CERC-96-11, U.S. Army Engineer Research and Development Center, Vicksburg, MS.

U.S. Army Engineer District, Jacksonville. (1993). "Navigation study for Ponce de Leon Inlet, Volusia County, Florida -- 14310.” Reconnaissance Report, U.S. Army Engineer District, Jacksonville, Jacksonville, FL. 


\section{Appendix A Sample Model Parameter File}

The parameters required to run STWAVE are specified in the options.std file. A description of the file and formatting is given in Chapter 3 of the main text. An example parameter file for Yaquina Bay Entrance at Newport, OR (see Example 1 in Chapter 6 - main text) is given as follows:

$\begin{array}{lllll}0 & 1 & 1 & 1 & 3\end{array}$

110157

131117

14686 


\section{Appendix B Sample Bathymetry File}

The bathymetry required to run STWAVE is specified in the depth. in file. A description of the file and formatting is given in Chapter 3, "Bathymetry." An example of the first row (starting with $\mathrm{J}=\mathrm{NJ}$ ) of the bathymetry file for Yaquina Bay Entrance at Newport, OR (Chapter 5, "Build STWAVE Cartesian Grid") is given as follows (depths in meters relative to mean tide level):

\begin{tabular}{|c|c|c|c|c|}
\hline & ? & & & \\
\hline & & 295 & 4 & 91 \\
\hline 45.525253 & 45.168720 & 44.934937 & 44.753963 & 45.227501 \\
\hline 45.381058 & 45.078934 & 44.749165 & 44.173389 & 43.706909 \\
\hline 43.200413 & 42.864304 & 42.718304 & 42.552567 & 41.984577 \\
\hline 41.584068 & 41.581631 & 41.595505 & 41.608906 & 41.114693 \\
\hline 40.779945 & 40.480919 & 39.474430 & 39.658737 & 39.700066 \\
\hline 39.478432 & 39.481739 & 39.362648 & 38.426922 & 37.489922 \\
\hline 36.998165 & 36.513798 & 36.748604 & 37.013935 & 36.346466 \\
\hline 35.320770 & 35.138374 & 35.586994 & 35.580254 & 35.479980 \\
\hline 34.844318 & 34.245529 & 33.885906 & 33.983131 & 34.072853 \\
\hline 33.580402 & 33.224022 & 32.847286 & 32.452747 & 32.628101 \\
\hline 32.529854 & 31.978901 & 31.437374 & 30.874306 & 30.525604 \\
\hline 30.289108 & 30.109001 & 29.668436 & 29.209021 & 29.025633 \\
\hline 28.913048 & 28.339758 & 27.856483 & 27.660454 & 27.450241 \\
\hline 27.198229 & 26.932903 & 26.698179 & 26.465672 & 26.488281 \\
\hline 26.445293 & 25.880035 & 25.253780 & 24.910845 & 24.707207 \\
\hline 24.630911 & 24.686291 & 24.185822 & 23.762606 & 23.608511 \\
\hline 23.580662 & 23.160681 & 22.718637 & 22.439632 & 22.313131 \\
\hline 21.931955 & 21.434870 & 21.035362 & 20.962799 & 20.753426 \\
\hline 20.374048 & 20.099985 & 20.066952 & 20.025595 & 19.114258 \\
\hline 18.769199 & 19.031534 & 18.911980 & 17.971195 & 17.398960 \\
\hline 17.377380 & 17.077021 & 16.958942 & 16.618668 & 16.451231 \\
\hline 16.231750 & 15.705775 & 15.137889 & 14.560424 & 14.812372 \\
\hline 15.064322 & 15.316270 & 13.664304 & 16.208809 & 16.184008 \\
\hline 16.021345 & 15.079105 & 14.334208 & 14.016557 & 13.685314 \\
\hline 13.354072 & 13.022829 & 12.641250 & 12.542627 & 0.000000 \\
\hline 0.000000 & 0.000000 & 0.000000 & 0.000000 & 0.000000 \\
\hline 0.000000 & 0.000000 & 0.000000 & 0.000000 & 0.000000 \\
\hline 0.000000 & 0.000000 & 0.000000 & 0.000000 & 0.000000 \\
\hline 0.000000 & 0.000000 & 0.000000 & 0.000000 & 0.000000 \\
\hline 0.000000 & 0.000000 & 0.000000 & 0.000000 & 0.000000 \\
\hline 0.000000 & 0.000000 & 0.000000 & 0.000000 & 0.000000 \\
\hline 0.000000 & 0.000000 & 0.000000 & 0.000000 & 0.000000 \\
\hline 0.000000 & 0.000000 & 0.000000 & 0.000000 & 0.000000 \\
\hline 0.000000 & 0.000000 & 0.000000 & -2.000000 & -2.000000 \\
\hline-2.000000 & -2.000000 & -2.000000 & -2.000000 & -2.000000 \\
\hline-2.000000 & -2.000000 & -2.000000 & -2.000000 & -2.000000 \\
\hline-2.000000 & -2.000000 & -2.000000 & & \\
\hline
\end{tabular}




\section{Appendix C Sample Incident Wave Spectrum File}

The input two-dimensional spectrum required to run STWAVE is specified in the spec. in file. A description of the file and formatting is given in Chapter 3, "Incident Wave Spectra." An example of a file header and the energy densities (meters squared/hertz/radian) in the first five frequencies $(0.01000$ to $0.05000 \mathrm{~Hz}$, with 35 direction bins per frequency) of the spectrum for Yaquina Bay Entrance at Newport, OR (Chapter 5, "Generate Input Spectra for STWAVE") are given as follows:

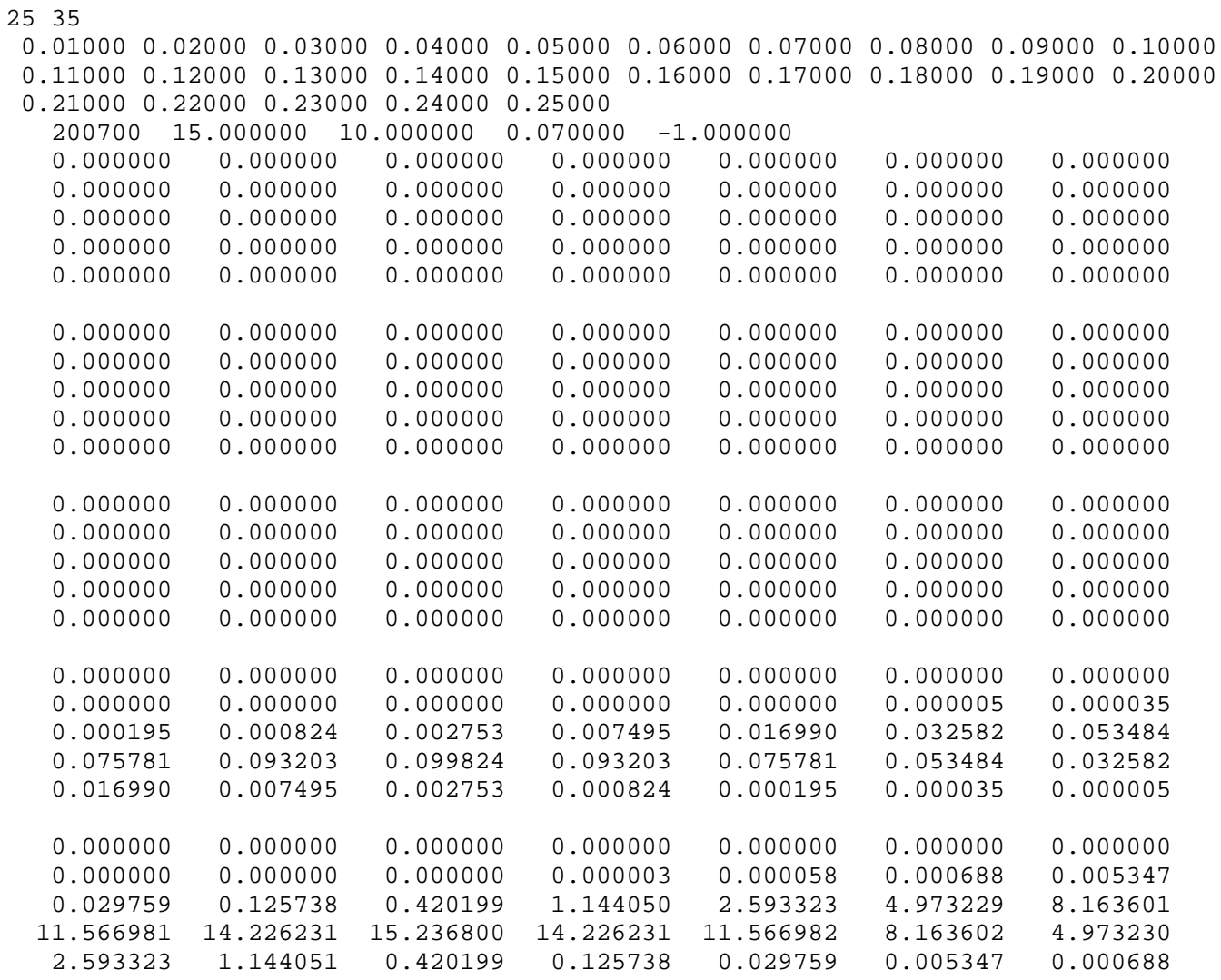




\section{Appendix D Sample Current Field File}

The input current field required to run STWAVE is specified in the current. in file. A description of the file and formatting is given in Chapter 3, "Incident Wave Spectra." An example of the first row $(J=N J)$ of the current file for Yaquina Bay Entrance at Newport, OR (Chapter 5, "WaveCurrent Interaction") is given as follows ( $u$ and $v$ velocity components in meters/second):

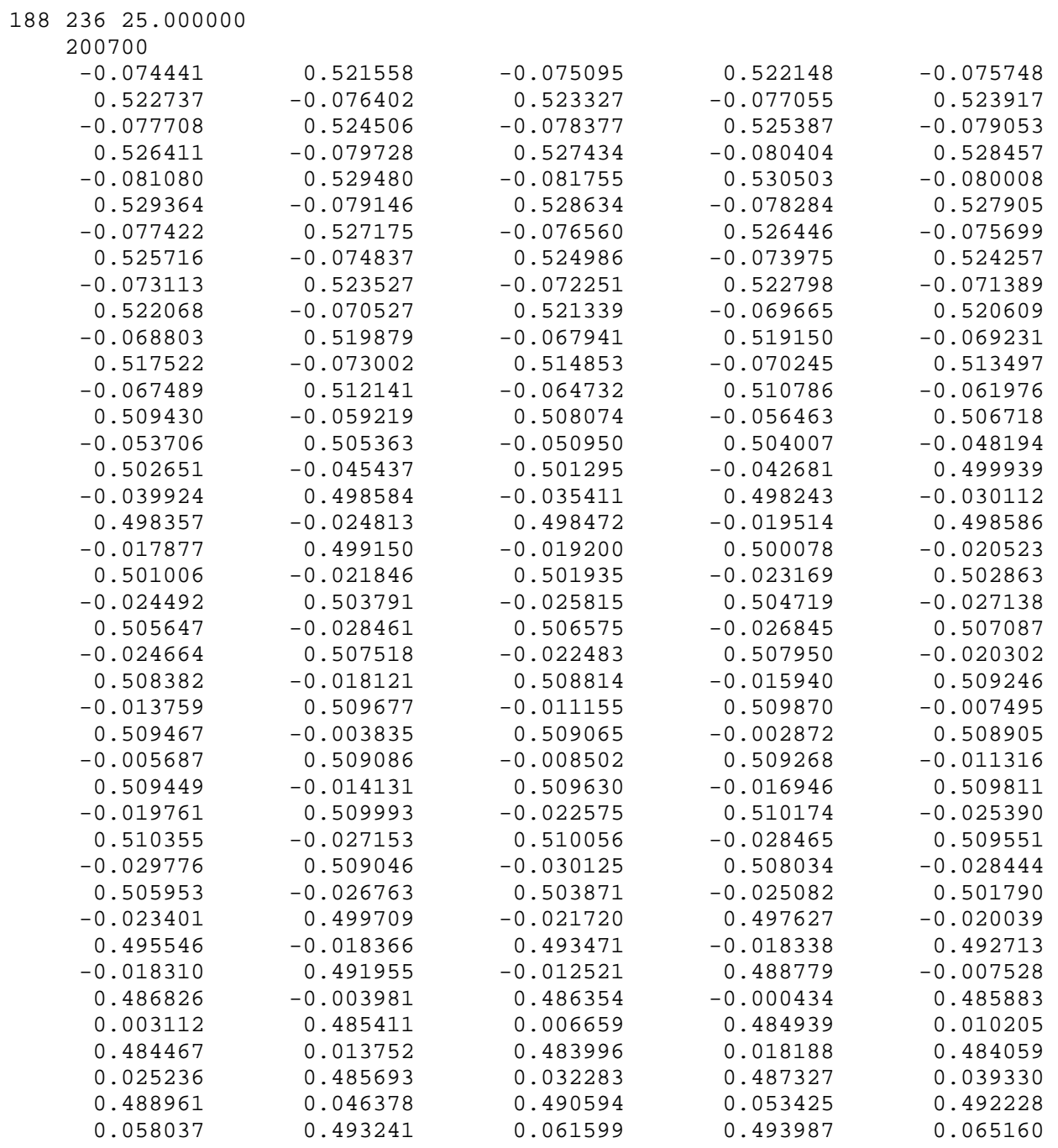




\section{Appendix E Sample Wave Parameter File}

STWAVE model result parameters $H_{m o}, T_{p}$, and mean wave direction, $\theta_{m}$, are written to file selhts.out for each selected grid cell identified in the STWAVE input model parameters file (or SMS monitoring station). A description of selhts.out is given in Chapter 4, "Selected Wave Parameters." An example of the selected wave parameter file for Yaquina Bay Entrance at Newport, OR (Chapter 5, "Identify Monitoring Stations") is given as follows:

\begin{tabular}{rrrrrrc} 
Event ID & $\underline{\mathrm{I}}$ & $\underline{\underline{\mathrm{J}}}$ & $\underline{\underline{H}}_{\mathrm{mo}}$ & $\underline{\mathrm{T}}_{\mathrm{p}}$ & $\underline{\boldsymbol{\alpha}}_{\underline{\mathrm{m}}}$ & $\underline{\text { Breaking }}$ \\
\hline 200700 & 110 & 157 & 8.52 & 1.0 & 18. & 0 \\
200700 & 131 & 117 & 7.13 & 1.0 & 20. & 0 \\
200700 & 146 & 86 & 4.85 & 1.0 & 17. & 0 \\
175500 & 110 & 157 & 4.39 & 1.0 & 18. & 0 \\
175500 & 131 & 117 & 4.98 & 1.0 & 19. & 0 \\
175500 & 146 & 86 & 4.63 & 1.0 & 16. & 0
\end{tabular}




\section{Appendix F Sample Wave Breaking File}

Because the STWAVE model parameter IBREAK was set to 1, wavebreaking indices were written to the project.brk file. A description of the file is given in Chapter 3, "Model Parameters." An example of the first three rows $(J=N J)$ of the breaking file for Yaquina Bay Entrance at Newport, OR (Chapter 5, "Model Control") is given as follows ( $0=$ non-breaking, $1=$ breaking):

\begin{tabular}{|c|c|c|c|c|c|c|c|c|c|c|c|c|c|c|c|}
\hline & 18 & & & & 25 & & & & & & & & & & \\
\hline 0 & 0 & 0 & 0 & 0 & 0 & 0 & 0 & 0 & 0 & 0 & 0 & 0 & 0 & 0 & 0 \\
\hline 0 & 0 & 0 & 0 & 0 & 0 & 0 & 0 & 0 & 0 & 0 & 0 & 0 & 0 & 0 & 0 \\
\hline 0 & 0 & 0 & 0 & 0 & 0 & 0 & 0 & 0 & 0 & 0 & 0 & 0 & 0 & 0 & 0 \\
\hline 0 & 0 & 0 & 0 & 0 & 0 & 0 & 0 & 0 & 0 & 0 & 0 & 0 & 0 & 0 & 0 \\
\hline 0 & 0 & 0 & 0 & 0 & 0 & 0 & 0 & 0 & 0 & 0 & 0 & 0 & 0 & 0 & 0 \\
\hline 0 & 0 & 0 & 0 & 0 & 0 & 0 & 0 & 0 & 0 & 0 & 0 & 0 & 0 & 0 & 0 \\
\hline 0 & 0 & 0 & 0 & 0 & 0 & 0 & 0 & 0 & 0 & 0 & 0 & 0 & 0 & 0 & 0 \\
\hline 0 & 0 & 0 & 0 & 0 & 0 & 0 & 0 & 0 & 0 & 0 & 0 & 0 & 0 & 0 & 0 \\
\hline 0 & 0 & 0 & 0 & 0 & 0 & 0 & 0 & 0 & 0 & 0 & 0 & 0 & 0 & 0 & 0 \\
\hline 0 & 0 & 0 & 0 & 0 & 0 & 0 & 0 & 0 & 0 & 0 & 0 & 0 & 0 & 0 & 0 \\
\hline 0 & 0 & 0 & 0 & 0 & 0 & 0 & 0 & 0 & 0 & 0 & 0 & 0 & 0 & 0 & 0 \\
\hline 0 & 0 & 0 & 0 & 0 & 0 & 0 & 0 & 0 & 0 & 0 & 0 & & & & \\
\hline 0 & 0 & 0 & 0 & 0 & 0 & 0 & 0 & 0 & 0 & 0 & 0 & 0 & 0 & 0 & 0 \\
\hline 0 & 0 & 0 & 0 & 0 & 0 & 0 & 0 & 0 & 0 & 0 & 0 & 0 & 0 & 0 & 0 \\
\hline 0 & 0 & 0 & 0 & 0 & 0 & 0 & 0 & 0 & 0 & 0 & 0 & 0 & 0 & 0 & 0 \\
\hline 0 & 0 & 0 & 0 & 0 & 0 & 0 & 0 & 0 & 0 & 0 & 0 & 0 & 0 & 0 & 0 \\
\hline 0 & 0 & 0 & 0 & 0 & 0 & 0 & 0 & 0 & 0 & 0 & 0 & 0 & 0 & 0 & 0 \\
\hline 0 & 0 & 0 & 0 & 0 & 0 & 0 & 0 & 0 & 0 & 0 & 0 & 0 & 0 & 0 & 0 \\
\hline 0 & 0 & 0 & 0 & 0 & 0 & 0 & 1 & 1 & 1 & 1 & 1 & 1 & 1 & 1 & 1 \\
\hline 1 & 1 & 0 & 0 & 0 & 1 & 0 & 0 & 0 & 0 & 0 & 0 & 0 & 0 & 0 & 0 \\
\hline 0 & 0 & 0 & 0 & 0 & 0 & 0 & 0 & 0 & 0 & 0 & 0 & 0 & 0 & 0 & 0 \\
\hline 0 & 0 & 0 & 0 & 0 & 0 & 0 & 0 & 0 & 0 & 0 & 0 & 0 & 0 & 0 & 0 \\
\hline 0 & 0 & 0 & 0 & 0 & 0 & 0 & 0 & 0 & 0 & 0 & 0 & 0 & 0 & 0 & 0 \\
\hline 0 & 0 & 0 & 0 & 0 & 0 & 0 & 0 & 0 & 0 & 0 & 0 & & & & \\
\hline 0 & 0 & 0 & 0 & 0 & 0 & 0 & 0 & 0 & 0 & 0 & 0 & 0 & 0 & 0 & 0 \\
\hline 0 & 0 & 0 & 0 & 0 & 0 & 0 & 0 & 0 & 0 & 0 & 0 & 0 & 0 & 0 & 0 \\
\hline 0 & 0 & 0 & 0 & 0 & 0 & 0 & 0 & 0 & 0 & 0 & 0 & 0 & 0 & 0 & 0 \\
\hline 0 & 0 & 0 & 0 & 0 & 0 & 0 & 0 & 0 & 0 & 0 & 0 & 0 & 0 & 0 & 0 \\
\hline 0 & 0 & 0 & 0 & 0 & 0 & 0 & 0 & 0 & 0 & 0 & 0 & 0 & 0 & 0 & 0 \\
\hline 0 & 0 & 0 & 0 & 0 & 0 & 0 & 0 & 0 & 0 & 0 & 0 & 0 & 0 & 0 & 0 \\
\hline 0 & 0 & 0 & 0 & 0 & 0 & 0 & 1 & 1 & 1 & 1 & 1 & 1 & 1 & 1 & 1 \\
\hline 1 & 1 & 1 & 0 & 0 & 1 & 0 & 0 & 0 & 0 & 0 & 0 & 0 & 0 & 0 & 0 \\
\hline 0 & 0 & 0 & 0 & 0 & 0 & 0 & 0 & 0 & 0 & 0 & 0 & 0 & 0 & 0 & 0 \\
\hline 0 & 0 & 0 & 0 & 0 & 0 & 0 & 0 & 0 & 0 & 0 & 0 & 0 & 0 & 0 & 0 \\
\hline 0 & 0 & 0 & 0 & 0 & 0 & 0 & 0 & 0 & 0 & 0 & 0 & 0 & 0 & 0 & 0 \\
\hline 0 & 0 & 0 & 0 & 0 & 0 & 0 & 0 & 0 & 0 & 0 & 0 & & & & \\
\hline
\end{tabular}




\section{Appendix G Sample Radiation Stress Gradient File}

Radiation stress gradients were calculated and written to the STWAVE output file, radstress. A description of the file is given in Chapter 3, "Model Parameters." An example of the radiation stress file for Yaquina Bay Entrance at Newport, OR (Chapter 5, "Model Control") is given as follows:

\begin{tabular}{|c|c|c|c|c|}
\hline & \multicolumn{2}{|c|}{25.00000} & & \\
\hline 200700 & & & & \\
\hline $6.6950223 E-03$ & $-3.2863615 E-04$ & $1.4794922 \mathrm{E}-03$ & $1.9378655 E-05$ & $-2.2567750 \mathrm{E}-04$ \\
\hline $878328 \mathrm{E}-04$ & $-3.9071273 E-03$ & $-1.1065673 E-03$ & & $-3.7914276 E-04$ \\
\hline $56004 E-03$ & $2.5077819 \mathrm{E}-04$ & $-4.3723295 E-03$ & 6.810379 & -2.37 \\
\hline $1.2184905 \mathrm{E}-03$ & $3.5499572 \mathrm{E}-03$ & $1.8328476 \mathrm{E}-03$ & $7.7973939 E-03$ & $2.7407454 \mathrm{E}-03$ \\
\hline $2.1935655 \mathrm{E}-03$ & $2.9315948 E-03$ & $-3.0966951 E-03$ & 1.97 & $3 E-03$ \\
\hline$E-03$ & $2830 E-03$ & $87 E-04$ & -9 & -8 \\
\hline $344 E-03$ & $-1.7865753 E-03$ & -7.06 & -2 . & -5 \\
\hline 3 & $30 E-03$ & -1 & -1 & -1 \\
\hline-5 . & $15 E-03$ & -1 & -8 & -7 \\
\hline-6 & $4 E-03$ & -2 . & -8 & \\
\hline $558 E-03$ & 7. & -1.19 & & -5 \\
\hline-6 & $94 E-03$ & 1.0 & & \\
\hline $740 E-03$ & $4.8939516 \mathrm{E}-03$ & 3.04 & 3. & -7 \\
\hline 1.61 & $48 E-02$ & -2.36 & -1 & $1 E-03$ \\
\hline $385 E-02$ & $-1.4142228 \mathrm{E}-03$ & -3.67 & -1 & -03 \\
\hline-2 & $86 E-03$ & -3.24 & -2.1 & -3 \\
\hline $963 E-02$ & $-2.0566939 E-03$ & 1.08 & $-1 \cdot 6$ & $9 E-03$ \\
\hline-3.64 & $16 \mathrm{E}-03$ & 2.44 & -6.6 & 03 \\
\hline $196 \mathrm{E}-02$ & $9487 E-03$ & -1.20 & 3.0 & -3 \\
\hline$E-03$ & $39 E-03$ & $6 E-03$ & 8.6 & $0 E-03$ \\
\hline$-8.0078887 E-03$ & $9022 E-03$ & -8.85 & 1.5 & $9 E-02$ \\
\hline$E-03$ & $83 E-03$ & $3 E-03$ & -03 & $1 E-03$ \\
\hline$-6.3802721 E-03$ & $2.3565674 \mathrm{E}-03$ & -1.44 & $5-03$ & $4 E-02$ \\
\hline $8.8541035 \mathrm{E}-04$ & $382 E-02$ & $4 E-04$ & -9 & $6 E-04$ \\
\hline$-8.1194881 \mathrm{E}-03$ & $-1.7316820 \mathrm{E}-04$ & $0 E-02$ & $3 E-04$ & $2 E-02$ \\
\hline $9534 \mathrm{E}-03$ & $364 E-02$ & -1.86 & $2 E-03$ & $5 E-03$ \\
\hline $3645 E-02$ & $983 E-03$ & $8 E-02$ & -4 & $9 E-0$ \\
\hline$-5.7125473 E-03$ & $-1.4620438 \mathrm{E}-02$ & $49 E-03$ & $7 E-02$ & $34 \mathrm{E}-03$ \\
\hline-1 & & $6 \mathrm{E}-02$ & -7 & -1 \\
\hline $3238 E-03$ & $-1.4727631 \mathrm{E}-02$ & $-8.4551238 E-03$ & $461082 E-02$ & $-7.3479461 E-0$ \\
\hline
\end{tabular}




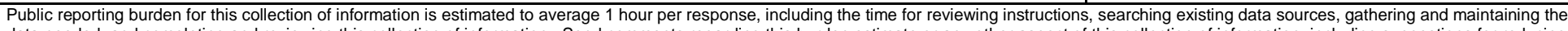

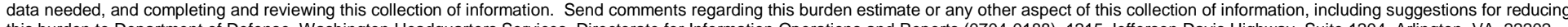

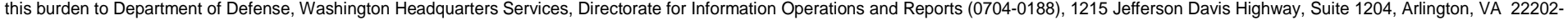

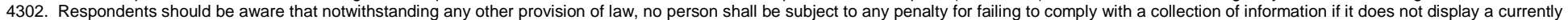
valid OMB control number. PLEASE DO NOT RETURN YOUR FORM TO THE ABOVE ADDRESS

\begin{tabular}{l|l|l} 
1. REPORT DATE $(D D-M M-Y Y Y Y)$ & 2. REPORT TYPE & 3. DATES COVERED (FrOm - To)
\end{tabular}

February 2001

4. TITLE AND SUBTITLE

Final Report

STWAVE: Steady-State Spectral Wave Model; User's Manual for STWAVE, Version 3.0

5a. CONTRACT NUMBER

5b. GRANT NUMBER

5c. PROGRAM ELEMENT NUMBER

6. AUTHOR(S)

Jane McKee Smith, Ann R. Sherlock, Donald T. Resio

5d. PROJECT NUMBER

5e. TASK NUMBER

5f. WORK UNIT NUMBER

\section{PERFORMING ORGANIZATION NAME(S) AND ADDRESS(ES)}

8. PERFORMING ORGANIZATION REPORT NUMBER

U.S. Army Engineer Research and Development Center

Coastal and Hydraulics Laboratory

ERDC/CHL SR-01-1

3909 Halls Ferry Road

Vicksburg, MS 39180-6199

U.S. Army Corps of Engineers
Washington, DC 20314-1000

10. SPONSOR/MONITOR'S ACRONYM(S)

11. SPONSOR/MONITOR'S REPORT NUMBER(S)

12. DISTRIBUTION / AVAILABILITY STATEMENT

Approved for public release; distribution is unlimited.

\section{SUPPLEMENTARY NOTES}

\section{ABSTRACT}

This report describes application of the steady-state spectra wave model, STWAVE. The purpose of STWAVE is to provide an easy-toapply, flexible, and robust model for nearshore wind-wave growth and propagation. Recent upgrades to the model include calculation of radiation stresses and increase in computational speed. STWAVE has also been incorporated into the Surface-Water Modeling System, which provides a user interface and supporting software for grid generation, interpolation of current fields, generation of input spectra, and visualization of model output.

\section{SUBJECT TERMS}

Steady-state spectral wave model Surface-Water Modeling System

16. SECURITY CLASSIFICATION OF:

a. REPORT

UNCLASSIFIED b. ABSTRACT

c. THIS PAGE

UNCLASSIFIED
Wave breaking

Wave-current interaction

17. LIMITATION
OF ABSTRACT

Wave growth

Wave modeling

\begin{tabular}{|c|l|}
$\begin{array}{c}\text { 18. NUMBER } \\
\text { OF PAGES }\end{array}$ & \begin{tabular}{l} 
19a. NAME OF RESPONSIBLE PERSON \\
\cline { 2 - 2 } 80
\end{tabular} \\
\cline { 2 - 2 } & $\begin{array}{l}\text { 19b. TELEPHONE NUMBER (include area } \\
\text { code) }\end{array}$ \\
\hline
\end{tabular}

